\title{
CAMBODIAN AND LAOTIAN STUDENTS' EXPERIENCES OF LANGUAGE BARRIERS, CULTURAL DIFFERENCES, AND TEACHER-STUDENT RAPPORT IN A UNIVERSITY IN VIETNAM: A GROUNDED THEORY APPROACH
}

By

My Ngoc Doan

\begin{abstract}
A thesis
submitted to the Victoria University of Wellington in partial fulfilment of the requirements for the degree of Master of Education
\end{abstract}

Victoria University of Wellington 2012 


\begin{abstract}
An increasing number of international students have enrolled in university degree programmes in Vietnam in recent years and this has presented a range of new pedagogical opportunities and challenges in the higher education context of the nation. Currently, little is known about international students' academic experiences in Vietnamese universities although the literature suggests that effective teacher-student relationships are an important factor in establishing effective teaching and learning processes. This study employs grounded theory to examine the influence of teacher-student relationships on international students' academic experiences at a university in Vietnam that is located in a region that draws in students from the neighbouring countries of Cambodia and Laos. A mixed research design combining data from questionnaires and in-depth interviews was used in this research. Data from questionnaires were collected from all Cambodian and Laotian international students who were enrolled at a university in the An Giang province in Vietnam's Mekong Delta. These data were supplemented by in-depth interviews with a sample group of the students. The findings from this study show that while the Cambodian and Laotian international students reported good relationships with their Vietnamese teachers and having no difficulty in adapting to Vietnamese culture, they also struggled with the challenges of studying in a new language and this made it difficult for them to communicate effectively with their teachers or participate fully in classroom activities.
\end{abstract}




\section{ACKNOWLEDGEMENTS}

This thesis would not have been possible without the guidance, help, and sacrifice of several individuals who in one way or another have contributed and extended their valuable assistance in the preparation and completion of this study.

First and foremost, my utmost gratitude to my supervisor, Dr. Joanna Kidman, whose guidance and encouragement I will never forget. Dr. Kidman has given me invaluable input through her broad base of knowledge and her professional perceptiveness. I especially appreciate her taking the time to read and give me timely feedback despite her busy schedule. She has been my inspiration as I hurdle over all the obstacles in the completion of this research. She was not merely a teacher of a body of knowledge but also a role model in supervising, motivating and encouraging my independence. Most of all, her understanding and sympathy of my situation has created the best conditions for me to complete my thesis.

This thesis would not have been possible without the enthusiastic participation of international students at An Giang University. I am so thankful for their willingness to participate in the entire data collection process which provided me with valuable information to complete my thesis.

I also would like to thank Karen Commons and other staff in Student Learning Support Service of Victoria University of Wellington who have accompanied my Master's journey from the first year I arrived in New Zealand. Their kind support means a lot to me. They always tried their best to provide me with the best support they could so that I could complete my Master's degree at Victoria University. I am so thankful for their patient reading of every draft of my writing and for their valuable feedback and encouragement.

I also would like to express my sincere thanks to the examiners of my thesis who have given their valuable time reading this thesis and providing me with valuable feedback so that I can improve my intellectual work. 
I am especially grateful to the Vietnam International Education Development (VIED) who granted me a scholarship to pursue my studies at Victoria University of Wellington, New Zealand. I am so thankful for their financial and spiritual support throughout my two years here. I also would like to thank Dr. Doan Huu Luc who always inspires and encourages me to pursue my study goals. His strong-minded and valuable integrity will always be an excellent model for me to follow throughout my whole life. I also would like to thank Ms. Vuong Thi My Tam who generously gave me two years study leave and always encouraged me during the time I studied abroad.

To my loving family, I owe special thanks for their ongoing support, love, and sacrifice. My husband has been most patient and supportive of my study goals. Without his love and encouragement, I would never have achieved my academic ambition. I also owe my little daughter lots of love because I had to leave her when she was only one year old to pursue my studies abroad. Sometimes, I felt so depressed missing my beloved baby and felt like I would not continue my study anymore. I understand that the last two years have been so hard for both you and me. Finally, I dedicate this thesis to my loving parents and parentsin-law who have encouraged me and helped me to take care of my little baby so that I could pursue my academic dreams. 


\section{ABBREVIATIONS}

AGU

EPP

IELTS

MOET

MoEYS

NZARE

PDR

TOEFL

UNESCO

VIED

VUW
An Giang University

English Proficiency Programme

International English Language Test System

Ministry of Education and Training (Vietnam)

Ministry of Education, Youth, and Sport (Cambodia)

New Zealand Association for Research in Education

People's Democratic Republic

Test of English as a Foreign Language

United Nations Educational, Scientific and Cultural Organization

Vietnam International Education Development

Victoria University of Wellington 


\section{Table of Contents}

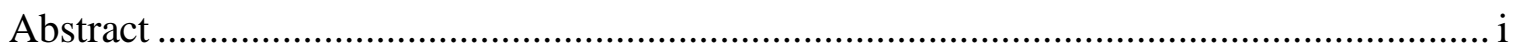

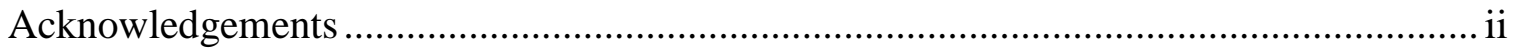

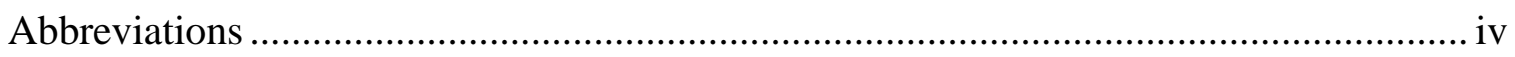

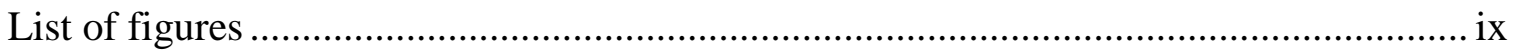

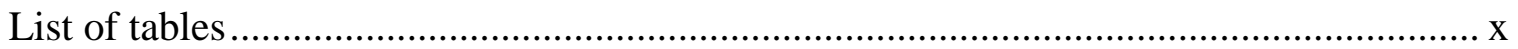

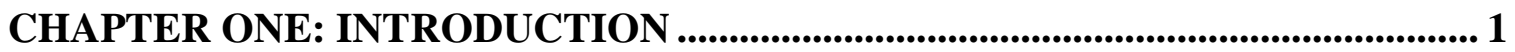

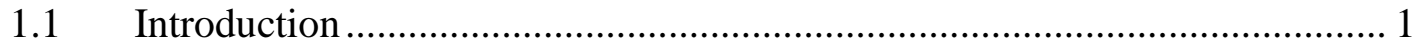

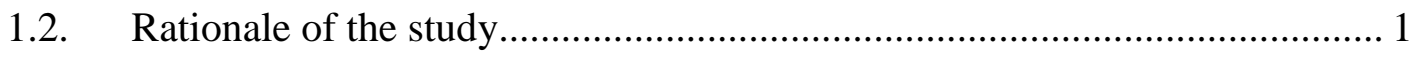

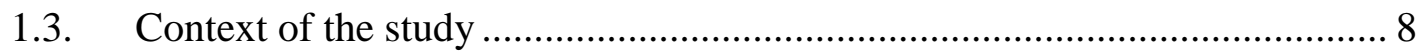

1.4. Purpose of the study and research questions............................................. 10

1.5. Significance of the study ......................................................................... 11

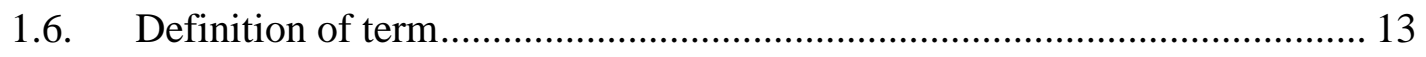

1.7. Limitations of the study ………………................................................ 13

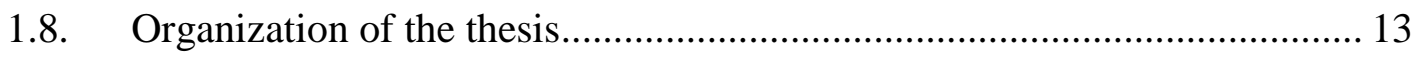

CHAPTER TWO: LITERATURE REVIEW ................................................................. 15

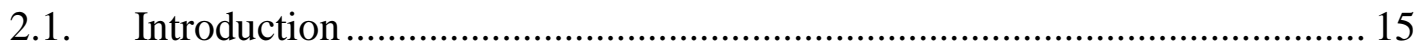

2.2. The role of teacher-student relationships in teaching and learning ............. 16

2.2.1. The Hall and Kidman (2004) map (model) of teaching and

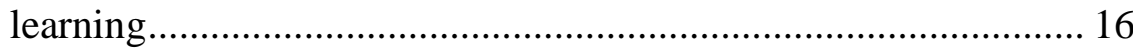

2.2.2. Factors contributing to rapport in teacher-student relationships . 17

2.3. International students' difficulties when studying abroad ............................ 23

2.3.1. Cultural differences....................................................................... 25

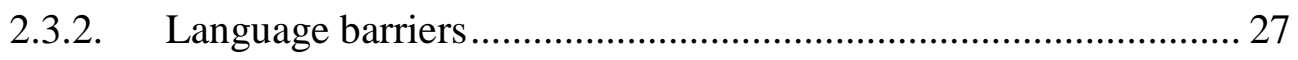

2.4. An overview of higher education in Vietnam, Cambodia, and Laos ........... 30

2.4.1. The education system in Vietnam .................................................. 30

2.4.2. Higher education in Cambodia.................................................... 37

2.4.3. Higher education in Laos PDR ................................................... 41 
2.5. Factors attracting Cambodian and Laotian students to study higher education

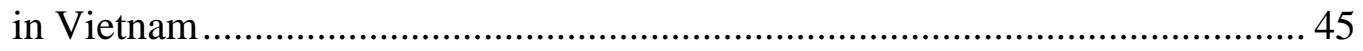

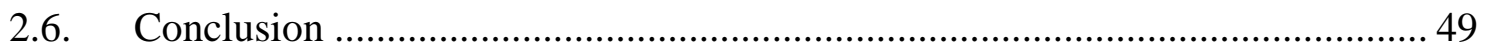

CHAPTER THREE: METHODOLOGY ...........................................................50

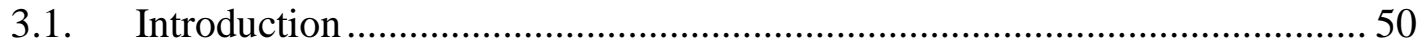

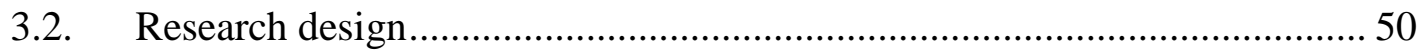

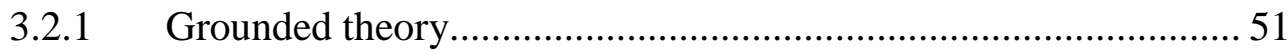

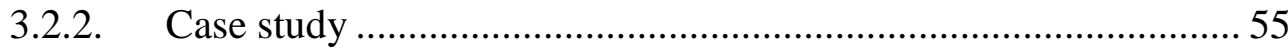

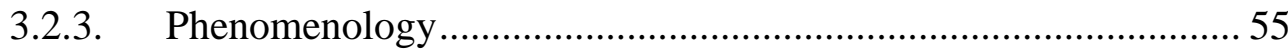

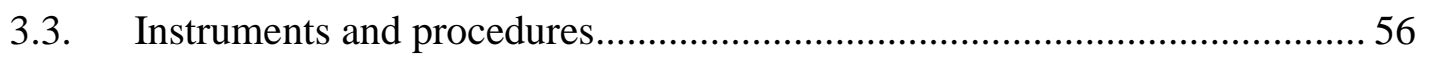

3.4. Participants and recruitment.................................................................... 58

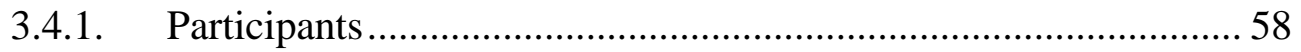

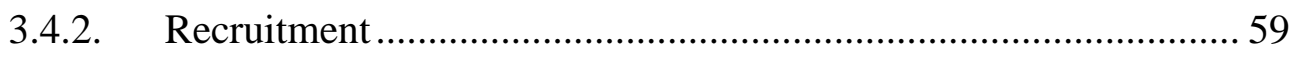

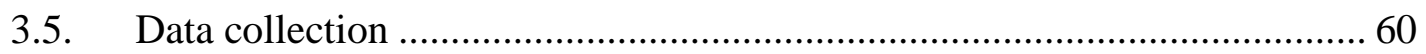

3.5.1. Quantitative and qualitative data from questionnaires................... 60

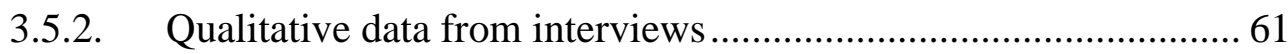

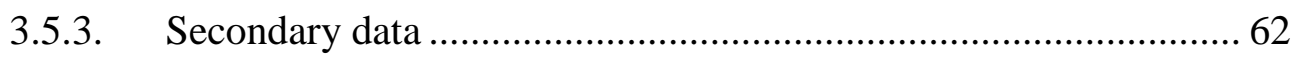

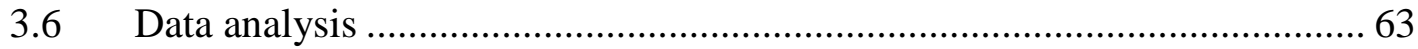

3.6.1. Questionnaire analysis ................................................................ 64

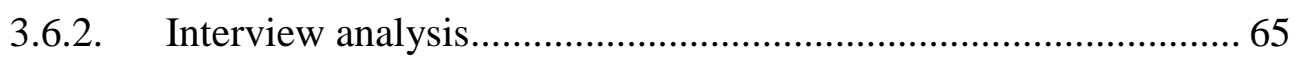

3.6.3. The integration of findings from questionnaires and interviews .. 65

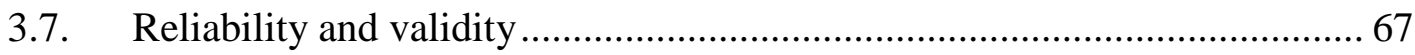

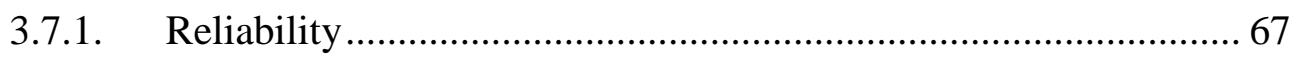

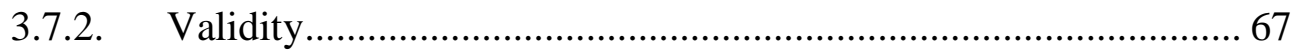

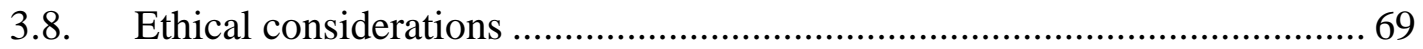

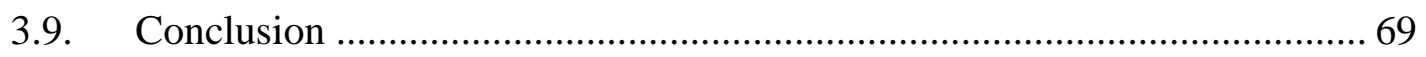

CHAPTER FOUR: THE STUDY FINDINGS .............................................................. 70

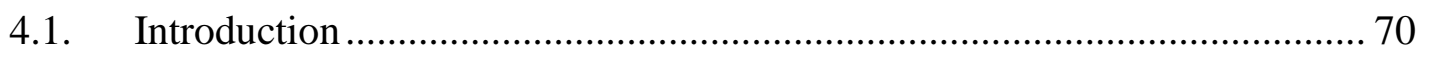

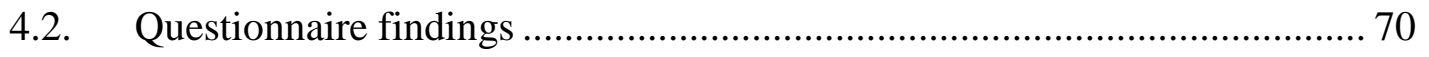

4.2.1. The participants' background information..................................... 71 
4.2.2. The participants' perceptions and experiences of the effect of language barriers on their relationships with Vietnamese teachers and their academic performance while studying at An Giang University

4.2.3. The participants' perceptions and experiences of the effect of cultural differences on teacher-student relationships and academic performance

4.2.4. The participants' experiences of their academic performance and satisfaction levels with the academic experiences while

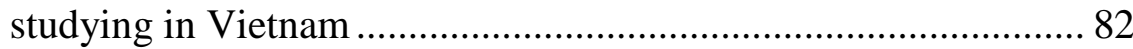

4.2.5. Conclusion of questionnaire findings......................................... 87

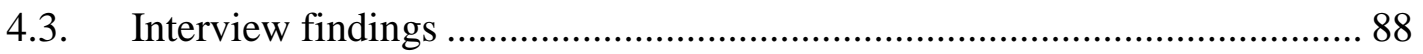

4.3.1. Characteristics of the interviewees................................................. 88

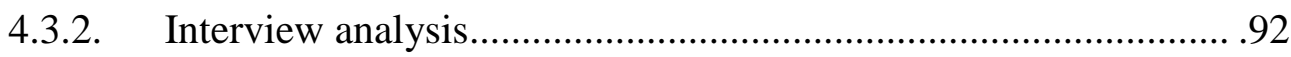

4.3.3. Conclusion of interview findings ................................................ 128

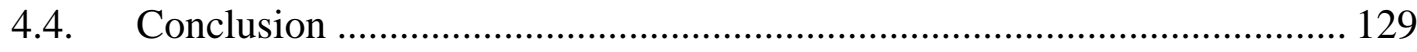

\section{CHAPTER FIVE: INTEGRATION, DISCUSSION, AND RECOMMENDATION.130}

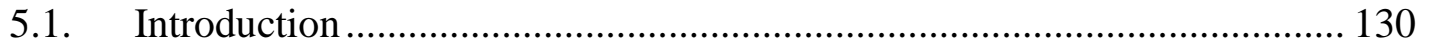

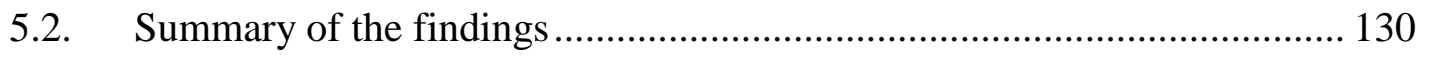

5.2.1. Findings of questionnaires and interviews of international students' responses on research question 1 - "What are Cambodian and Laotian students' perceptions and experiences of linguistic and cultural differences when they are studying at An Giang University?"

5.2.2. Findings of questionnaires and interviews of international students' responses on research question 2 - "How do teacher-student relationships affect international students' academic performance when they are studying at An Giang University?". 134

5.2.3. Findings of questionnaires and interviews of international students' responses on research question 3 - "What are international students' expectations, levels of satisfaction, and recommendations when they are studying at An Giang University?" ......................................... 135 
5.3. Integration of findings with the literature ............................................ 136

5.3.1. Linguistic barriers .......................................................... 136

5.3.2. Cultural differences ............................................................... 137

5.3.3. International students' expectations and satisfaction levels........ 139

5.4. Implications and recommendations for practice .................................. 139

5.5. Implications and recommendations for future research .......................... 141

5.6. The paradigm of international students' academic experiences at a higher education institution in Vietnam ....................................................... 142

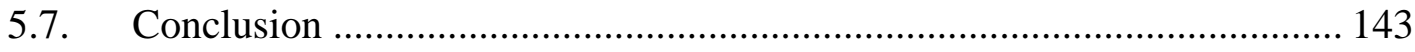

CHAPTER SIX: CONCLUSION .............................................................................. 145

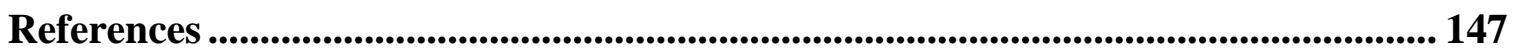

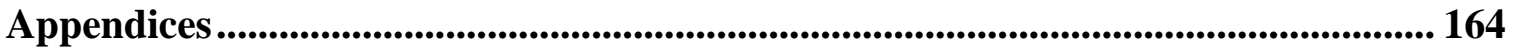

Appendix A: Information sheet (Questionnaire) ............................................. 164

Appendix B: $\quad$ Participant consent form (Questionnaire) ........................................ 166

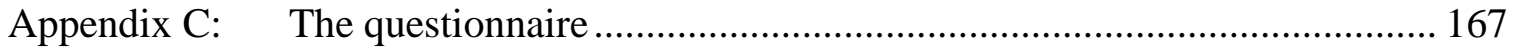

Appendix D: $\quad$ Information sheet (Interview) .................................................. 172

Appendix E: Consent to participants in the research (Interview) $\quad$............................ 174

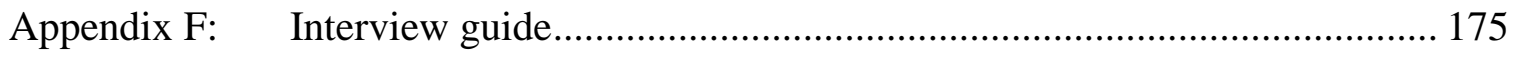

Appendix G: Information sheet (For the Head of Department) ............................. 177

Appendix H: Research consent form (For the Head of Department) ....................... 179 


\section{Lists of Figures}

Figure 2.1: The Relational Map of Teaching and Learning (Hall \& Kidman, 2004).. 16

Figure 2.2: The structure of the national education system of Vietnam..................... 32

Figure 2.3: The growth of higher education institutions in Vietnam ......................... 34

Figure 2.4: The growth of international students enrolment in higher education in

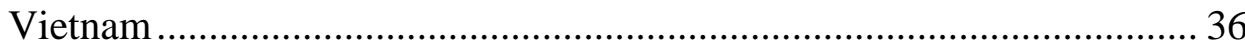

Figure 2.5: The structure of the national education system of Cambodia .................. 40

Figure 2.6: The percentage of each school age group enrolled for education in

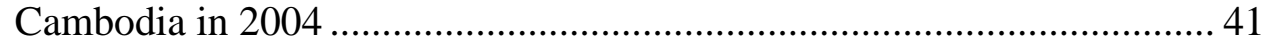

Figure 2.7: Programme levels of the national education system of Laos PDR .......... 43

Figure 2.8: The percentage of each school age group enrolled for education in Laos

PDR in 2004

Figure 2.9: The percentage of each school age group enrolled for education in Vietnam in 2004

Figure 2.10: Key agricultural export commodities in 11 months of 2007

Figure 3.1: Grounded theory coding from Open Coding to Axial Coding Paradigm . 52

Figure 3.2: Diagram of the data analysis of the study ......................................... 54

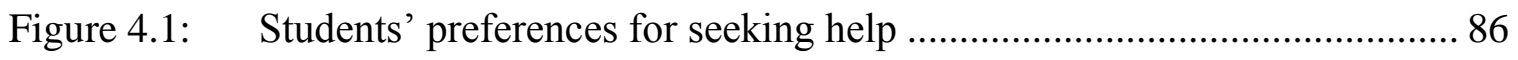

Figure 4.2: Where students found help during their study in Vietnam ..................... 86

Figure 4.3: Students' ranking of the important factors contributing to their academic

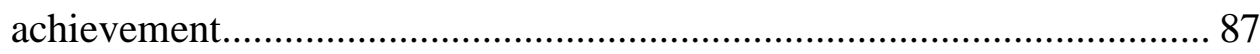

Figure 5.1: The correlation between students' levels of study and students' confidence in Vietnamese language proficiency 131

Figure 5.2: The paradigm of international students' academic experiences at a higher

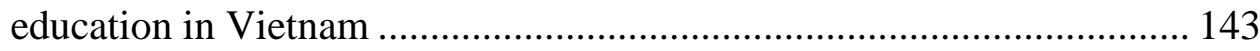




\section{Lists of Tables}

Table 4.1: The age range of the participants ........................................................ 72

Table 4.2: $\quad$ Students' confidence in their Vietnamese proficiency............................ 73

Table 4.3: Students' perceptions of the impact of linguistic barrier on their relationships with their Vietnamese teachers ..................................... 74

Table 4.4: Students' difficulties in communicating in Vietnamese ......................... 75

Table 4.5: Students' relationships with their Vietnamese teachers......................... 77

Table 4.6: Students' difficulties in participating in class activities.......................... 77

Table 4.7: Students' perceptions of the impact of cultural differences on their academic

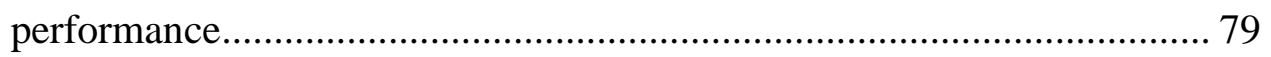

Table 4.8: Students' perceptions of the impact of cultural differences on their relationships with Vietnamese teachers ........................................... 80

Table 4.9: Students' experiences of help from Vietnamese teachers understand cultural

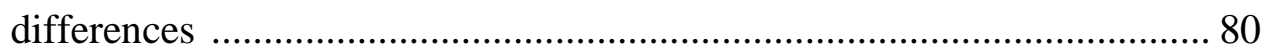

Table 4.10: Students' difficulties in adapting to Vietnamese culture ........................ 81

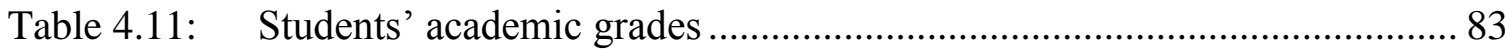

Table 4.12: $\quad$ Students' self-evaluation of their academic performance ........................ 83

Table 4.13: Students' satisfaction with their academic performance........................... 84

Table 4.14: $\quad$ Students' explanations for their academic satisfaction levels.................. 84 


\section{CHAPTER ONE \\ INTRODUCTION}

\subsection{Introduction}

This thesis examines international students' experiences of language barriers, cultural differences and their rapport with Vietnamese teachers while studying at a higher education institution in Vietnam. In this chapter, the research rationale, significance, research purpose, and the context are presented. In addition, the main research questions are identified. This chapter also outlines how the study was organized.

\subsection{Rationale of the study}

The internationalization of higher education across the world has led to an increase in the number of international student enrolments especially in the past 25 years (Charlesworth, 2007). Knight (2007) has argued that there are many challenges in terms of how this environment affects international students. These challenges include language barriers in the classroom, different kinds of learning styles, and the need to develop methods to effectively assess all students in a culturally diverse classroom (Crose, 2011). In light of this, it is important for university administrators and staff to think seriously about the kinds of challenges that international students face and the adjustments they must make when studying abroad (Crose, 2011).

International student enrolment in higher education institutions in Vietnam is also gradually increasing. An annual report of the Vietnam International Education Development (VIED) in 2011 showed that the number of international students studying at universities in Vietnam increased from 916 students in 2010 to 1,370 students in 2011. Although this is a much smaller overall number of students compared with that of other well-known universities in the world, it marks a new step forward in the internationalization of higher education in Vietnam. 
Most international students enrolled in universities in Vietnam are from the neighbouring countries of Cambodia and Laos. The number of Laotian and Cambodian students studying in higher education in Vietnam has gradually increased over time. A recent report from the Annual Meeting of Laotian students in Vietnam in November 2010 showed that 4,709 Laotian students were registered in Vietnamese universities between 2006 and 2010 (Vietpeace reporter, 2010). At the same time, a report from the Annual Meeting of Cambodian students in Vietnam tabled in December 2010 showed that 1,100 Cambodian students enrolled in Vietnamese universities from 2006 to 2010 (Bao Moi Reporter, 2011). Although the number of Laotian and Cambodian students is still very small compared to 1,700,000 Vietnamese higher education students (Annual report from MOET, 2010), it shows that higher education in Vietnam is joining the trend towards internationalization. The level of education they receive varies from undergraduate, post-graduate levels as well as professional degrees and certifications. Cambodian and Laotian students studying in higher education come from various backgrounds; for example, some are governmental officers, others have come from high school, or are lecturers in higher education institutions. However, most Laotian and Cambodian students studying in Vietnam are governmental officers in their own countries who have received scholarships either from their own governments or from the Vietnamese government. Most of these scholarships enable students to complete short training courses for professional degrees, certifications, and undergraduate degrees. After finishing undergraduate degrees in Vietnam, most of these students return home to continue working for their own governments at a higher level of responsibility (Thanhnien Reporter, 2008).

\section{- The higher education context in Vietnam}

Higher education in Vietnam's recent history has developed against a backdrop of war and slow economic development. However, despite these challenges, higher education in Vietnam has gradually improved in size and quality.

Political, economic, and educational development in Vietnam has been framed by periods of foreign occupation. China occupied the country until the tenth century and the French occupied Vietnam until the mid-twentieth century. In addition, two decades of civil war slowed the pace of development until the 1970s. In the immediate post-war period, the 
national government prioritized the rebuilding of the economy from the post-war aftermath and the education system received little attention. Soon after the Declaration of Independence that declared to the world the success of the Viet Minh Independence revolution in 1945, Ho Chi Minh, the country's leader, focused on improving the education system. During that time, the education system was widely reformed in urban areas across the country although for a long period of time, the education system in Vietnam continued to be out-dated and lacked status (Nguyen, 2011).

However, since that time, education has been considered increasingly important to the development of the country. Subsequently, funding for education development in Vietnam has been accorded a much greater priority by the government.

In the past 26 years, the 'Đổi Mới' policy has been the most significant policy change aimed at fostering educational development in Vietnam. In 1986, the Vietnamese National Assembly approved the implementation of the 'Đổi Mới' (renovation) policy which was a multifaceted approach to development in Vietnam. Đổi Mới is the name given to the economic reforms initiated in Vietnam in 1986 which have the goal of creating a "socialistoriented market economy" where the state plays a decisive role in the economy but private enterprise and cooperatives also play a significant role in commodity production. In the 1990s, the Đổi Mới facilitated a range of new international relationships as Vietnam opened the door to the capitalist West and East Asia for the purpose of establishing diplomatic relationships. The Communist Party of Vietnam has since reaffirmed its commitment to the socialist economic orientation but affirms that the Đổi Mới economic policy shall strengthen socialism (Dao, 2003). Accordingly, economic recovery strategies have been put in place and higher education has become an important part of this process (Runckel, 2009). These moves are part of the internationalization or globalization process of the Vietnamese economy. Since the Đổi Mới, the country has achieved major transformations that have affected every aspect of economic and social life in Vietnam, including education.

The role of education, and higher education in particular, in increasing international cooperation as part of the development process has also been demonstrated in Vietnamese education legislation. For example, the importance of a "knowledge society" was highlighted in Vietnam's Education Law in 1998 (Article 1 and Article 15) which 
emphasizes the importance of teachers, researchers, and higher education specialists in the nation's development.

Education is also seen to play an important role in maintaining and strengthening relationships with neighbouring and foreign countries. Vietnam's 2005 Education Law (Article 108) emphasized the need for educational cooperation with foreign countries and the importance of entering the globalised educational arena. The importance of building good international relations has also been recognized and incorporated in Vietnam's government policy. For sustainable development, the government has acknowledged that Vietnam needs to strengthen long-term relationships with neighbours such as Laos, Cambodia, and Thailand as well as widen its international relationships with other countries around the world through establishing educational programs such as exchange programs and sponsored scholarships for international students to study in Vietnam. In this way, it is hoped that by engaging with globalization in education forums, Vietnam will have an improved capacity to maintain peaceful relationships with other countries.

The admittance of Vietnam into the World Trade Organization in 2007 has placed greater pressure on the government to improve the quality of the higher education system, and establish a system of "world-class universities" within the country. While higher education institutions across the world compete for international student enrolments, higher education in Vietnam still needs to build the quality of teaching and learning in order to compete with other educational institutions globally. The notion of the 'world-class university' is now seen as a central priority in education policy in Vietnam. The first step for achieving these goals has been to encourage international students to enrol in undergraduate degrees in Vietnamese universities and to this end a system of scholarships has been established for them by the Vietnamese government.

Higher education in Vietnam has seen some significant improvements. The number of universities in Vietnam has increased in order to accommodate the needs of its population of 88 million (e.g. the number of higher education institutions has risen from 153 in 1999 to 376 higher education institutions in 2009) (Luu, 2011). There has been greater emphasis placed on improving the quality of teaching at universities and this can be seen most clearly in the 322 Project of the Vietnamese International Education Development (VIED). This 
academic capacity-building project enables Vietnamese lecturers to study in prestigious universities in different parts of the world. After graduating, these lecturers actively contribute to the nation's higher education development. As a result of the VIED project, the number of internationally recognized researchers working in higher education institutions in Vietnam has significantly increased (VIED, 2011).

However, as higher education in Vietnam has become more "internationalized", problems have also emerged. Pham and Fry (2004) argue that "the quality of Vietnamese higher education is still problematic both according to the official evaluation and public opinion" (p.211). Tran (2011) contends that the rapid increase of international students in different countries increases the pressure on academics to satisfy the diverse needs of international students. In light of these ideas, it is important that Vietnamese academics think seriously about how they might contribute to improving the academic experiences of international students who come to Vietnam to study.

Education in Vietnam retains some shortcomings that may negatively affect international students' learning in higher education. These shortcomings include poor teaching methods and culturally inappropriate behaviour of some Vietnamese teachers towards their students. In practice, teaching in Vietnam has been heavily teacher-centred, and some studies have shown that many teachers are unreflective and maintain their authority largely by transmitting knowledge to passively listening students (Nguyen, 2003; Sloper \& Le, 1995). Negative comments have also been made about Vietnamese teachers' behaviour towards students when teachers are known to be unfriendly and show no respect to their students (Dantri, 2011). This is discouraging for Laotian and Cambodian students many of whom are not fluent speakers of Vietnamese and may feel very isolated in these situations.

Cohen (2003), Lee and Rice (2005), Campbell and Li (2008) argue that a central goal of higher education should be to prepare culturally competent individuals who have the ability to work effectively with people from different backgrounds. However, teaching and learning in multi-linguistic cultural contexts may present challenges for both teachers and students. Ryan and Carroll (2005) argue that in western institutions, many lecturers experience anxiety as a result of the dilemmas associated with addressing international students' needs and keeping up with the expectations and standards of the institutions at the 
same time. Similarly, teachers are required to communicate well and clearly about lessons with international students in ways that will help them to meet teaching and learning outcomes. In particular, Vietnamese teachers who teach Laotian and Cambodian students may encounter a number of difficulties in achieving successful academic outcomes if they have not found ways of working constructively with students from different countries and cultures.

It is important that teachers find ways of helping their international students overcome difficulties so that they are able to perform well academically. Kidman (1994) argues that academic staff not only need training in teaching skills, but they also need to acknowledge how their students experience the learning environment. Additionally, there is an increasing amount of research on the issue of how teachers mediate between issues of culture and regional politics with international students in their pedagogical practice (Hamre \& Pianta, 2001; Singh \& Doherty, 2002; Crosnoe, Johnson, \& Elder, 2004; Hamre, Pianta, Downer, \& Mashburn, 2008; and Peguero \& Bondy, 2011). Arguments from Hall and Kidman (2004), Elson-Green (2007), Brown and Reushle (2010), and Peguero and Bondy (2011) have also focused on the importance of teachers in students' academic success. Yet, as Apfelthaler, Hansen, Keuchel, Mueller, Neubauer, Ong and Tapachai (2007) have argued "despite the fact that both learning styles and cross-cultural differences have been important research topics for decades, surprisingly little work has been done on comparisons of learning behaviour across cultures and its impact for teachers working in a culturally mixed setting" (p.15). These arguments support the idea that teachers have an important role in enhancing international students' academic outcomes and there is a need for further research in this area.

International students come to Vietnam to obtain degrees or certificates, new knowledge and skills. To be able to succeed, they need to find ways of engaging with the new culture and overcoming the difficulties of learning a new language. The importance of the role of teacher-student relationships and its connection with academic achievement has drawn the attention of researchers internationally (Hullena, 2004; Averill, 2009; Peguero \& Bondy, 2011). 
Language barriers and cultural differences can cause numerous difficulties for international students when they are studying overseas. Campbell and Li (2008) characterized language difficulties and cultural differences as intercultural communication barriers, unfamiliar patterns of classroom interactions, lack of knowledge of academic norms and conventions, inadequate learning support, difficulties in making friends with domestic students, and lack of belonging, all these combining to affect Asian students' perceptions and levels of satisfaction with their learning experiences at the university. International students go through multiple processes of psychological, physical, and mental adjustment (Campbell \& $\mathrm{Li}, 2008$ ). They are responsible for fulfilling their educational needs as well as the needs of their daily lives. The topic of international academic experiences has been widely researched by many notable educators such as Sakthivel (2003), Marr (2005), Campbell and Li (2008), Zhang and Mi (2010), Zhadko (2011). However, no research or literature to date has identified the challenges that Laotian and Cambodian students face when they are studying at universities in Vietnam.

Being an international student myself, and studying at Victoria University of Wellington, I initially encountered many obstacles with language, cultural differences, and academic life in New Zealand. However, the abundance of academic support and encouragement from lecturers and student learning support services has helped me to overcome many difficulties. This acknowledgement has encouraged me to do research that investigates how Laotian and Cambodian students experience language barriers, and cultural differences, and the level of rapport they have with their teachers in Vietnam. I am also interested in how these factors affect their academic achievement in the Vietnamese university setting.

In summary, this study investigates some of these tensions by focusing on exploring Laotian and Cambodian students' experiences and perceptions of the effect of language difficulties and cultural differences on their teacher-student relationships and their academic performance while studying in Vietnam. Gu, Schweisfurth and Day (2009) assert that the experiences of international students provide an indicator of the quality of the provision of education. In addition, Kidman's (1994) research about students' experiences has recommendations for university teachers, academic staff, and administrators about improving the teaching-learning environment. Her later paper with Hall (2004) emphasizes the importance of establishing good rapport in teachers' academic relationships with 
students. Following on from these two studies, I have chosen to explore the academic experiences of international students at An Giang University focusing particularly on the quality of teacher-student relationships and how these are played out in the linguistic and cultural context of that institution. Hopefully, this study will raise awareness amongst Vietnamese teachers who are teaching international students in universities in Vietnam. In addition, this study aims to provide a source of reliable information for administrators to assist them to develop appropriate policies in educating Laotian and Cambodian students in Vietnamese universities.

In order to investigate the topic of Cambodian and Laotian students' experiences of language barriers, cultural differences, and teacher-student rapport in a university in Vietnam, I developed questionnaires and interview guides to collect data from Laotian and Cambodian students who were studying at An Giang University.

\subsection{Context of the study}

The research site is located in the Mekong Delta which is in the An Giang province of Vietnam. An Giang province has established close relationships with the Champasak province of Laos and the Kandal and the Phnong Penh province of Cambodia. In addition, An Giang province is known as the most important granary of South Vietnam thanks to the natural agricultural environment and development of successful agricultural techniques. Consequently, agriculturalists and scientists from Laos and Cambodia frequently come to An Giang to learn agricultural skills by attending workshops and forums in An Giang Province.

An Giang University (AGU) was established in 2000. It is administered by the People's Committee of An Giang province. The Agriculture Department is the biggest and most important department in AGU. Since its establishment, a number of international researchers and specialists have conducted their agricultural and environmental research at the University. According to the annual report of AGU, the University has held many international workshops and research projects on agriculture. Since 2007, the People's Committee of An Giang Province has granted scholarships to learners from Laos and Cambodia that enable them to enrol in Vietnamese language competence courses and 
undergraduate degrees majoring in agriculture at AGU. This initiative is a way of strengthening relationships between An Giang province and Laos and Cambodia as well as satisfying the increasing need to apply new agricultural practices in Laos and Cambodia.

However, as a newly established university, the administration system and academic policies of AGU are based on those of other prestigious universities such as The Vietnam National University in Ho Chi Minh City and The Vietnam National University in Ha Noi but many of its policies and programmes are still under development. In addition, no training is provided to administrative staff and teachers who are in charge of international students at the university. Consequently, it is sometimes a challenge for staff at AGU and foreign students from Laos and Cambodia to work together to improve academic outcomes at AGU. Most importantly, these international students have to study and complete the same four-year undergraduate degree which is taught in the Vietnamese language as Vietnamese students. Anecdotally, it appears that some teachers at AGU have yet to learn how to carry out a class effectively with a mix of indigenous students whose mother tongue is Vietnamese and foreign students who have a low competence in Vietnamese. However, no formal research has been undertaken at the university yet. The current research will contribute to the evidence-base for the university.

At the time this study was conducted there were 24 international students in total who were enrolled at AGU. This included 17 Laotian students and 7 Cambodian students. Twelve Laotian students were enrolled in a nine-month Vietnamese language proficiency class which they had to complete before they started their undergraduate degree with other Vietnamese students at the University. The other five Laotian and seven Cambodian students had recently graduated from their undergraduate degree programme. All the international students who were enrolled in the undergraduate programme were doing their studies in the Natural Resources and Agriculture Department at AGU.

The Laotian and Cambodian students involved with this study were in the process of working through language difficulties associated with their studies. All of these students studied a nine-month Vietnamese language competence course before entering their undergraduate degrees. Normally, international student studying at overseas universities, have to obtain a standard language requirement of the university, for example TOEFL or 
IETLS, or EPP. However, the Laotian and Cambodian students at AGU only needed to attend a nine-month Vietnamese language competence course before they started their undergraduate degrees. It should be noted here that the language of instruction is $100 \%$ Vietnamese and the undergraduate degree programme is largely made up of Vietnamese students for whom Vietnamese is their first language. Many of the Laotian and Cambodian students have to deal with language barriers in their classrooms. Teachers in these classes with Laotian and Cambodian students also face difficulties in moderating their teaching in order to satisfy both the international students' needs and the needs of local Vietnamese students.

\subsection{Purpose of the study and research questions}

This study aims to investigate Laotian and Cambodian students' experiences of linguistic difficulties, cultural differences, and their rapport with Vietnamese teachers. Moreover, this study also examines how these experiences of Laotian and Cambodian students may affect their academic performance and levels of satisfaction while they are studying at AGU, Vietnam. International students would face difficulties in their new environment of culture and language. While teacher-student relationship is necessary for successful academic outcome, it may be problematic for Laotian and Cambodian students to build good relationships with Vietnamese teachers because of their limitation of language. It is necessary to examine their perceptions and real experiences in order to improve their academic lives as well as hopefully prevent possible obstacles during the time they are studying at AGU. By this way, AGU would gain prestige and respect from Laos and Cambodia in order to increase the number of international students' registration in Vietnamese higher education.

The objectives of this research are:

- To investigate Laotian and Cambodian students' expectation, level of satisfaction and their recommendation when they are studying at An Giang University.

- To investigate Laotian and Cambodian students' perceptions and experiences of the effect of linguistic difficulties on their academic performance and their teacherstudent relationships. 
- To investigate Laotian and Cambodian students' perceptions and experiences of the effect of a different culture on their academic performance and their teacher-student relationships.

- To provide helpful recommendations for administrators at AGU so that they can adjust policies of the university in order to assure good quality of teaching and learning for international students at the university.

- To provide recommendations for future research in order to improve the academic experiences of international students who are attending higher education in Vietnam.

The purpose of this study is to investigate academic experiences and teacher-student relationships of Laotian and Cambodian students at AGU. The following research questions are sought to be answered in this study:

Central research question:

"What are the academic experiences of Cambodian and Laotian students at a Vietnamese university: A grounded theory approach?"

Sub-questions:

- What are Laotian and Cambodian students' perceptions and experiences of the linguistic and cultural differences when they are studying at An Giang University?

- How do teacher-student relationships affect international students' academic performance in different language and cultures?

- What are international students' expectations, satisfaction levels, and recommendations when they are studying at An Giang University?

\subsection{Significance of the study}

Although it is important to understand international students' needs and difficulties for a successful academic outcome, no previous research exists about academic experiences of Laotian and Cambodian students in higher education in Vietnam. The result of this research will hopefully add to the body of knowledge and will provide insight to discourse in the field of international students at Vietnamese higher education. 
The study offers Laotian and Cambodian students an opportunity to voice their views regarding their academic experiences in Vietnamese higher education as well as their perceptions and real experiences of the effect of linguistic and cultural differences on their teacher-student relationships and their academic performance. The findings of this study are potentially useful and informative to a wide spectrum of people working in higher education involving international students in Vietnam.

While it seems that education in Vietnam has not emphasized the necessity of teacherstudent rapport in teaching and learning, this study would like to place an emphasis on the essential role of rapport between teachers and students, especially between teachers and international students in an effective teaching and learning process.

Higher education institutions in Vietnam can benefit from this research by understanding international students' academic experiences and difficulties and will be able to prepare international students to adapt to the new environment of culture and language when they are studying at Vietnamese higher education. Recruitment and retention program administrators can gain knowledge that will allow them to serve international students more effectively. Academic and students' affairs administrators and staff should find this study useful for international students' activities and recommend findings from this study to international students at Vietnamese higher education. The results might be used for developing training and resource materials for prospective international students.

Graduate students preparing to work in the area of international education will find a comprehensive analysis of the selected literature on the following topics: internationalization of higher education, international students' difficulties, and teacherstudent relationships. The result of the study provides an overview of a wide range of issues on international students' experiences regarding new language and culture.

Prospective international students preparing to pursue their education in Vietnam will find a comprehensive description of the experiences of Laotian and Cambodian students and might use that information to prepare themselves to meet the requirements and demands of the Vietnamese education and life abroad in Vietnam. 
As indicated above, beyond all practical implications that the results of this study could offer, the findings might bring new insights to discourse in the field of international education and call for further research.

\subsection{Definition of term}

For the purpose of this research, the following definition will be used:

International student is a person who is currently enrolled in college classes in a foreign country, and is not permanent resident of this foreign country (Zhadko, 2011).

\subsection{Limitations of the study}

This study aims to explore the teacher-student relationships of Laotian and Cambodian students with Vietnamese teachers. However, data was only collected from Cambodian and Laotian students. It is better if the researcher can collect data from Vietnamese teachers who are teaching these Laotian and Cambodian students.

The researcher in this study has a deep interest in internationalization of higher education and rapport between teachers and students. The fact that the researcher herself is an international student might be a limitation to this study. The researcher might assume that some notions of the experiences of international students might be self-explanatory while an outsider might need more details to be able to fully comprehend the notion. In this case, the researcher will address this issue with awareness.

\subsection{Organization of the thesis}

This thesis is organized into six chapters. Chapter one presents an introduction to the thesis. Chapter two provides an overview of the relevant literature review and the theoretical framework for the study. Chapter three describes the research design and methodology of the study. The sample selection, data collection methods, procedures, and data analysis are also described in chapter three. Chapter four presents the findings from the questionnaires 
and interviews. Chapter five provides a summary and integration of findings from questionnaires and interviews. The findings are also placed into context with the academic literature in the field. This is followed by a discussion about the implications of the research and recommendations for practice and future research are provided. A paradigm outlining international students' experiences at a higher education in Vietnam is also introduced in chapter five. Finally, chapter six concludes the thesis. 


\section{CHAPTER TWO \\ LITERATURE REVIEW}

\subsection{Introduction}

This study explores Laotian and Cambodian students' experiences of language barriers, cultural differences, and rapport with Vietnamese teachers. It also examines how these experiences affect their academic expectations, levels of satisfaction with their studies and seeks their suggestions for ways of improving their overall academic experience at An Giang University. In this chapter, a range of literature is reviewed in order to provide a background understanding of the key themes of the study.

The literature reviewed in this chapter focuses on the role of teacher-student relationships and examines the factors that can help teachers to establish good relationships with their students. In addition, this study aims to explore Laotian and Cambodian students' experiences in higher education in Vietnam and in light of this, some of the literature on international students is reviewed. A review of higher education in Vietnam, Laos and Cambodia is also provided in this chapter. Literature regarding factors that attract international students to study in higher education in Vietnam is also discussed in this chapter. 


\subsection{The role of teacher-student relationships in teaching and learning}

\subsubsection{The Hall and Kidman (2004) map (model) of teaching and learning.}

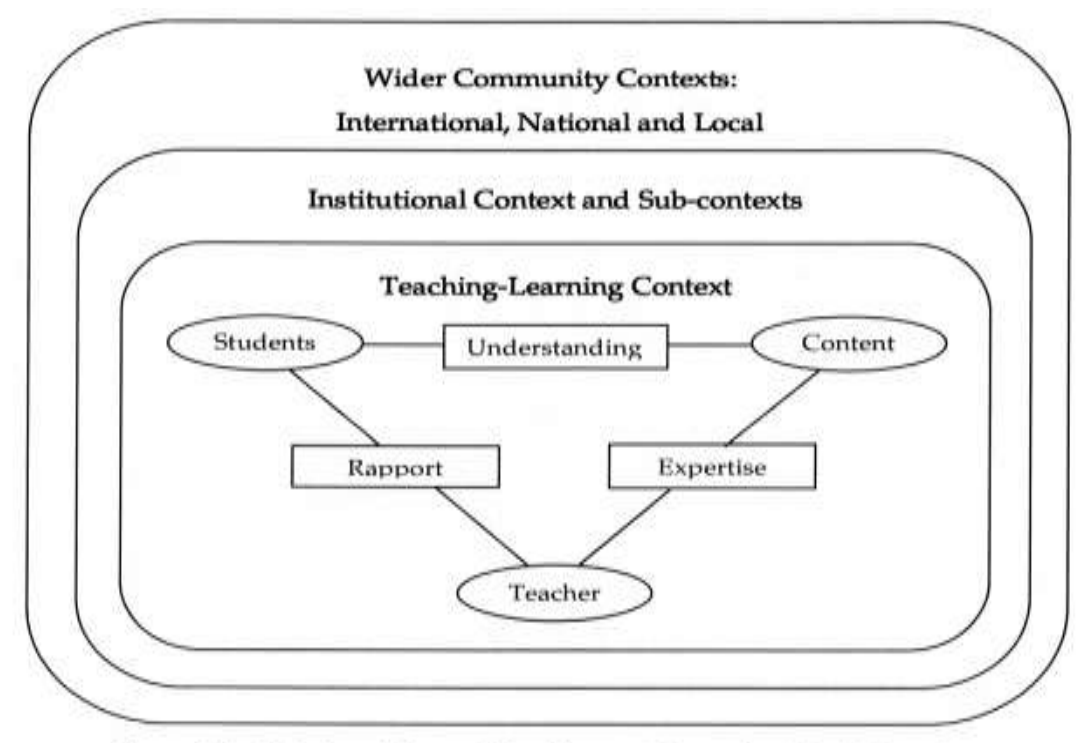

Figure 2.1: $\quad$ The Relational Map of Teaching and Learning (Hall \& Kidman, 2004)

This research is derived from the researcher's interest in the relational map of teaching and learning developed by Hall and Kidman (2004). This relational map of teaching and learning (T-L) demonstrates both the multifaceted and complex nature of teaching and learning and the importance of teacher-student relationships in the higher education teaching and learning process. Using this T-L map as a way of thinking about teaching and learning, Hall and Kidman (2004) argue that the teaching and learning process is affected by a range of contextual factors. These contexts include wider international contexts, national and local environments, institutional contexts and sub-contexts, and the teaching and learning context. The teaching and learning context is placed at the heart of the T-L map and it is directly affected by the way that relationships between the teacher, the student, and the content are managed. Hall and Kidman (2004) argue that effective teaching and learning takes place when students understand the content, which is supported both by the teachers' expertise in the subject, and the rapport that is developed between teachers and students. They argue that the teacher's level of expertise is an important factor in communicating content in an appropriate way. At the tertiary level, teachers enhance their 
expertise of the content by keeping abreast of their subjects, conducting research, networking with colleagues and integrating up-to-date research findings into their teaching (Hullena, 2008). Hall and Kidman (2004) emphasize that good rapport is derived from teacher's attitudes, values, behaviours, beliefs, and skills and they argue that these factors can be channelled in ways that promote positive academic outcomes.

Hall and Kidman's (2004) relational map of teaching and learning suggests that effective teaching and learning usually involves a good level of rapport between teachers and students. It is therefore important to establish rapport between teacher and student for an effective teaching and learning process.

\subsubsection{Factors contributing to rapport in teacher-student relationships.}

There is a clear link in the teaching and learning literature between positive teacher-student relationships and positive academic outcomes and this is discussed further in this section.

\subsubsection{The role of teachers in promoting academic outcomes.}

Laotian and Cambodian students studying at An Giang University face several challenges in their academic lives. These challenges may relate to cultural differences or language barriers. As international students enrolled in undergraduate degree programmes, they spend much of their time in the classroom so teachers play an important role in helping students adapt to the new culture and language environment. Vang (2010) argues that classroom teachers often have more insights than administrators in identifying students' needs because they are with the learners for greater periods of time so it is important to explore these factors in some depth.

In the learning process, teachers and students are two of the most important key elements. Many educators acknowledge the importance of establishing positive teacher-student relationships as part of an effective teaching and learning process. The relationships between teachers, students, and academic achievement have drawn the attention of researchers internationally (Hill \& Hawk, 2000; Hall \& Kidman, 2004; Duff, Boyle, Dunleavy \& Ferguson, 2004; Hullena, 2008; Averill, 2009). Bishop, Berryman, Tiakiwai, \& 
Richardson (2003) found a correlation between positive teacher-student relationships and high academic quality. Hall and Kidman (2004) argue that the academic process is affected by many different contexts and factors in which the rapport or relationship between teachers and students directly affects the learning outcomes. Pianta (1999) agrees that the relationships between teachers and students contribute to the teaching and learning process and successful academic outcomes. Hamre and Pianta (2001) also argue that the relationships between teachers and students play an important role in students' academic achievements as well as shaping their personalities as learners. Supporting this point of view, Elson-Green (2007), and Hamre, Pianta, Downer and Mashburn (2008) contend that the teaching and learning process needs to facilitate a collaborative engagement between teachers and students. Averill (2009) asserts that "understanding more about effective teacher-student relationships will help inform educators how academic, emotional, and social aspects of teacher practice can be improved, and thereby enable the quality of, and equity in, student learning opportunities to be enhanced" (p.2). Acknowledging this crucial factor, Averill (2009) focuses on exploring the factors that contribute to effective teacherstudent relationships within a multicultural classroom in New Zealand. Similarly, Brown and Reushle (2010) focus on the importance of establishing a positive two-way exchange of information between teachers and students. More recently, Peguero and Bondy (2011) have argued that a consistent relationship between teachers and students in academic life and also in students' daily lives is the first step for promoting academic success.

While motivation and engagement are very important factors in teaching and learning, effective teacher-student relationships do not simply motivate and engage students, they also motivate and engage teachers in the teaching and learning process. Recent research has shown that effective teacher-student relationships affect student engagement, motivation, and achievement. For example, Hullena (2008), Averill (2009), Hullena and Hullena (2010) argue that teacher-student relationships greatly influence students' motivation and achievement.

Those teachers closest to the students often have a key role in students' academic success. Vang (2010) argues that classroom teachers have a better perspective on identifying students' needs because they are with the learners most of the time in class. Teachers can also help international students understand and adapt to the new cultural environment as 
Vang (2010) argues, "these teachers can play another vital role in multicultural education by making sure that cultural factors are taken into consideration when prescribing individualized education plans for students of minority cultures" (p.320). Furthermore, Strunk and Chang (1999), and Strang (2008) argue that students' learning styles are often shaped by their cultures; therefore, teachers in a multicultural education setting need to be aware of this so that they can help students become familiar with new learning styles or processes in a new country.

Although the role of teachers in multicultural education settings and the relationships between teachers and students have been acknowledged as being very important for students' academic learning and life experiences, Peguero and Bondy (2011) assert that the relationships between teachers and students have received less attention from educators themselves. Moreover, Crosnoe, Johnson, and Elder (2004) argue that under some circumstances student-teacher relationships can block educational success if race or ethnicity becomes an invisible barrier in student-teacher relationships.

These arguments emphasize the importance of the role of teachers in students' success. Students can be more motivated and engaged with learning if teachers support them and are willing to build rapport in the classroom. The role of rapport is especially important in multicultural classrooms with groups of international students, some of whom may be experiencing difficulties with the language of instructions or differences in cultural priorities or understandings.

\subsubsection{Teachers' attitudes, values, behaviours, beliefs, and skills.}

As noted earlier, Hall and Kidman (2004) argue that rapport, or positive teacher-student relationships, derives from teachers' attitudes, values, behaviours, beliefs, and skills. Hullena (2008) lists several factors that contribute to teacher-student relationships. They include an understanding of the students' cultural worlds; being sensitive to students'

moods; listening and dialogue; spending time interacting with students; recognizing, accepting, and valuing individuality; showing consideration, concern, and compassion; acting in students' best interests; promoting students' self-esteem and self-confidence; being encouraging and promoting students' strengths; empowering students and involving 
them in decisions making; using humour appropriately; teaching well; developing a sense of community, connection, and belonging; managing the classroom well and creating safe classroom environments; showing respect and related values; and modelling appropriate behaviours and values. Each of the factors identified by Hullena (2008) were supported by evidence from the literature in the field. It is therefore crucial that educators recognize the importance of enhancing rapport if an effective teaching and learning process is to be created. This thesis aims to explore the main factors affecting the relationships between teacher and students in tertiary education particularly as they relate to teachers' attitudes, values, behaviours, and skills and in this respect; the literature is a useful way of thinking about these issues.

\subsection{Spending time interacting with students to understand the worlds of students.}

Developing an understanding of students' backgrounds and interests can emerge from spending time interacting with students, and this is seen by many researchers as a way of establishing good relationships with their students. Hill and Hawk (2000) claim that teachers who have a good understanding of their students' lives and the worlds they live in are able to develop more positive classroom relationships with them. In contrast, Cothran, Kulinna, and Garrahy (2003) found that teachers who fail to understand their students have less positive relationships with them.

Teachers can gain an understanding of students' worlds by listening and talking with their students. Educators, such as Noddings (1992), Tarlow (1996), Wentzel (1997), Cothran and Ennis (2000), Hill and Hawk (2000), and Hellison (2003) argue that listening to students and engaging in dialogue with them can help to build teacher-student rapport. According to Noddings (1992), interactive dialogue forms the foundation of positive teacher-student relationships because it promotes an emotional connection between students and teachers. Furthermore, by spending time listening and interacting with students, teachers are more likely to form an understanding of their students' interests and dislikes. This will help teachers to create classroom environments that meet the needs of students and enhance their motivation and engagement in learning. According to Tarlow (1996), such interaction helps teachers meet their students' growth and development needs. Tarlow (1996) further 
suggests that in order to build positive relationships with students, teachers need to set aside time for interacting with students, inside or outside of the classroom. In this way, teachers can come to understand not only their students' academic interests, strengths, and weaknesses but also aspects of their students' personal lives that may affect their academic outcomes.

Understanding students' lived worlds requires that teachers are sensitive, approachable, accessible, and have an (appropriate) sense of humour. Tarlow (1996) points out that sensitivity can help teachers to understand and better meet the needs of their students. Being sensitive to students' moods also means that teachers can sympathize with their students. According to Tarlow (1996), effective interaction between teachers and students happens when teachers are accessible and approachable. In fact, students are more likely to tell their teachers when they are experiencing difficulties in the classroom if they perceive their teachers as being approachable. Hellison (2003) also contends that teachers need to show a sense of humour and to be approachable and accessible to their students. It seems that when students view their teachers as being approachable, accessible, and sensitive to their worlds, students are more likely to open up to teachers about their feelings about the teaching and learning process, as well as their interests and classroom difficulties.

\subsection{Showing consideration, respect, and valuing students.}

Showing consideration, respect, and valuing students is part of the process of establishing rapport between teachers and their students. Researchers such as Noddings (1992), Wetzel (1997), and Hullena (2008) argue that in order to establish positive teacher-student relationships, teachers need to show students consideration and respect. In tertiary education contexts as well, learners need to feel they are valued.

Teachers can demonstrate their consideration for students when they give students the chance to reflect. Hellison (2003) asserts that each student has the capacity for making good decisions, and rapport between students and teachers is fostered when teachers give students the opportunity and time for reflection, even though they might get it wrong. Giving students opportunities for intellectual reflection then, is another way of showing respect for them. In that way, students may feel a greater sense of belonging and being 
accepted. These kinds of practices may also enhance students' self-esteem and selfconfidence in the teaching and learning process.

Teachers can demonstrate respect for their students when they give students opportunities to be involved in classroom decision making. Hullena (2008) argues that respect is the most important part of classroom management. Without respectful relations between students and teachers, students are less likely to engage in classroom learning situations (Cothran \& Ennis, 2000). According to Cothran and Ennis (2000), accepting students' ideas and involving them in classroom decision making can improve teacher-student relationships and affirm students' sense of belonging within the classroom. It also means allowing students to assume a sense of responsibility for their classroom community. Hullena (2008) also claims that a sense of belonging or a sense of connection is one of several components that promote positive teacher-student relationships. Cothran and Ennis (2000, as cited in Hullena, 2008) claims that having a sense of membership is an essential component of student engagement and learning.

In summary, students are usually more motivated and engaged with the classroom environment when teachers demonstrate consideration and respect for them and are willing to actively establish positive teacher-student relationships.

\subsection{Good teaching and classroom management.}

Good teaching is also important in tertiary environments. Cothran and Ennis (2000) state that knowledge of the subject and the curriculum is a factor in building good learning relationships. In addition, teachers need to listen to students' voices about how teaching can be improved. Wetzel (1997) argues that teachers need to think about their students' learning preferences as they construct the classroom curriculum.

Classroom management is also another factor contributing to the quality of teacher-student relationships. According to Hullena (2008), good classroom management is not only a requisite for good teaching and learning but it is also a factor influencing students' perceptions of care and rapport. Wetzel (1997) also claims that classroom management is 
one of several factors that play a significant role in the development of teacher-student rapport.

Hullena (2008) identifies a number of classroom management behaviours and techniques that positively affect students' attitudes towards their teachers. He argues that good classroom management involves teachers who are not only approachable, helpful, supportive, and caring, but also influential, authoritative, and capable of taking the lead. Hoy and Weinstein (2006, as cited in Hullena, 2008) identifies teachers with good classroom management as "teachers who were strict but not mean, teachers who had rules but were flexible in the application of them, and teachers who used their power not for oppression but in the moral interests of others. Also identified were teachers who were able to use humour to get students back on task, able to manage their own discipline issues, and teachers who were able to discipline in a fair and appropriate manner. This included not being biased, being prepared to listen to all sides of a story, being able to remain calm, and being able to impose sanctions without aggression, humiliation and hardness" (p.33). Teachers therefore need to be flexible in the way they interact with different students in different classroom situations.

In conclusion, rapport between teachers and students is an important factor in the teaching and learning context (Hall \& Kidman, 2004). However, it can be a demanding task for teachers to build good rapport. As mentioned above, in order to succeed in setting up good rapport with students, teachers are advised to spend time interacting with their students; showing consideration, respect, and valuing students; and promoting good teaching and classroom management. Most importantly, teachers need to be flexible in their behaviour and consideration for different students.

\subsection{International students' difficulties when studying abroad}

Host countries receive many benefits from international students, including financial benefits. Consequently, many host countries actively recruit international students. Zhang and Mi (2009) have argued that international students are welcomed for their contribution to the local economy and to the internationalization of the education system of host institutions but they contend that international students do not get exactly the same benefits 
as the host institutions. According to Kidman (1994), academic staff not only need training in teaching skills, but they also need to acknowledge their students learning experiences. Accordingly, international students' academic experiences also need consideration from the host institutions for enhancing the quality of academic achievements.

Many higher education researchers have noted that studying in a different country can be a challenging experience for international students who sometimes have difficulties adjusting to the new situations. These difficulties may relate to academic, sociocultural, and psychological adjustments (Marr, 2005; Zhang \& Mi, 2009). These educators have identified that the main problems that international students usually face are language shock, culture shock, homesickness, lack of study skills, and language proficiency (Marr, 2005; Zhang \& Mi, 2009; Unyapho, 2011). Language difficulties and culture differences are two of the most significant issues that have drawn attention from researchers in the field (see for example, Marr, 2005; Zhang \& Mi, 2009). In order to increase international student enrolments, host institutions need to provide a high quality of education and appropriate support services for international students. If the host institutions are committed to providing a good academic environment and support for international students, those students may be more encouraged to choose these institutions as their study destination. Zhang and Mi (2009) argue that in order for international students to succeed in their study and for the host nations to continue to attract students from overseas, the difficulties and problems facing international students must be addressed.

An Giang University (AGU), the case study university for this thesis, was established in 2000. It began recruiting international students in 2007. Since that time, 24 Laotian and Cambodian students have enrolled in Vietnamese language proficiency courses and undergraduate degrees. AGU has yet to fully establish a full range of policies aimed at supporting international students' needs so that they receive a high quality of education and academic support. Brown (2009) argues that culture and language barriers have been cast as major threat to the quality of academic achievement and the quality of the educational experience of international students. In fact, Laotian and Cambodian students at An Giang University must deal with many challenges as they do their studies and some of these problems are related to cultural differences and difficulties in following Vietnamese which is the language of instruction at the University. This section of the thesis presents a range of 
literature about the issues of language and culture that international students often face. Since there is no literature relating specifically to the language barriers or and cultural differences that Laotian and Cambodian students face while studying in Vietnam, literature from other educational systems has been drawn upon here.

\subsubsection{Cultural differences}

Although students from Laos and Cambodia may share some of the cultural similarities common to the South East Asian area, they also have to contend with the language and distinct regional culture of An Giang province. Cultural diversity continues to be an issue that needs to be addressed and the host institution is aware that it needs to provide greater support for international students in adapting to the new cultural environment. According to Campbell and Li (2008), international students' levels of satisfaction with their academic experiences in a new country are related to the degree they are able to adapt to the cultural conditions of the host country. The more easily they adapt to the new environment, the more positive their learning experiences are likely to be. This part of the literature review will introduce various arguments about the issue of cultural diversity in relation to international students.

Cultural differences may present challenges for international students in relation to differences in cultural values, and this may hamper the kinds of social interactions that take place in the host country. Diverse cultural priorities may also have an influence on how quickly, or how well, good relationships with peers and teachers can be established in the classroom. Campbell and $\mathrm{Li}$ (2008) argue that culture can be seen in terms of shared understandings about the values, norms, beliefs, and symbols that define what is acceptable within a society, which are shared by, and transmitted across, members of that society. International students studying in a new cultural environment sometimes have difficulties understanding the "foreign" values of the new country. Campbell and Li (2008) argue that people from different cultural groups have different ways of perceiving and organizing the world around them. Social and cultural shock has been discussed by Zhang and Mi (2010) who found that cultural differences can create social barriers for international students. They argue that host institutions need to acknowledge these issues and be willing to find out as much as possible about the difficulties international students face and the 
expectations they have, in order to address the issue appropriately. In that way, international students may feel more encouraged to enrol in these host institutions.

Social interaction with peers and teachers presents another challenge for many international students. Averill (2009) asserts that the characteristics of person-to-person interactions can vary from one culture to another. Cross-cultural interactions can often lead to misunderstandings which can undermine the quality of inter-personal relationships. For example, students in Vietnam are advised to bow to their teachers. However, in western culture, students and teachers seem to be more equal with each other and a "hi" is polite enough when they see their teachers. Another example is extracted from my own personal experience as an international student in New Zealand. In Vietnam, students are not permitted to call teachers by their teachers' first names; instead, students have to respectfully address them as "Teacher". It is quite different in New Zealand, where students normally call the teachers by their first names. These are some examples of teacher-student interaction that reflect different cultural values and behaviours. Duanmu and Chen (2009) argue that social interactions need to be handled sensitively because they have an effect on the kinds of relationships that teachers and international students establish. These relationships are also framed by cultural considerations. Zhang and Mi (2010) found that international students who have access to a network of supportive friends in the host country, experience lower levels of stress.

International students who are studying abroad sometimes experience what we might call 'culture shock' and this also includes 'academic culture shock'. Brown (2007) argues that "academic culture shock is a subset of culture [shock] and is a case of incongruent schemata about higher education in the students' home country and in the host country" (p.14). Duanmu and Chen (2009) confirm that academic culture shock is directly associated with the learning environment of an academic institution, which involves differences in the host country's education system, lecture style, assessment. This argument acknowledges that cultural values frame the kinds of teaching and learning styles that prevail in different higher education institutions in different countries and this is something that international students must learn to navigate. At the beginning of their studies, international students may feel frustrated with the teaching or assessment systems of the host institution. Duanmu and Chen (2009) argue that cultural differences are specific factors that are associated with 
academic behaviours and achievements. For example, Campbell and Li (2008) found that Asian students in a study they conducted had high learning expectations, achievement motivations, self, or parent-imposed learning pressures, a strong sense of competition, and deep respect for teachers. They found, however, that in a host institution in a new country some of the Asian international students in the sample group had experienced difficulties in adjusting to value placed by the host institution on independent learning and lower levels of instructor supervision and guidance.

Cultural differences do not only present challenges for international students; teachers at host institutions may also have difficulties in adapting to having international students in their classrooms (Campbell \& Li, 2008). They contend that while international students may find themselves isolated in the new culture; teachers also may find it hard to working in culturally diverse contexts with international students and provide them with appropriate levels of support. Averill (2009) also argues that the differences between the lives of teachers and their students can make it difficult for teachers to design instruction that capitalizes on the background experiences of their students. She calls for effective ways of preparing teachers to work in culturally diverse learning environments. In summary then, it can be seen that teachers play an important role in working with international students and providing them with appropriate levels of classroom support.

In conclusion, international students encounter various kinds of difficulties related to cultural issues such as social barriers, limited relationships with peers and teachers, academic culture shock particularly in relation to learning styles. To help international students gradually adapt to the new cultural environment, teachers need to be sensitive, dedicated and helpful to international students regarding cultural issues.

\subsubsection{Language barriers}

Language difficulties have been identified by various researchers in the field as a barrier to international students' classroom communication skills, ability to participate fully in classroom activities, and academic performance in general (Bradley \& Bradley, 1984; Sakthivel, 2003; Hellsten \& Prescott, 2004). Sakthivel (2003), Marr (2005), and Zhang and Mi (2009) have argued that language barriers are amongst the most important issues that 
need to be addressed with international students because these kinds of barriers may negatively affect international students' academic performance directly or indirectly. Laotian and Cambodian students enrolled in Vietnamese language proficiency programmes or undergraduate degrees at An Giang University (the case study university for this thesis) also face language problems in the classroom. As will be discussed in a later chapter, this has a negative impact on their overall academic performance and their level of satisfaction with their academic experience.

Studying in a foreign country in a foreign language is likely to be challenging for many international students. While good teacher-student relationships play an important role in international students' academic achievement, good language competence helps international students to establish good relationships with their teachers. Onsman (2010) identifies communication as an important issue for both teachers and students in higher education. The teacher-student relationship is a key determinant in students' levels of academic satisfaction and achievement. Campbell and Li (2008) found that the international students who participated in their study were generally satisfied with their teacher-student relationships and the pattern of classroom communication and that this translated into an overall level of international student satisfaction with their academic outcomes. Proficiency in the language of instructions in the host institution encourages open communication between international students and their teachers. This is important because having good communication with teachers means that students feel comfortable with their teachers and are more likely to discuss issues they are having both outside and inside the classroom. Lee (2007) contends that non-native speakers are also more likely to feel self-conscious and sensitive about others people's evaluation of their oral performance and are more likely to feel uncomfortable evaluated in a language in which they do not feel they are proficient in speaking. This may discourage international students from communicating in the language of the host institutions because they feel more at ease when speaking in their own mother tongue. Lee (2007) argues that proficiency in the language of the host institution provides opportunities for improved classroom communication and a better understanding of the classroom dynamics that underlie pedagogical engagement. Accordingly, international students who are proficient in the language of the host country are more likely to achieve good academic outcomes. 
Language barriers can also discourage international students from socializing with their teachers and friends. Difficulties in speaking the language of the host country can also negatively affect students' relationships with friends and teachers. Olanira (1993) states that language proficiency is a major source of social difficulty in intercultural communication. Campbell and Li (2008) and Zhang and Mi (2009) argue that language barriers can prevent international students from effectively communicating with their lecturers and other students, and can also discourage them from socializing with domestic students. International students may also feel anxious about communicating with their classmates and teachers and the lower frequency of engagement means that international students do not always have the confidence to improve their language skills in that way.

Being able to speak the language of the host country confidently and well also affects the academic performance of international students. Campbell and $\mathrm{Li}$ (2008) argue that language barriers can cause difficulties for international students in terms of understanding lectures, following instructions, understanding assessment criteria and procedures, completing assignments, and doing exams and tests. While it is important for students to take notes during lectures so they can review them at a later date, international students sometimes find it difficult to follow lecturers' instructions. Furthermore, it may take them longer time to complete assignments as they may have to refer to dictionaries frequently. International students may also face language barriers during class interactions, especially in oral performances such as class discussions (Aida, 1994). Ryan (2000) argues that students who study in a second language are often afraid to speak in class or seek help because of a lack of confidence in their ability to communicate and fear of embarrassing themselves or their teachers. Campbell and Li (2008) have also noted that international students are sometimes reluctant to speak in class if they fear ridicule about their accent or level of language proficiency. As a result, they argue, international students sometimes appear to be passive in class activities and group work; perhaps seeming to listen more than contributing verbally to class discussions. In support of this, Ramburruth and Birkett (2000) contend that "poor language and communication skills [are] a major problem in group assignments" (p. 186). Duanmu and Chen (2009) conclude that students who have a relatively poor level of written language ability tend to have lower grades. 
In brief, it is necessary for international students to obtain a good level of foreign language competence before they begin their overseas studies. This would increase their level of academic achievement, and assist them in gaining a clearer understanding of the cultural environment of the host country.

\subsection{An overview of higher education in Vietnam, Cambodia, and Laos}

\subsubsection{The education system in Vietnam.}

\subsubsection{Historical and political context.}

The historical and political context of Vietnam has had a significant influence on the way the higher education system of the nation has developed. Nguyen (1993) and Tran and Ha (2000) have identified five main themes that have been important in the building of the education system of Vietnam.

Firstly, Vietnam is known as a war-torn country that has had a long struggle in freeing itself from foreign domination. Up until a thousand years ago, it was dominated by the Chinese and endured threats from the Mongols later; up until 1975, it endured external domination by the French, Japanese, and the USA. Secondly, Vietnam suffers from frequent natural disasters such as floods and typhoons resulting from its geographical location and a lengthy coastline along the East Sea. Annually, damage from natural disasters costs the country millions of US dollars and hundreds of Vietnamese lives (Tran \& Ha, 2000). A third theme is 'Nam Tiến' (expansion to the South)-this relates to Vietnam's quest for additional land and territory, which arises because of the high population density in Vietnam (Fry, 2009). Fourthly, Vietnam continues to be influenced by Chinese culture and intellectual influences persisting from 1,000 years of Chinese domination. For example, Tu (1993) argues that Vietnamese culture is affected by Confucian worldviews and in this respect it differs from its neighbours' culture such as Thailand, Laos, and Cambodia. Finally, Luong (2003) suggests that village life with its rich cultural traditions dramatically shape Vietnamese cultural and social values and behaviour. 
It should be noted here that the Vietnamese language that is spoken today has only become widely used since 1919 . In the seventeen centuries prior to that time, the Chinese language had been the official language of Vietnam. Later the Nôm language was created, although it is based on the Chinese language. In the seventeenth century, a romanized Việt script was developed with the great contribution of Alexandre de Rhodes - a French missionary and scholar (Tran \& Ha, 2000).

Although Vietnam has been dominated by different foreign countries over a long period of time, it also has a tradition of higher education and educating international students. The Royal College (Văn Miếu Quốc Tử Giám) founded in 1076, is known as the first higher education institution in Southeast Asia (Fry, 2009). During the French colonial period in the late nineteenth century, several colleges were set up to offer fields of study such as pharmacy, pedagogy, agriculture, and engineering. Later in Hanoi, a University of Indochina was established which also served students from the Laos and Cambodia part of the Indochina French colony. Also in the period 1945-1954, three colleges teaching medicine, pharmacy, and pedagogy, were formed in the revolutionary area in the north. In the 19451975 periods, when Vietnam was divided into the North and South, there were two separate systems of higher education. The system in the North reflected Soviet influences (Nguyen, 1993). In the South, the system was based on the earlier French colonial model, although later, a strong American influence was introduced. During the intense bombing of the North, college physics, for example, was being taught in caves. After liberation and independence in 1975, Vietnam's system of higher education was unified. At that time, there were 51 universities and 56,000 students in the North and 18 universities with 116,500 students in the South (Luong, 2003).

With a population of nearly 88 million in 2011, Vietnam is one of the most densely populated countries in Asia (LaoDong Reporter, 2011). Accordingly, its population is approximately twenty times of that of New Zealand. Meanwhile, the land area of Vietnam is approximately the same as that of New Zealand. This level of population density places a tremendous pressure on the Vietnamese economy to provide meaningful employment and educational opportunities for its citizens, especially its young people (Pham, 1998). 
A major change in Vietnamese education occurred in 1990 when the Ministry of Education and the Ministry of Higher Education were merged into the Ministry of Education and Training (MOET) (Pham, 1998). Since then, MOET has had responsibility for all education and training at the national level. According to Pham (1998), MOET is divided into 19 separate departments and several related units, of which the most important are units responsible for primary and secondary education, higher education, teacher education, and adult education, as well as the finance and planning department. MOET's responsibilities cover every level of education, including pre-school, general education, professional education, tertiary education, and continuing education. To transfer from upper secondary to university education, college education, professional secondary or vocational training, students need to take an entrance examination. Similarly, to transfer from university education to a Master's degree or Doctor of Philosophy, learners need to take an entrance examination. If learners obtain a standard grade in the entrance examination, they can continue their education at an advanced degree level. The education system of Vietnam is described in the following diagram.

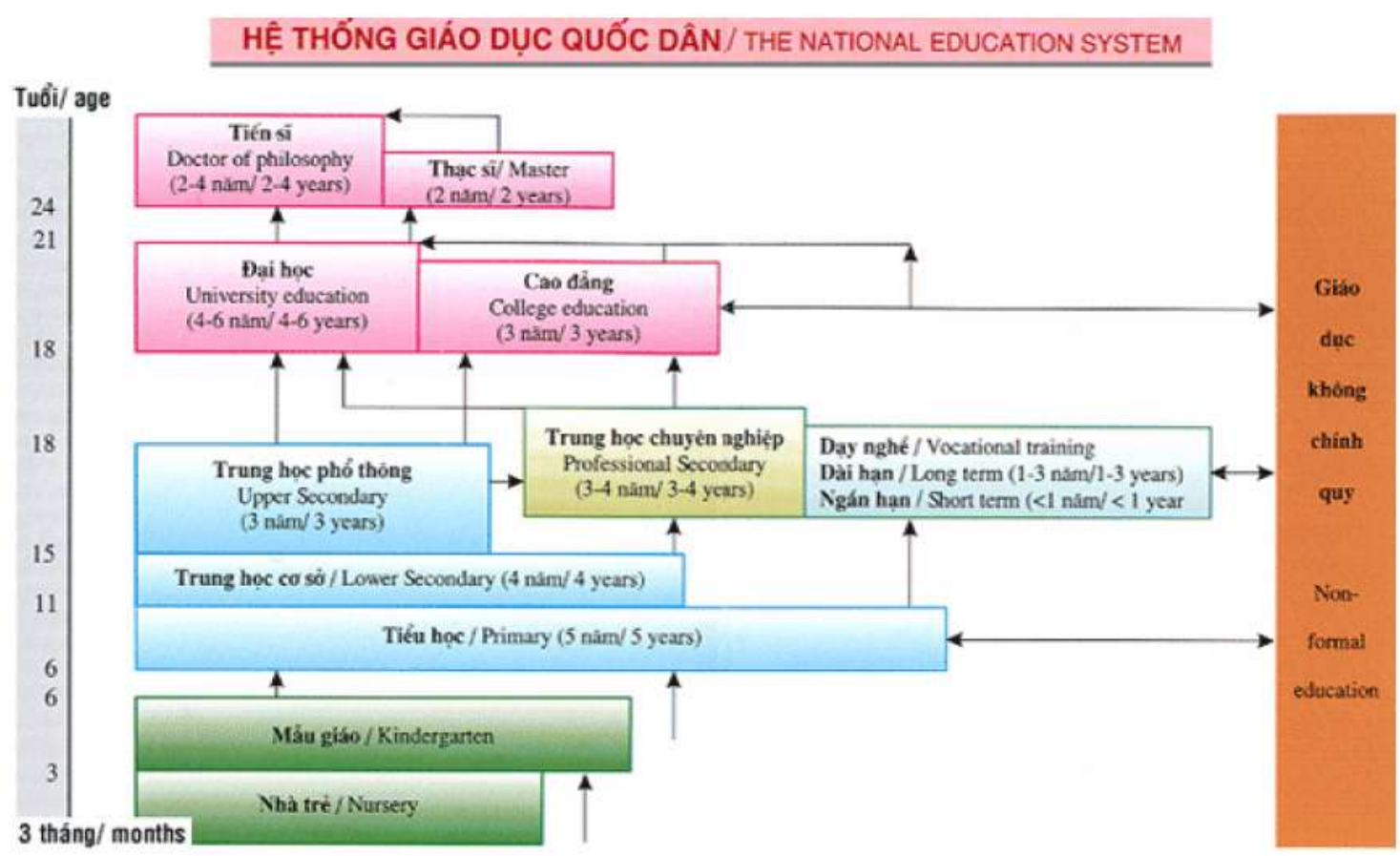

Figure 2. 2: The structure of the national education system of Vietnam

adapted from http://forum.hanu.vn:88/forums/storage/17/7495/vnedusystem.gif 


\subsubsection{Higher education in Vietnam.}

Higher education in Vietnam has drawn the attention of educators nationally and internationally. A range of literature relating to higher education in Vietnam has been written by key scholars, such as Sloper and Le (1995), Pham (1998), Pham and Fry (2004), Dai (2006), Hayden and Lam (2007), Fry (2009), Luu (2011).

In response to the 1986 Đổi Mới (Innovation) mentioned earlier, significant changes have taken place in Vietnam and this has included the reshaping of the education system (Pham, 1998). This has led, in recent years, to a dramatic expansion in Vietnamese higher education, reflecting the rapid economic development that took place the 1990s as well as a related growth in demand for higher education to prepare young people for jobs in the modern sector. MOET has also encouraged and authorized the establishment of many new universities and educational institutions in different parts of the country aimed at providing high quality human resources to support the strategic development of the country.

Although MOET plays a leading role in education in Vietnam, there are two kinds of higher education institutions: public and non-public institutions (Luu, 2011). Public higher education institutions in Vietnam are administered by MOET or other ministries, government agencies or local authorities. Non-public institutions, or private institutions, are either administered by non-governmental agencies or with the cooperation of foreign organizations, or are $100 \%$ administered by foreign organizations. For example, Hanoi Medical College is administered by the Ministry of Health and the Water Resource University is administered by the Ministry of Agriculture and Rural Development. An Giang University is administered by the People's Committee of An Giang province and RMIT University is totally administered by a foreign organization in Vietnam. A further example are the two National Universities which though nominally under MOET, operate independently as separate entities and report directly to the Office of the Government of Vietnam. MOET has also encouraged and authorized the establishment of more universities and educational institutions within the country with the aim of providing high quality human resources for the sociocultural development of the country. 
To meet the needs of higher education in the country and for the purpose of increasing the financial benefits that can be derived from education, the number of higher education institutions have significantly increased in the last decade. The following chart illustrates the growth of higher educational institutions in Vietnam between 1999 and 2009. This chart is based on 2011 MOET statistics. From 153 institutions in the school year 1999-2009, this number has rocketed up to 376 in the school year 2009-2010. The figure in the following chart shows that the number of higher educational institutions in Vietnam has increased gradually from 1999-2000 to 2005-2006. This number dramatically accelerated from 255 institutions in 2005-2006 to 322 institutions in 2006-2007. After that period, this number steadily increased to 376 institutions in 2009-2010. Obviously, this significant growth in the number of higher educational institutions might aim to meet the increasing needs of the learners, the sociocultural development of the country and to shift from "pure education" to education for financial benefits purpose (doing business with education).

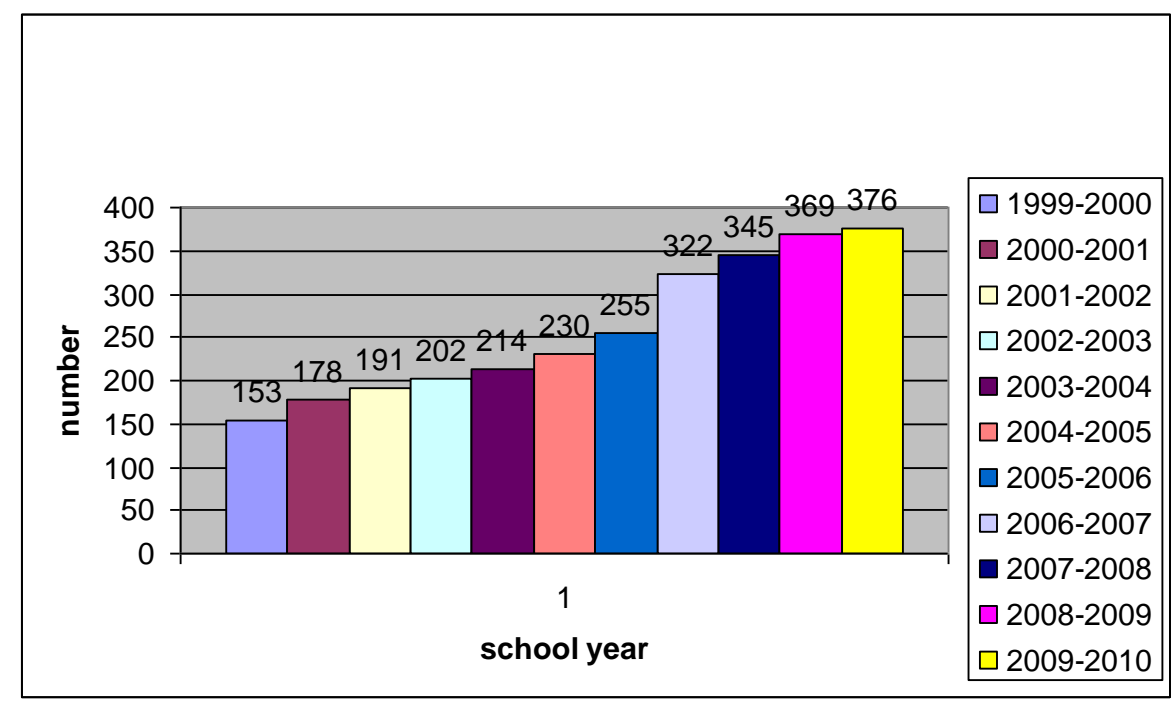

Figure 2.3: The growth of higher education institutions in Vietnam (MOET, 2011)

Internationalization has been another important aspect of Vietnamese higher education reform. To reduce the financial burden on the government and to meet the need for good quality higher education in Vietnam, Decree No. 06/2000/ND-CP, initiated in 2000, opened the door for international universities to offer education in Vietnam and to provide incentives to encourage such international investments (Dai, 2006). Initially, RMIT University from Australia opened an international campus in Ho Chi Minh City in 2001. Later, other overseas universities opened campuses in Vietnam. These universities included 
the University of Hawaii's MBA program, Troy State University, Washington State University MBA program, University of Houston, University of Greifswald (Germany), University of Technology in Sydney, Toulon University, France, and Liege University in Belgium (Dai 2006). Victoria University of Wellington (VUW) has also established two campuses in Ho Chi Minh City and Hanoi. VUW offers undergraduate study, known as the joint - program, which includes two years study in Vietnam and a further two years of study in Wellington, New Zealand.

Although MOET mainly administers the overall educational system in Vietnam, some changes have occurred. Decree 85/2003 and Decree No. 166/2004/ND-CP have given local education authorities more power and responsibility to initiate long-term local education programs in their respective areas. Further, universities now have greater autonomy over their funding, training, research, human resources, and international cooperation programmes (Hayden \& Lam, 2006). According to Hayden and Lam (2006), the Resolution No. 14/2005, dated November 2, 2005 and the Government's Higher Education Reform Agenda 2006-2020 have allowed university and college managing boards to prepare their own spending plans and to implement them under oversight from MOET (Hayden \& Lam, 2006). Much discussion is occurring about how these new policies and others might facilitate better quality research and teaching while also providing a legal framework of responsibility and with increased accountability. Accordingly, universities enhance cooperation with international institutions and organizations to take advantage of financial support from these international institutions and organizations. At An Giang University (AGU), education for Laotian and Cambodian students has been one of several important strategies developed that aim to enhance the prestige of AGU and strengthen international relationships and academic cooperation.

In Vietnam, higher education is offered to both domestic students and international students. According to Pham (2009), since the 1960s the number of Laotian students enrolled in higher education in Vietnam has increased. In addition, in the 1980s the number of Cambodian students enrolled in higher education in Vietnam has also increased. Offering higher education services for Laotian and Cambodian students at that time was viewed as a way of helping neighbouring countries with education during a difficult period of civil wars in these countries. The number of Laotian and Cambodian students has 
gradually increased in higher education institutions in Vietnam. Statistics from a report of The Vietnamese International Education Development (VIED) in 2011 show that recently, not only Laotian and Cambodian students are enrolled in higher education in Vietnam but also international students from other countries such as China, Mongolia, Korea, and the Czech Republic. The following diagram shows that the number of international students in Vietnam continues to increase particularly with regard to the number of international students from Cambodia and Laos.

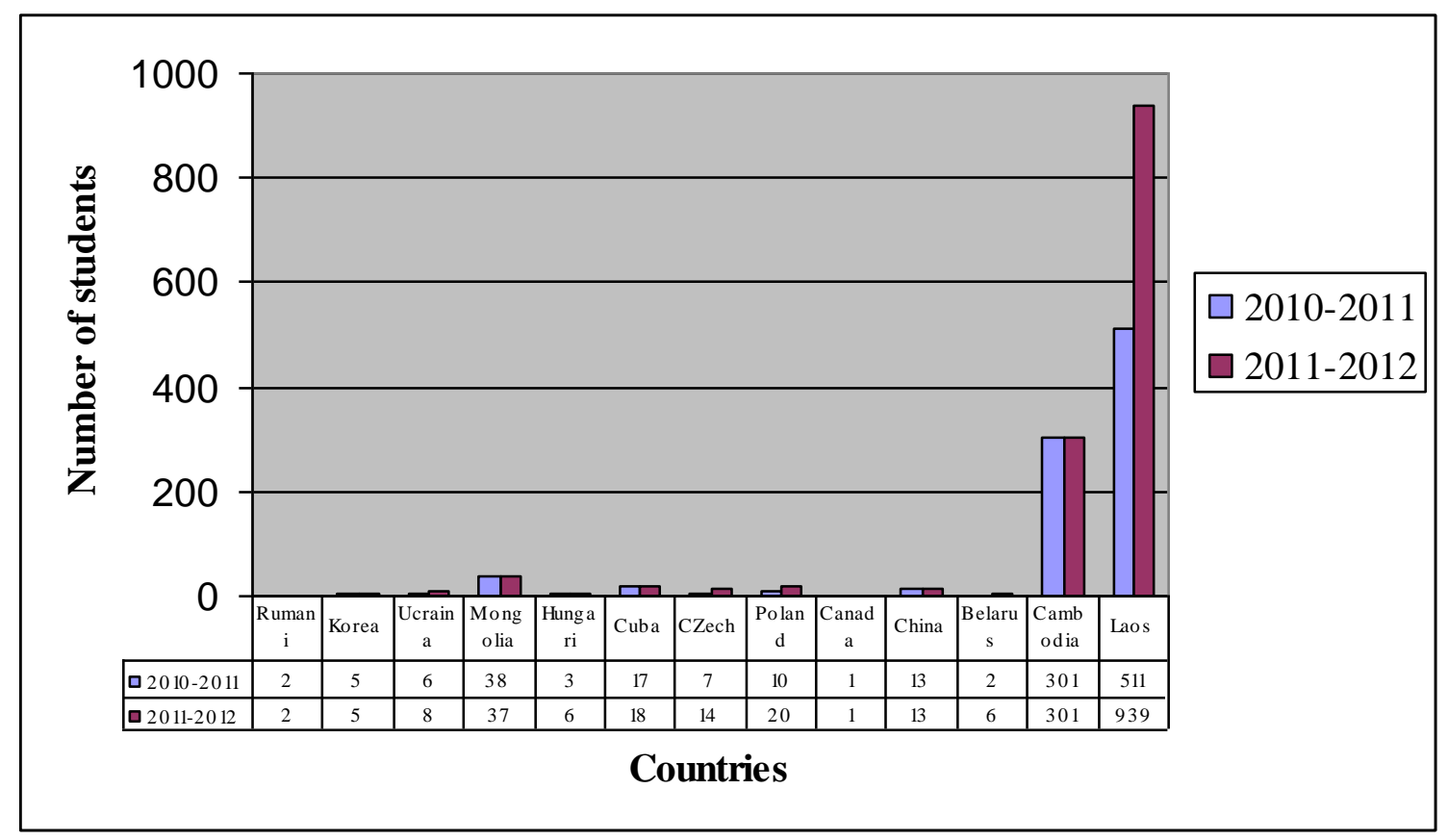

Figure 2.4: The growth of international students enrolment in higher education in Vietnam (VIED, 2011)

In conclusion, Vietnam has a long history of development in higher education. Indeed, the first higher education institution of Southeast Asia was established in Vietnam. Although Vietnam has struggled to free itself from foreign domination for a long time, education has never been neglected. Since liberation and independence in 1975, the educational system in Vietnam has been through many stages of innovation. Since 1990, higher education in Vietnam has been developed at a greater pace. Significantly, in only one decade (from 2000 to 2010) the number of higher education institutions increased from 153 institutions to 376 institutions (Figure 2.3). Internationalization of higher education is also prioritized with the aim of providing qualified human resources for the development of the country. Recruiting 
international students, especially Laotian and Cambodian students, is one of the key strategies to strengthen international relationships, develop the economy, and gain greater academic prestige in the eyes of other foreign countries.

\subsubsection{Higher education in Cambodia.}

Higher education in Cambodia has had a long history of ups and downs. Although some educational policies have successfully achieved their goals, the higher education system in Cambodia has experienced obstacles in terms of financing, autonomy and academic freedom, ineffective restructuring programs and faculties, lack of research capacity, and inadequate quality assurance.

Reform has been taken place in higher education in Cambodia after being interrupted by the wars of the recent past. Although higher education institutions in Cambodia were totally abandoned for about four years between 1975 to 1979 during the Khmer Rouge regime, education is now one of the prioritized sectors of the country (Chealy, 2009). In 1979 the largest and oldest university in Cambodia, the Royal University of Phnom Penh, reopened after the collapse of the Khmer Rouge regime. From 1997, there was significant growth in the number of newly established universities and institutes and this is a consequence of educational reform that has allowed private providers to set up partnership programmes (Chhing \& Dy, 2009). In 2001, Cambodia introduced a nationwide education reform that lead to a significant growth in the number of higher education institutions in the country (Keng, 2009). In 2007, there were 62 higher education institutions comprising a mixture of degree-level institutions and sub-degree level institutions (2-year courses) falling into two groups: public and private. (Keng, 2009) stated that according to statistics from the Accreditation Committee of Cambodia, amongst the 62 higher education institutions in Cambodia, 22 are public. The remaining 40 universities are private. The fast growth in the number of higher education institutions may lead to a low-quality level of education. Moreover, a large number of degree graduates may not be equally matched with demand from the labour market (Chapman, 2009).

Financial support was provided in order to develop the higher education system in Cambodia. According to a report from the Ministry of Education, Youth and Sport 
(MoEYS) in 2005, a large proportion of the national budget allocated for higher education went to staff remunerations, and enhancing teaching and learning quality (Chealy, 2009). The World Bank has sponsored higher education in Cambodia with US\$25 million given to project-based assistance to improve the quality and efficiency of education (Chealy, 2009). This project is considered a major factor in improving higher education provision in Cambodia.

For a long period of time, academic autonomy and academic freedom were not features of higher education in Cambodia. According to Chansopheak (2009), higher education institutions in Cambodia are not mandated to grant degrees. In general, degrees are conferred by institutions, approved, and signed by the Ministry of Education, Youth and Sports (MoEYS). Currently, no university degree in Cambodia is valid without the signature and stamp of its in-charge ministry. Delegation of authority to higher education institutions to confer degrees to their students without any signature from the ministry on the diplomas is still under debate in the Cambodian higher education context (Chansopheak, 2009). This stamp of approval reflects that the hierarchical culture prevalent in the country is hard to change (Chealy, 2009). Worldwide experience suggests that social policy can interfere with academic freedom in many ways such as access to information, selection of research topics, report of research results, and expression of opinion in public (Chealy, 2009). However, the role of government in the appointment of state university presidents in Cambodia could be a crucial juncture in the pattern of academic freedom of the current system. The environment and mechanisms inside the university such as academic senate, free academic debate, and research meetings do not seem to have matured yet in Cambodia. Government strategy and policy reforms within the Education Strategic Plan (ESP) 2006-2010 focus on issues such as increasing access and equity of enrolment opportunity to realize the Royal Government of Cambodia's pro-poor policy; improving quality assurance at both institutional and system levels (public and private); and strengthening institutional management and development. Chealy (2009) states that the strategies and policies have created new terrain for Cambodian higher education. Recent changes in higher education include the restructuring of degree programs and faculties. Of these changes, the first is the introduction of Foundation Year Study as a significant step in academic program reform of Cambodian higher education. Second is the implementation of a credit and credit transfer system in the Cambodian higher education system. However, a 
full credit system has not yet been implemented due to the lack of understanding of the concept (Chapman, 2009).

A wide range of problems has been seen in Cambodian higher education. Higher education in Cambodia is currently at its massification stage (Chealy, 2009). University education is known to fulfil three basic functions, including training, research, and providing consultation services. In Cambodia the last two functions seem to be absent in both public and private higher education institutions (Chansopheak, 2009).

Research has not been a priority in Cambodian higher education both public and private institutions. This not only results from the inadequacy of the budget but also from other infrastructure inadequacies such as copyright regulations and the lack of research facilities and laboratories of necessary size and scope. Despite the weakness of doing research at university level, the MoEYS would like to improve research in higher education. Consequently, two research departments have been established. They are the Scientific Research Department and the Pedagogical Research Department at the ministerial level. These research departments have received great assistance from foreign counterparts (UNESCO, 2006).

Quality in education has also been an emerging issue in higher education in Cambodia. According to Chealy (2009), in March 2003 The Royal Decree No. NS/RKT 03/03/129 visualized the improvement of the quality of higher education through establishing the Accreditation Committee of Cambodia. According to the Decree, it is mandatory that all higher education institutions, local and foreign, obtain accreditation status from the Accreditation Committee of Cambodia in order to grant degrees (Chealy, 2009). This official emergence of the Accreditation Committee of Cambodia has created a new landscape for Cambodian higher education (Chapman, 2009). However, this Accreditation Committee of Cambodia is younger than most higher education institutions in Cambodia. Until now, with the exception of the success of the implementation of the Foundation Year Program, the Accreditation Committee of Cambodia has not yet executed its institutional accreditation to any single institution (Chapman, 2009). 
The education system in Cambodia is described by the following chart. After completing upper secondary, students are required to take an entrance exam into higher education. Cambodian higher education is basically separated into two different but interrelated streams, namely academic and vocational. The two streams are under supervision of two different government ministries functioning as in-charge ministries. The academic stream is under supervision of the Ministry of Education, Youth and Sports (MoEYS), while the vocational stream is under the Ministry of Labour and Vocational Training. In addition to the management and supervision of the two in-charge ministries, numerous specialized ministries also play important roles in provision of higher education services.

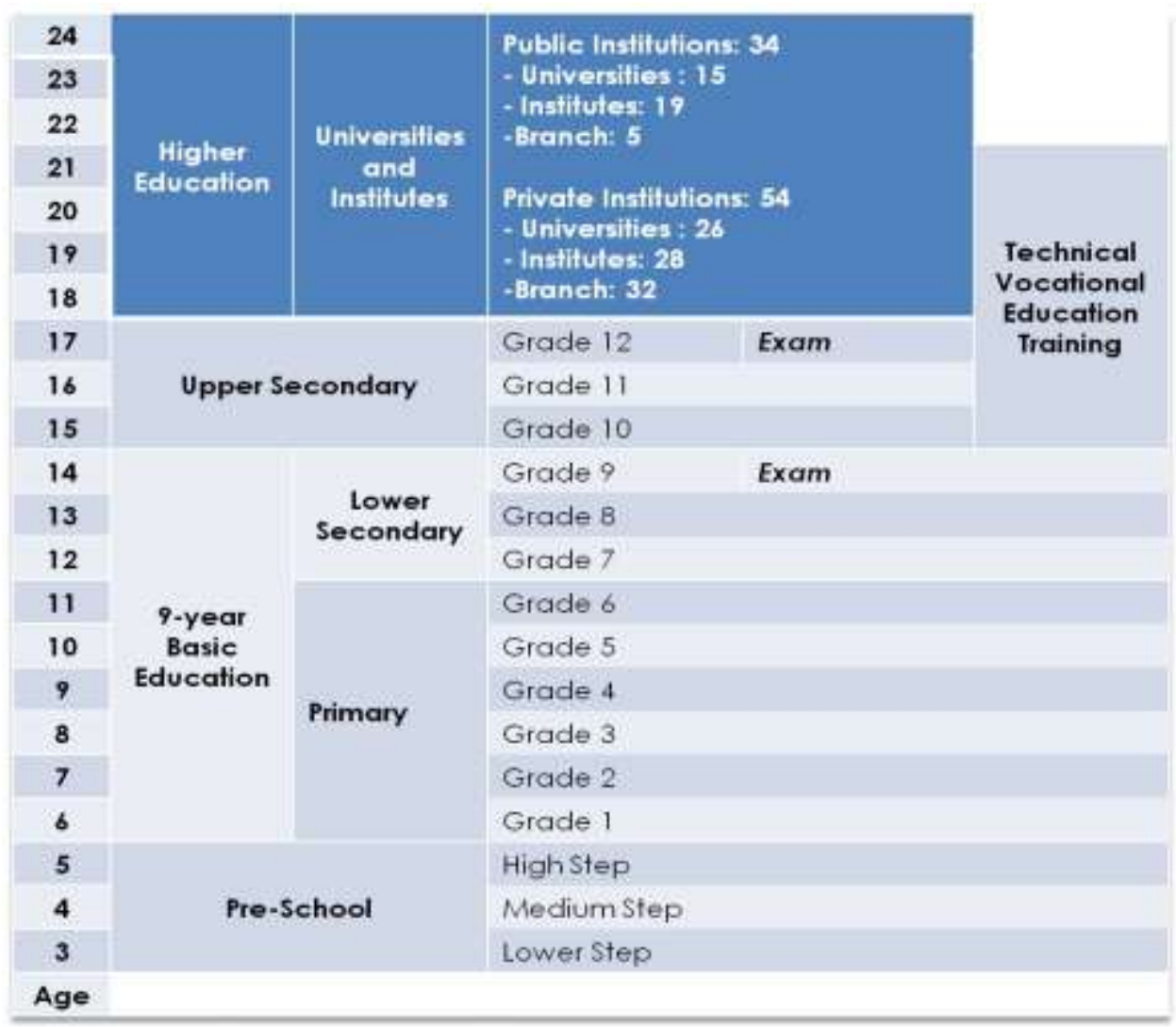

\section{Figure 2.5: The structure of the national education system of Cambodia}

adapted from http://wanict.com/?page_id=137

In 2004, The Financial World Times illustrated the percentage of students at each age group in the following chart. Figure 2.6 shows that $100 \%$ of the primary student age were enrolled in primary level. This number dramatically reduces to only $19 \%$ enrolled in secondary. Surprisingly, the percentage of students enrolling in higher education was only 
3\%. These statistics show an unsustainable number in students enrolling in education. In 2004, the numbers in tertiary education were 25,416 students (The Financial World Times, 2004).

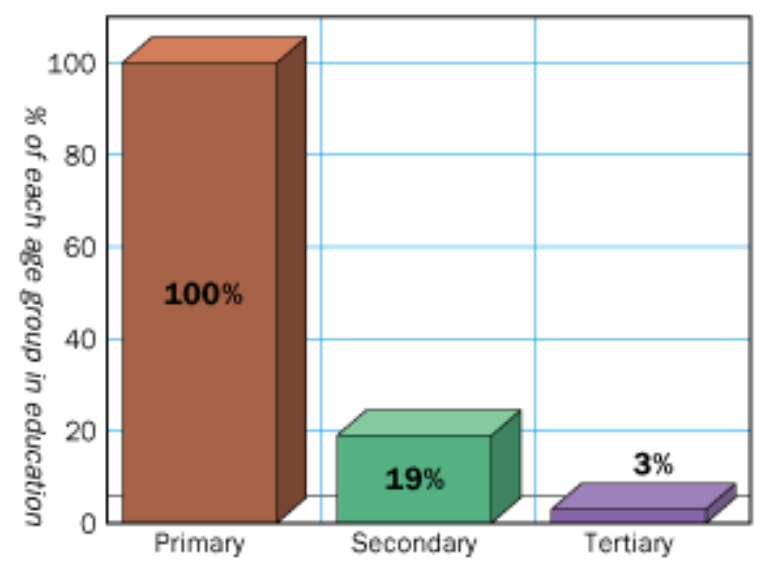

Figure 2.6: The percentage of each school age group enrolled for education in Cambodia in 2004

adapted from http://dev.prenhall.com/divisions/hss/worldreference/KH/education.html

In conclusion, although higher education in Cambodia has achieved certain improvements with different policies launched by the MoEYS, there are still noticeable shortcomings that need to be more effectively addressed. Examples of these shortcomings are financing, autonomy and academic freedom, ineffective restructuring programs and faculties, lack of strengthening research capacity, and inadequate quality assurance. In order to effectively improve the higher education system, it is necessary for Cambodia to strive for international cooperation and support. Obviously, sending students to study at higher education in foreign countries is one effective strategy to learn from other countries. Then, implementation in Cambodian higher education would be more effective.

\subsubsection{Higher education in Laos PDR.}

Laos has instigated a period of higher education reform in recent years aimed at creating a better education system. Contemporary Laotian society and education have their origins in a range of disparate factors such as an indigenous cultural heritage, colonialism, socialist revolution, and most recently, a movement toward a free market economy and privatization (Ogawa, 2009). Since 1986, the Government of Laos People's Democratic Republic (Laos PDR) has shifted from a centrally planned economy to a market-oriented economy. Part of 
this effort was to support the overall development of both the economy and the education system. Moreover, the national strategic plan aims to elevate the country from its current state of least developed country in the region to that of becoming a well developed nation. In this respect, it is intended that Laos will catch up with other ASEAN countries by 2020 (Ogawa, 2009). Education is considered to be one of the most important engines for the country to achieve its development goals (Adam, Geok, \& Lin, 2001). Consequently, over the past two decades, the Government of Laos People's Democratic Republic (Laos PDR) has implemented several important educational reforms including increasing the number of higher education graduates. Globalization and increased attention to ideas about the knowledge economy have increased the country's desire to strengthen its higher education system. However, the country depends heavily on foreign assistance due to the limited financial resources in education (Adam, Geok, \& Lin, 2001).

Laotian education has a long history. Traditional temple schools, established during the $17^{\text {th }}$ century to give young boys a Buddhist education, brought basic literacy to the Laos territories. During the French colonial period, the 1917 Law on Education passed by the French colonial government introduced a common education system for its Indochina territories (Vietnam, Laos, and Cambodia) (Ogawa, 2009). Since 1917, learners from Laos PDR who wanted to pursue higher education have had to enrol in higher education institutions in Hanoi, Vietnam. At that time, all of Indochina was served by only one educational institution based in Hanoi (Ogawa, 2009). After 1955, with American aid, the Royal Lao Government began constructing elementary and secondary schools in major population centres. The first higher educational institution was established in Laos in 1958 (Ogama, 2009). This first institution, Sisavangvong University, was located in Vientiane.

The educational system in Laos is similar to that of Vietnam and Cambodia. The general education system in Laos comprises pre-school education (creche and kindergarten), primary education (five years), lower secondary education (three years) and upper secondary education (three years). Then learners continue their higher education with a higher education program as shown in the chart below. There are 3-year higher diploma programs as well as 4-6 years bachelor's degree programs for students who have completed upper secondary school in Laos PDR. 


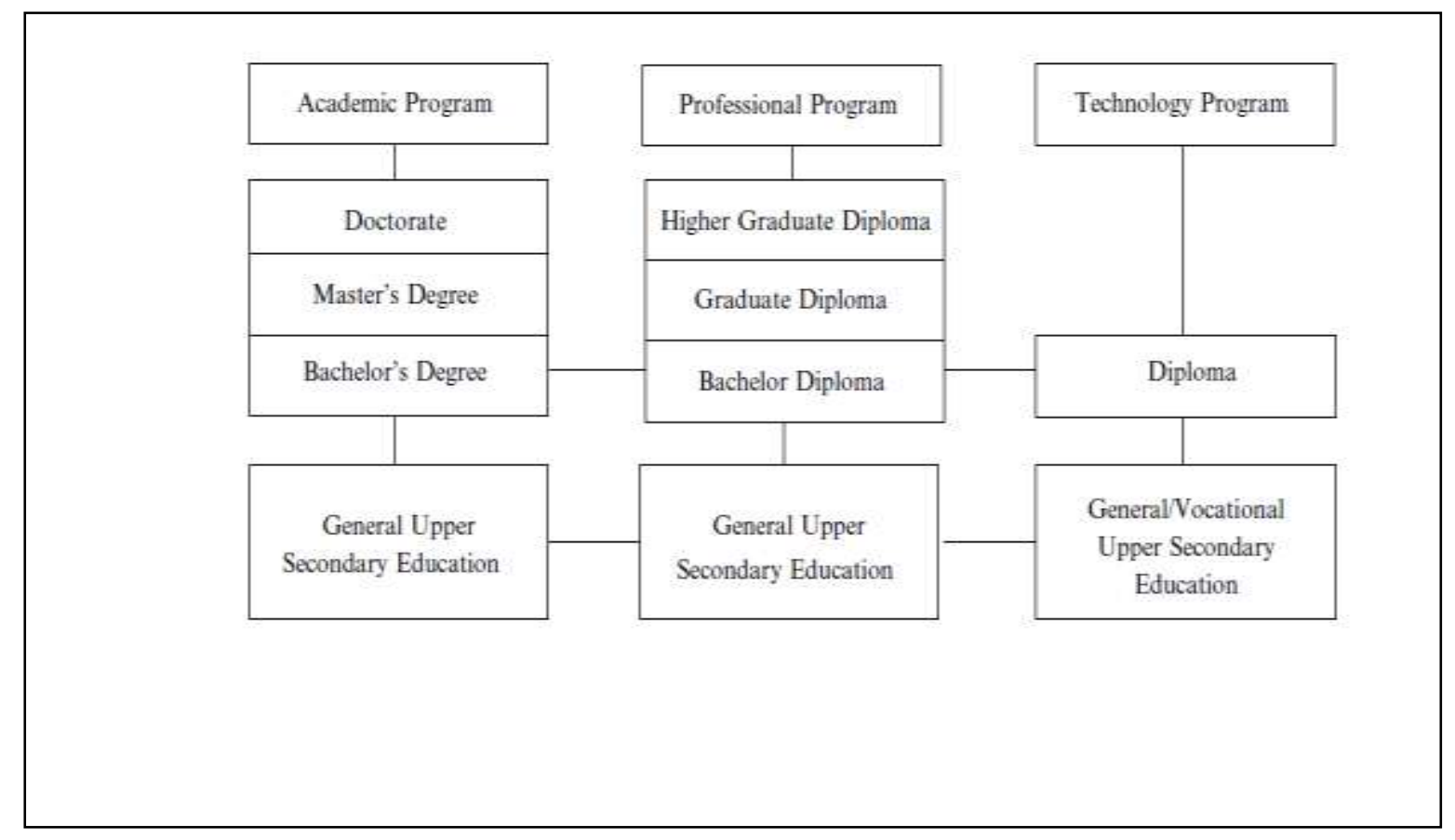

\section{Figure 2.7: Programme levels of the national education system of Laos PDR (UNESCO, 2006)}

The number of students enrolled in higher education in Laos is very low in comparison with other levels of education. Statistics from The Financial Times World Desk Reference in 2004 showed a high percentage of enrolment in primary level schooling $(72 \%$ of the primary age group). The number of students enrolled at secondary level was only $22 \%$ of the secondary age group. Only $3 \%$ of those old enough to attend tertiary education were enrolled in higher education programmes. These statistics reflect an urgent need for higher education to feature in Laos's strategic plan to strengthen human resources for the country's development. The Third National Development Plan on education policy in 1991 also emphasized strengthening the education system for human resource development (Ogama, 2009). 


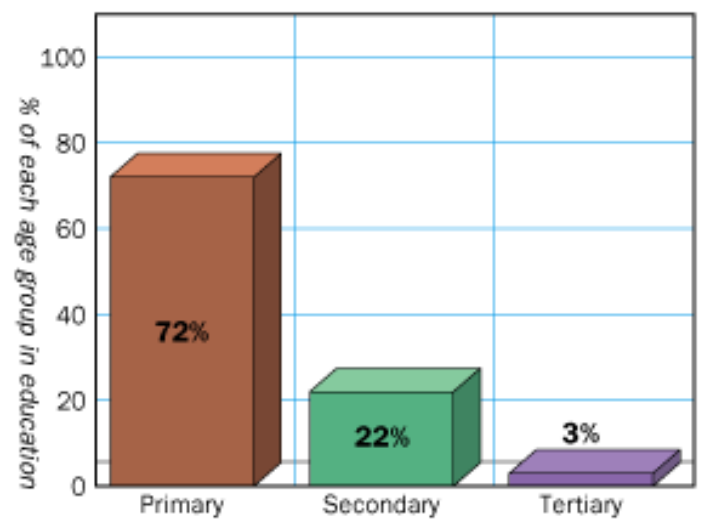

Figure 2.8: The percentage of each school age group enrolled for education in Laos PDR in 2004

adapted from http://dev.prenhall.com/divisions/hss/worldreference/LA/introduction.html

In order to strengthen the nation's research capacity, Laos's government has encouraged higher education institutions to widen their international cooperation programmes with other countries. According to Ogama (2009), currently higher education in Laos comprises three public institutions. These institutions are The National University of Laos (NUOL); Souphanouvong University (SU); and Champasak University (CU). Moreover, there are 5 teacher-training colleges, and 31 private higher institutions. Although higher education is the fastest growing area within the education system in Laos, few staff members are qualified to conduct research as they did not have a higher degree (Ogama, 2009). With the increasing demand for a qualified education system, NUOL has currently established partnerships with 63 foreign universities, institutions, and organizations in training students and staff exchanges. Joining research and postgraduate programs by cooperating with one university in Australia, one university with Canada, six universities with China, nine universities in France, two universities in Germany, ten universities/institutions in Japan, eight universities in the Republic of Korea, two universities in Thailand, three universities/institutions in USA, and 11 universities in Vietnam (Phetsiriseng, 2009).

In conclusion, the education system in Laos, which was traditionally based on Buddhist education, underwent slow progress in the past. The Laotian government has recently focused on strengthening higher education to meet the development needs of the country. 
The government has emphasized the need to increase the number of students enrolled in higher education but in order to achieve this it is necessary for Laos to seek international cooperation and help.

\subsection{Factors attracting Laotian and Cambodian students to study higher education in Vietnam}

Although learners may prefer pursuing higher education in many developed countries such as America, Australia, Britain, Japan, or New Zealand; Vietnam is also known as a good destination for international students, especially for those who are studying agricultural science (TuoiTre Reporter, 2011; ThanhNien Reporter, 2011). According to Robert, Chou, and Ching (2009), many students travel to popular host nations such as the United States or Britain to enrol in academic programs with world-renowned scholars. Vietnam is also a popular destination for Laotian and Cambodian students. Moreover, Vietnam has a propitious tropical climate which is good for agriculture. Vietnam is also well known for its achievements in agricultural science. In addition, the international relations policies between the Vietnamese, Laotian, and Cambodian governments emphasize the desire to strengthen a long-term academic relationship between the countries. Finally, yet importantly, the comparatively low tuition fees and living costs are also attractive to Laotian and Cambodian students.

Laotian and Cambodian students pursue higher education in Vietnam because they may consider that an education in Vietnam might provide them with better opportunities than are available to them in Laos and Cambodia. A report on the education system in Vietnam, Laos, and Cambodia, published in The Financial World Times in 2004 illustrated the status of education in these countries. Statistics in Figure 2.6 (p. 41), Figure 2.8 (p. 44), and Figure 2.9 (p. 46) showed that Vietnam was the leading country in the region with the highest number of students enrolled in primary and secondary education. For example, at primary school level, Vietnam and Cambodia achieved $100 \%$ of students of primary school age group enrolled in primary education. Meanwhile, Laos had only $72 \%$ of students of primary school age enrolling in primary education. At secondary level, Vietnam remained the leading role with $67 \%$ of students of secondary school age enrolling in secondary education. Although Laos has a smaller percentage of primary school enrolment than that 
of Cambodia, Laos surpassed Cambodia with $22 \%$ of secondary school age enrolment in secondary schools. Meanwhile, only $19 \%$ of secondary school age enrolled in secondary schools in Cambodia. It is noticeable that the number of students enrolled in higher education reduced dramatically in all three countries. Vietnam retained the leading position with $10 \%$ of higher education enrolment. Cambodia and Laos had the same percentage, only $3 \%$ of higher education school age enrolled in higher education. Statistics in an annual report of MOET in 2011 showed that the number of higher education enrolments in Vietnam increased to 1,700,000 students. Overall, Vietnam has retained its leading position which may be one of the reasons why students from Laos and Cambodia wish to pursue higher education in Vietnam.

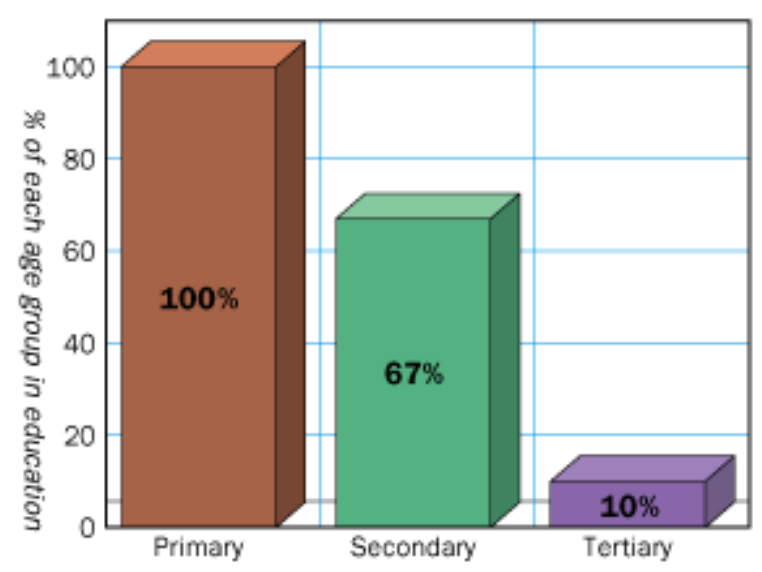

Figure 2.9: The percentage of each school age group enrolled for education in Vietnam in 2004

adapted from http://dev.prenhall.com/divisions/hss/worldreference/VN/introduction.html

Secondly, Vietnam is well known for its excellent capacity in rice exports due to its propitious weather for agriculture and its abundance of fertile agricultural land. According to a report from VINANET (2011) Vietnam is known as the second biggest international rice exporter, just after Thailand, with an export forecast of 8 million tons in 2011. A report from CIA World Fact Book in 2007 stated that Vietnam is now the world's largest producer of cashew nuts, with a one-third global share; the largest producer of black pepper, accounting for one-third of the world's market; and the second-largest rice exporter in the world, after Thailand. According to Pham (2008), the agricultural industry contributes $21 \%$ to the nation's GDP. The following chart illustrates key agricultural export commodities in 
the 11 months of 2007 (Pham, 2008). These agricultural achievements resulted from a fertile land with a high percentage of alluvial soil and propitious tropical weather for agriculture. Although Vietnam has $17 \%$ farming land and $42 \%$ hills and mountains, good land and weather conditions for agriculture mean Vietnam remains one of the biggest rice exporters. Agriculture is considered the main economy sector in Vietnam. It has been emphasized in every meeting of The National Assembly of Vietnam; therefore, Vietnamese government has promulgated priority policy for enhancing agricultural capacity, such as low interest rates for agricultural purposes loans, and finance and resources for poor farmers (Pham, 2008). Moreover, research in the agricultural field has led to considerable achievements that aim to modernize agricultural techniques and improve agricultural productivity (TuoiTre Reporter, 2010). According to Robert, Chou, and Ching (2009), international students tend to choose destinations that can provide them with good scholarly knowledge. Accordingly, the agricultural achievement of Vietnam is one of determining factors that attract international students to Vietnam.

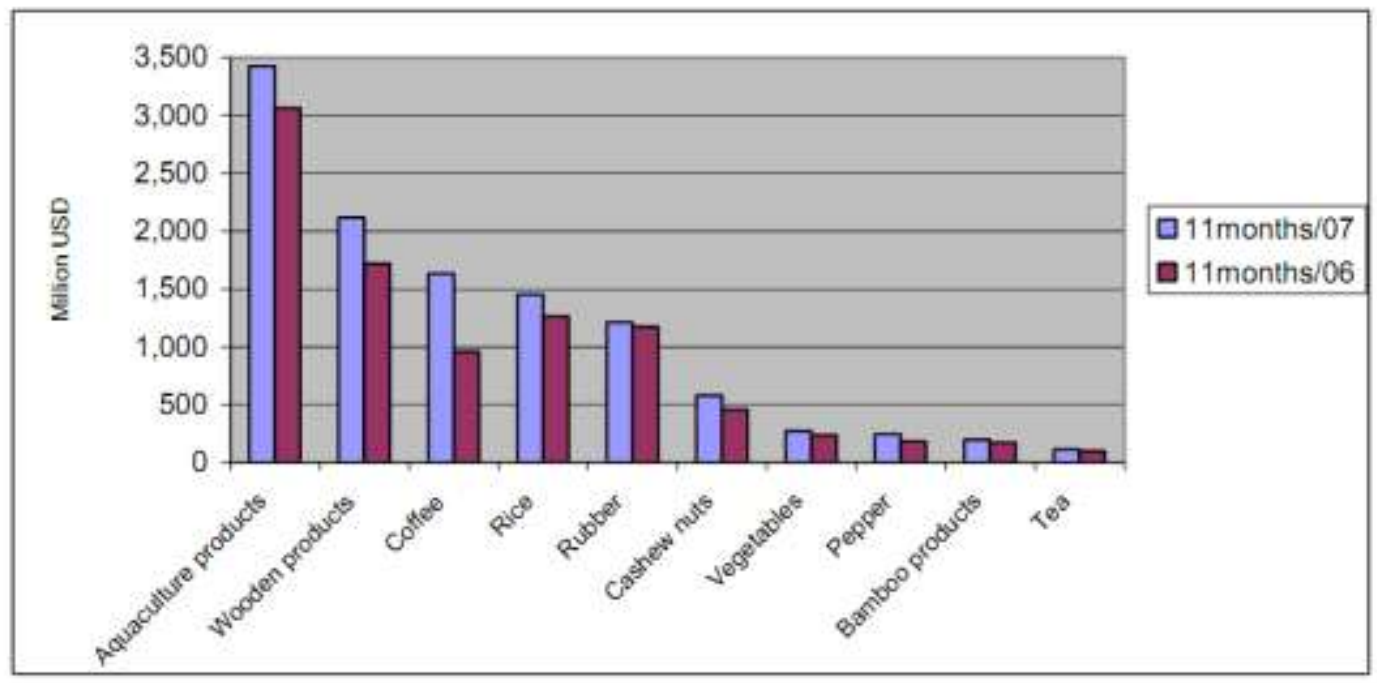

Figure 2.10: Key agricultural export commodities in 11 months of 2007 (Pham, 2008)

Thirdly, Vietnam has successfully widened and enhanced international relationships with foreign countries that may create more opportunities for the development of the country. Statistics from The Ministry of Foreign Affairs of Vietnam in 2007 showed that Vietnam has established diplomatic relationships with 178 countries, having membership of 63 international organizations, includi0ng the United Nations, ASEAN, NAM, Francophone, 
WTO, ECOSOC, UNDP, UNFPA and UPU Executive Councils, as well as, among others, the Non-Aligned Movement, and Francophonie. It maintains relations with over 650 NonGovernmental Organizations worldwide. According to the Foreign Policy of Vietnam, Vietnam always focuses on promoting comprehensive and efficient cooperation with ASEAN and Asia-Pacific countries, especially neighbours such as Laos and Cambodia. Evidence for this foreign policy is the continual scholarships programs granted Laotian and Cambodian students studying in higher education in Vietnam. Moreover, student exchange programs have been encouraged at higher education institutions in Vietnam.

Finally, while the living costs and tuition fees are of big concern for international students, studying and living in Vietnam will not cost internationals as much as in other countries. Low living cost is one of the important factors that international students consider when choosing a destination (TuoiTreOnline, 2011). A recent survey by the Asian Development Bank (ADB) shows that Vietnam ranks the second lowest living cost country compared with 23 other countries in the Asia Pacific region (Vietnam Business News, 2010). The tuition fee for higher education in Vietnam remains very low. Accordingly, the highest tuition fee for higher education is VND 350.000/month which is equivalent to about US\$ 17/month (DanTri Reporter, 2010). Low tuition fee and living costs are emphasized as one of the important factors that attract international students to study in Vietnam (DanTri Reporter, 2011).

In conclusion, Vietnam is a developing country but it has begun a process of internationalization of the higher education sector and it is able to attract international students because of its innovative education system that also aims to produce productive learners which is improving and is considered better than some neighbours'; it has excellent agricultural conditions and a record of achievement in this area of knowledge and practice; an open foreign policy; and low living costs and tuition fees. All of these factors are attractive for international students and as a result, the number of international students studying in higher education in Vietnam has been gradually increasing (TuoiTre Reporter, 2011; ThanhNien Reporter, 2011). 


\subsection{Conclusion}

This literature review has focused on the role of teacher-student rapport in establishing an effective teaching and learning process. It concludes that teacher-student rapport is especially important for international students while they are studying in a different language and culture environment. Factors that may contribute to establishing rapport between teachers and students that have been discussed in this chapter include the importance for teachers to spend time interacting with their students in order to learn about their lived worlds; showing consideration, respect, and valuing students; establishing good teaching practices and effective classroom management. It is also argued that international students may face language difficulties and cultural differences when they are studying overseas. This chapter also provides a comparative review of the educational systems and higher education systems of Vietnam, Laos, and Cambodia. Finally, this chapter also discusses the reasons why higher education in Vietnam can attract student enrolment from Laos and Cambodia.

It is very noticeable that most of the literature on international students' difficulties and teacher-student relationships are derived from western higher education institutions. It seems that little has been done to explore Laotian and Cambodian students' experiences when they are studying in higher education in Vietnam. This study aims to fill this gap in the literature. The next chapter describes the research methodology used in this study. 


\section{CHAPTER 3 METHODOLOGY}

\subsection{Introduction}

This chapter describes the methodological approach of this study. The choice of a mixed methods research design informed by grounded theory is presented and explained. This chapter also discusses characteristics of the research participants, the data collection procedure, data analysis, measure, limitations of the study, and ethical considerations.

\subsection{Research design}

A mixed methods research design was selected for this study. According to Johnson and Christensen (2012), quantitative data is useful for making generalizations about the research population under investigation. On the other hand, Flick (1992) argues that qualitative research approaches provide flexibility in terms of methodologies and theories which allow the researcher to explore participants' perceptions and behaviours in depth. Both quantitative methods and qualitative methods have various strengths and weaknesses (Johnson \& Christensen, 2012). Following Creswell's (2008) suggestion that it is possible to offset the weaknesses of one methodological paradigm by incorporating the strengths of the other, I chose to employ a mixed methods approach to collect and analyse data, thereby mixing both quantitative and qualitative data into a single study in order to understand the research problem (Creswell, 2008). In this study, a triangulation design using quantitative data allowed me to generalize aspects of my findings, while qualitative data offered more in-depth and contextualized data about participants' perceptions (Creswell, 2008). The triangulation design allows the researcher to give equal priority to both quantitative and qualitative data and it is possible to supplement the results of the qualitative data sets with different kinds of data from the quantitative data sets (Creswell, 2008). In this study, analysis of case study and phenomenological data established a framework for forming conclusions based on grounded theory. 


\subsubsection{Grounded theory}

Grounded theory offers researchers a way of constructing theory from data (Glaser \& Strauss, 1967). Although grounded theory is generally used as a basis for qualitative research, Strauss and Corbin (1998) suggest it is possible for researchers to think of qualitative and quantitative methods in terms of an 'interplay' of approaches and in this respect these two methodological paradigms can "supplement each other" and foster the development of theory. Taking this advice, I selected a mixed method model that combined quantitative and qualitative data in order to generate theory from these two rich data sources.

This study aims to explore academic experiences of international students at An Giang University and grounded theory was selected as a theoretical framework because it is often used as a means of exploring the life-experiences of the participants. For example, Shank (2005) defines grounded theory as a method of building theory from the ground up beginning with participants' life-experiences. Creswell (2008) argues that grounded theory enables researchers to generate a broad theory about qualitatively-driven key phenomena which are grounded in the data. Grounded theory can also help researchers construct predictive statements about the experiences of individuals (Creswell, 2008). In addition, grounded theory was used in this study to give the participants a voice (Glaser \& Strauss, 1967; Charmaz, 2006). The study participants are Laotian and Cambodian international students who have experienced academic life in Vietnam and little is known about their experiences. As Creswell (2008) suggests, grounded theory allows researchers to generate theory when existing theories do not address the research problem. The literature showed that there has been no theory relating to international students' experiences in higher education institutions in Vietnam. The closest literature I could find was Zhadko (2011) who used grounded theory design for her research on international students' academic experiences. However, her study was conducted in the American higher education context.

There are three main approaches to think about grounded theory. These include Strauss and Corbin's (1998) systematic design, Glaser's (1992) emerging design, and Charmaz's (2006) constructivist approach. Each of these designs suggests a specific procedure to generate theory from data. The systematic design of Strauss and Corbin (1998) was selected for this 
study. Systematic design in grounded theory emphasizes the use of data analysis steps: open, axial, and selective coding (Creswell, 2008). Creswell (2008) suggests that open coding is the first phase of analysis. In this phase, the researcher forms initial categories of information about the phenomenon being studied and this is usually accomplished by segmenting information or breaking it down into smaller sets. The second phase is known as axial coding in which the researcher selects one open coding category, positioning it at the centre of the process being explored and relates other categories to it (Creswell, 2008). The third phase is known as selective coding in which the researcher generates a theory from the interrelationship of categories in the axial coding (Creswell, 2008).

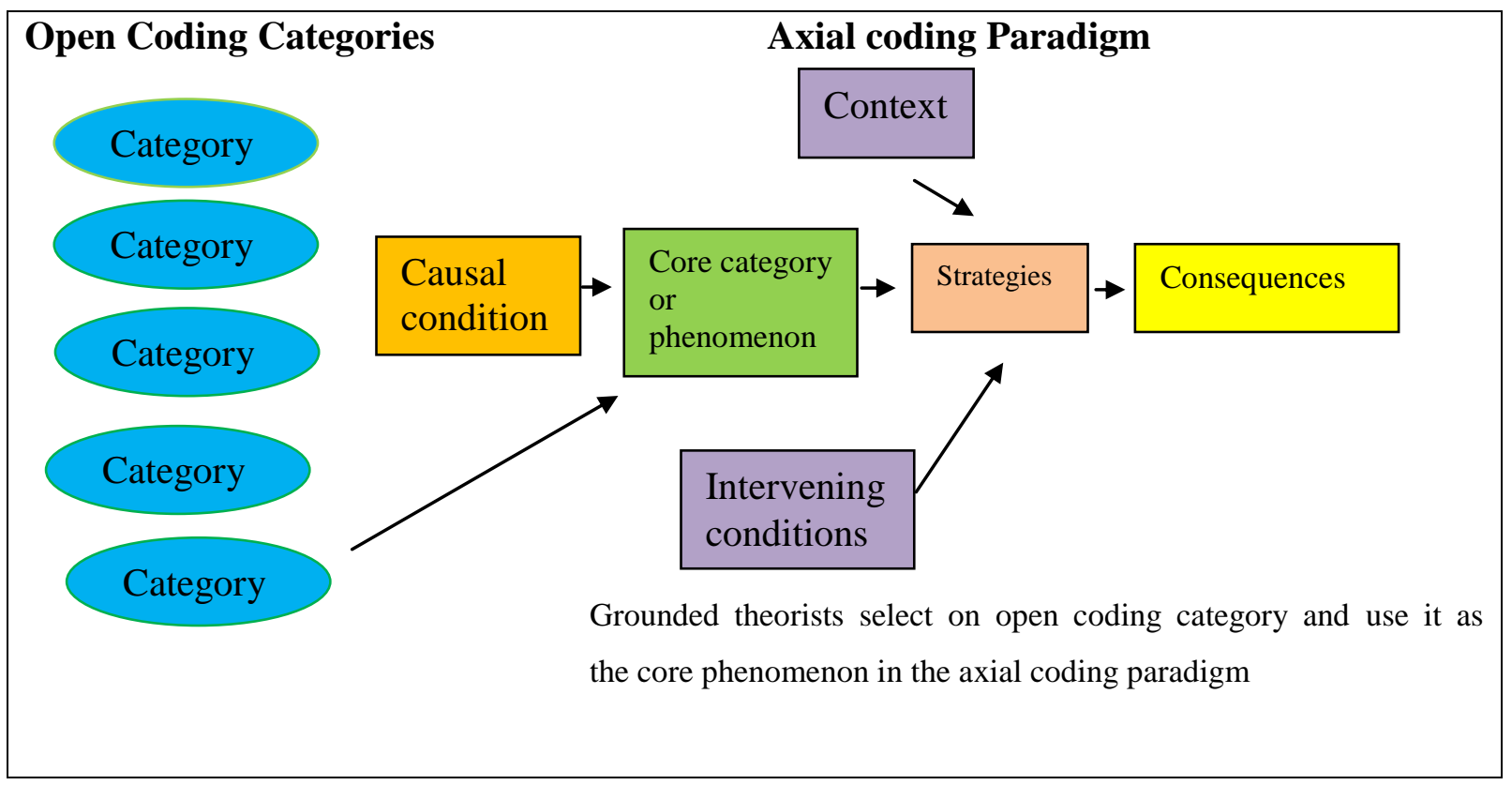

Figure 3.1: Grounded theory coding from Open Coding to the Axial Coding Paradigm (Creswell, 2008)

In this study, grounded theory consists of three phases as Creswell (2008) suggests. They are open coding, axial coding, and selective coding. Data was collected from questionnaires and interviews. Then, the researcher triangulated findings from questionnaires and interviews into categories or themes in an open coding format. The categories/themes included data about language difficulties, cultural issues, teacher- student relationships, and academic performance. In the next phase of data analysis, (the axial coding phase), I selected the category (theme) 'international students' as the core category. Each of the other 
categories identified in the open coding phase (mentioned above) were then related to the core phenomenon (i.e. language difficulties). From there, I reviewed the data and looked for information that related to the participants' experiences of language difficulties. Thus, I checked for data about causal conditions, context, consequences, and so on. From that point, I moved to the last phase of analysis (the selective coding phase) and generated theory by analysing the way the various categories (themes) interrelated with each other in the axial coding phase of analysis. Finally, in selective coding phase, a theory of Laotian and Cambodian students' academic satisfaction at An Giang University was formed and this was based on the perceptions and real experiences of Laotian and Cambodian students. Figure 3.2 which I created with three analysis steps demonstrates how grounded theory was generated in this research. It is based on the three steps data analysis of Strauss and Corbin (1998). 


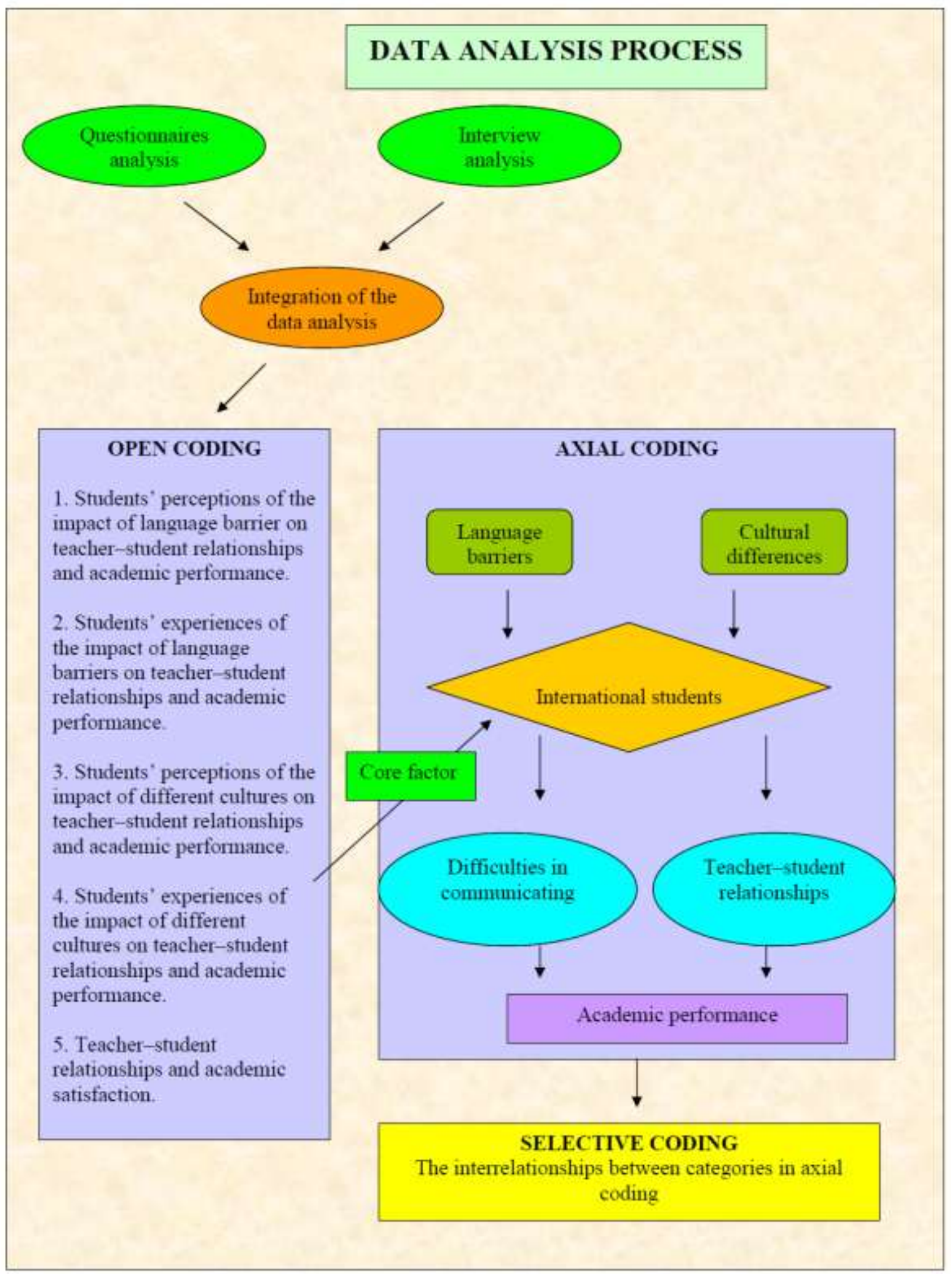

\section{Figure 3.2: Diagram of the data analysis of this study}




\subsubsection{Case study}

A case study approach was selected in this study to collect information from a 'bounded system' that included Laotian and Cambodian students who were enrolled at An Giang University in Vietnam. Merriam (1988), and Johnson and Christensen (2012) recommend that case study approaches can be an effective way of collecting data in qualitative studies where the aim is to obtain a detailed account and analysis of one or more cases. The main aim of this research is to gain detailed insights into the experiences of Laotian and Cambodian students studying at An Giang University; and to use this information to construct wider generalizations about larger groups of Laotian and Cambodian students who are studying in Vietnam. Johnson and Christensen (2012) suggest that a collective case study is an appropriate mechanism for researchers who wish to "gain greater insight into the research topic by concurrently studying multiple cases in one overall research" (p.397). Accordingly, a collective case study approach was used in this research by examining international students' responses (each student being viewed as an individual case study subject) in the recorded interviews. Then, I compared similarities and differences between the questionnaire findings and the interview findings and this formed the basis of my theorizing. Understanding these similarities or dissimilarities may lead to better understanding or better theorizing (Creswell, 2008). Data from multiple case studies was compared for similarities and differences between cases in a cross-case analysis (Johnson \& Christensen, 2012). Cross-case analysis between interviews participants formed the basis of themes which informed the theorizing undertaken as part of the grounded theory design of this study.

\subsubsection{Phenomenology}

I also decided to use phenomenology in this study. According to Merriam (1988) and Johnson and Christensen (2012), phenomenology refers to one or more individuals' consciousness and lived experiences of a phenomenon. Phenomenology is also recommended by Shank (2005) as a suitable approach when the researcher wants in-depth insights into the meanings and the life-worlds of a person or a group of people. Smith (2008) comments that "phenomenology involves [a] detailed examination of the participants' lived experiences; it attempts to explore personal experiences and is concerned 
with an individual's personal perception" (p. 54). Based on these characteristics of phenomenology and the nature of this particular study, phenomenology was chosen for this thesis project. Johnson and Christensen (2012) argue that phenomenology is used to understand the commonality of individuals' experiences or the essence of the experience. In this study, I wished to explore the commonality of international students' experiences of academic life, their relationships with Vietnamese teachers, and their perceptions and experiences of the correlation between student-teacher relationships and academic performance at An Giang University. In phenomenological terms, data was collected from several individuals through in-depth interviews that depicted their experiences of these matters (Johnson \& Christensen, 2012). In this study, in-depth interviews were conducted in order to elicit data about the Laotian and Cambodian students' academic experiences of studying at An Giang University. In the data analysis process of phenomenology, the researcher searches for significant statements that have particular relevance to the phenomena being studied (Johnson \& Christensen, 2012). Accordingly, during the analysis process of this study, I looked for themes that related to the international students' academic experiences of studying in the linguistic and cultural contexts of a Vietnamese university. Using this phenomenological framework, I was able to compare data from each interview and check for commonality and differences in their experiences which then helped me to construct a grounded theory from the data.

\subsection{Instruments and procedures}

In this research, quantitative and qualitative data were collected with questionnaires and indepth interviews.

Quantitative data was collected in the form of questionnaires which were administered to all international students enrolled at An Giang University at the time the study took place $(\mathrm{N}=24)$. Questionnaires were used to obtain information about thoughts, feelings, attitudes, beliefs, values, perceptions, personality, and behavioural intentions of the research participants (see Appendix C). Johnson and Christensen (2012) describe questionnaires as a self-report data-collection instrument that research participants fill out as part of a research study. They argue that questionnaires can provide researchers with a basis for further generalizations about the research population. In this thesis study, the questionnaires 
contained both closed and opened-ended questions. The questionnaires were constructed in conversational Vietnamese using wording that was as clear and precise as possible and contained no double negatives. The questionnaires were pilot tested before they were administered to the research participants. A Likert rating scale and ranking were also used in some questions.

Johnson and Christensen (2012) recommend that researchers establish rapport with participants to avoid obtaining unbiased data. The researcher established rapport with participants by explaining the purposes of the research, the likely research benefits and making sure that the participants were aware that their responses would be treated in confidence. Signed participant consent forms were obtained before the questionnaires were issued. Once the questionnaire data had been collected, data was coded and input into Excel and SPSS programs which are designed for data analysis.

Qualitative interviews were also conducted and these consisted of a mix of closed and open-ended questions. Qualitative interview or in-depth interview data provides nuanced information about the participants' experiences (Johnson \& Christensen, 2012). In this research, qualitative interviews provided in-depth information about the Laotian and Cambodian students' academic experiences. The researcher established rapport with interviewees by explaining the purposes and likely benefits of the research; pointing out that their responses would be treated in confidence. Establishing this rapport with interviewees created a friendly environment that was conducive to the collection of strong data (Johnson \& Christensen, 2012). Participant consent forms were signed by the interviewees before each interview. Following Creswell's (2008) advice, I conducted each interview in a quiet classroom so that the interview process would not be disturbed. During each interview, interviewees' responses were recorded electronically, and I also took notes while they were speaking. The order of questions in the interview was flexible. If necessary, follow-up questions were asked to further clarify certain points.

Creswell (2008) argues that "open-ended interviews that provide actual words of people in the study offer many different perspectives on the study topic and provide a complex picture of the situation" (p.510). The qualitative data I collected in the interviews allowed me to gain an in-depth view of the research topic. 


\subsection{Participants and recruitment}

\subsubsection{Participants}

The researcher included twenty-four Laotian and Cambodian students currently enrolled at An Giang University into the quantitative data collection. This figure represented the total number of international students enrolled at An Giang University at the time the study took place. The research sample was made up of seven Cambodian students and seventeen Laotian students. There were three females and twenty-one males. Twelve of the Laotian students had started their nine-month long Vietnamese competence program in January 2011. These students needed to complete this course before they began their undergraduate degree studies at An Giang University in October 2011. Twelve of the Laotian and Cambodian students had already completed their undergraduate degrees at An Giang University that June. Their ages ranged from eighteen to forty years. In order to assure the reliability of the study and appropriately generalize the findings, all international students enrolled at An Giang University were included in the questionnaire data. The method of including all individuals in a given population is known as conducting a census (Johnson \& Christensen, 2012). Johnson and Christensen (2012) suggest when the research population is very small; including all the individuals in your study is the best way of ensuring that the researcher can make accurate generalizations about the population. For that reason, all international students from Laos and Cambodia ( $\mathrm{N}=24$ students) were included in the questionnaire phase of the study. Questionnaires were used to collect a mix of quantitative and qualitative data from all of the research population, so that the data that was generated would be powerful enough to make accurate generalizations.

After administering the questionnaire, purposive sampling was used for the qualitative interview participants. Purposive sampling helps to specify the characteristics of the research population by identifying individuals who have those characteristics (Johnson \& Christensen, 2012). In addition, purposive sampling allowed me to explore the phenomena being studied at a deeper level through selecting cases that were likely to be "informationrich" with respect to the purposes of the study (Gall, Borg, \& Gall, 1996). In addition, Denzin and Lincoln (2000) argues that purposive sampling provides the widest possible range of data to include into the thick description of case study research. Purposive 
sampling led me to select four Laotian students and two Cambodian students. Strauss and Corbin (1998) suggest that the researcher's collect data until they reach the point of saturation or redundancy. Corbin and Strauss (2008) also suggest that although it is possible to reach theory saturation after five interviews, it is often better to look for more participants than that. In addition, Seidman (2006) also suggests that research can draw to a close when saturation has occurred and little new information is added by additional participants. Therefore, after collecting background data by questionnaires from the whole research population, six international students were purposively selected for participation in the qualitative interviews. These purposive samplings included two students who had received the best grades within the whole group; two students who had received the poorest grade reports within the whole group; and, two students with grade reports in the middle range. It was believed that by selecting purposively in that way, I could collect information from international students who had different experiences of the University, and hence different perspectives about their studies. This also allowed me to see how their experiences were similar or different from each other's and also to see what caused these differences and similarities.

\subsubsection{Recruitment}

In order to begin the recruitment, I obtained ethics approval from Ethics Committee of Victoria University of Wellington before returning to Vietnam to conduct the fieldwork. In Vietnam, I obtained permission to conduct the study at An Giang University from the Chair of Research Department of An Giang University (see Appendix H). Then, I sent formal invitations to Laotian and Cambodian international students at An Giang University to join the research as participants. Based on the students' voluntary agreement to participate in the research, I sent out a formal invitation to interested participants and provided them with more information regarding the purposes and benefits of the study (see Appendix A). Students who indicated their willingness to participate in the study were then asked to complete an informed consent form to participate in the questionnaires (see Appendix B). After administering the questionnaires, six international students were selected and invited to participate in qualitative interviews (see Appendix D). When these students agreed to participate in the qualitative interview, consent forms were collected before each interview (see Appendix E). 


\subsection{Data collection}

Quantitative and qualitative data for the study were collected from participants by questionnaires (see Appendix C) and qualitative interviews (see Appendix F). All data was collected in the Vietnamese language. These sources of data were subsequently translated into English.

The data collection procedure took six weeks. This duration allowed the researcher sufficient time to administer and analyse the questionnaires before conducting interviews with participants. The researcher also analysed the recorded data of each interview before starting a new interview. By this method, the researcher was able to looked for common themes in each interview.

\subsubsection{Quantitative and qualitative data from questionnaires}

Initially, the researcher collected quantitative data by asking all participants to complete the questionnaires (see Appendix C). Responses to these questionnaires provided background information about the participants. Data from questionnaires also provided objective information from Laotian and Cambodian students' real experiences. Information collected from questionnaires included international students' background information (age, nationality, the duration of their study at An Giang University, the duration of their Vietnamese language learning, and their study programs). The questionnaires also elicited information about international students' perceptions and experiences of the effect of language differences on their teacher-student relationships and their academic performance. Also collected from the questionnaires was information about the students' perceptions and experiences of the effect of cultural differences on their teacher-student relationships and their academic performance; and their perceptions and experiences of their academic achievement when they were studying at An Giang University. These questionnaires were designed in Vietnamese using simple Vietnamese so that Laotian and Cambodian students who had limited Vietnamese language proficiency could easily understand and provide appropriate responses. 
The participants' level of proficiency in the Vietnamese language varied considerably. Some Laotian students enrolled in the nine-month Vietnamese language class had been studying Vietnamese for only three months. Although the questionnaires were short and used simple language, some of these Laotian students needed some questions to be translated from Vietnamese into Laotian and vice versa. Luckily, one of the other participants was a Laotian student who was considered the most fluent Vietnamese student in the group and he offered to translate parts of the questionnaire into Laotian. This Laotian student translated some Vietnamese questions for these Laotian who had difficulty understanding some of the questions in the questionnaire. Before translating each question into Laotian, he checked with me first to make sure he was translating the meaning accurately. As a result, all the participants filled in every question. Some of the Laotian students who were enrolled in the Vietnamese language competence class also tried to supplement their written answers by giving me verbal explanations using simple words and sentences in Vietnamese. Some of them responded in the Laotian language so that they could clearly express their opinions and when this happened, I sought help from a Vietnamese teacher who was a fluent Laotian speaker.

\subsubsection{Qualitative data from interviews}

After administering the questionnaires and analysing the data for appropriate themes, six purposive participants were invited to participate in a semi-structured interview. This study aims to examine how linguistic and cultural differences may affect teacher-student relationships and their academic performance; and the how teacher-student relationships may affect international students' academic satisfaction at AGU. Therefore, the participants in the interviews were selected based on their academic outcomes as mentioned above. Interview invitations were accepted by all six participants. May (2001) asserts that qualitative interview method allows interviewees to speak more on their own terms rather than follow the more restricted framework of a structured interview. Merriam (1988) argues that a person-to-person encounter in which one person elicits information from another is the most common form of interview. With a semi-structured format, the interviews in this study were conducted in a relatively informal manner and the interviewees were given opportunities to focus on issues that interested them the most, rather than being pressured to comment on every single item (Johnson \& Christensen, 2012). Each interview lasted about 
thirty minutes. Only one interview reached nearly one and a half hours. The longest interview was conducted with a female Laotian student of the Vietnamese language competence class. This student was studying Vietnamese language at An Giang University before she began her postgraduate studies at another university in Vietnam. Before coming to study the Vietnamese language at An Giang University, she was employed as a lecturer at a university in Laos. She was therefore interested in the topic of the research which examined teacher-student relationships and academic performance. Understanding that the information she could provide was important for this study, she shared a lot informative data about her experiences of the Vietnamese language competence class in which she was enrolled.

The interviewees were asked about (a) their academic expectations, level of satisfaction with their academic experiences, and recommendations for improving the quality of their study at An Giang University; (b) their experiences as international students who were studying in the cultural and linguistic context of a Vietnamese university; (c) their experiences and perceptions of teacher-student relationships and their academic satisfaction. The timing of each interview was scheduled at the interviewees' convenience. After each interview, the researcher reviewed the data and looked for common themes so that she could compare interviewees' responses and note any arising themes from the following participants. The researcher conducted each interview in a quiet place to avoid interruptions during the interview. All the interviews were electronically recorded and with the permission of the interviewees, hand written notes were also taken. The interviews were then transcribed and translated from Vietnamese into English.

\subsubsection{Secondary data}

In order to have more data for this study, secondary data was also collected from students' academic reports after each school year. Johnson and Christensen (2008) define secondary data as "data that were collected, recorded, or left behind at an earlier time, usually by different people and often for an entirely different purpose than the current research purpose at hand" (p.217). Secondary data was also collected from reports of the Vietnam International Education Development Department of The Ministry of Education of Vietnam about the number of international students studying at higher education institutions in 
Vietnam. Reports of the numbers of higher education institutions, and the number of students enrolled in higher education in Vietnam were also collected from The Ministry of Education of Vietnam. With these reports, I was able to develop an overview of the national context of international study in Vietnamese universities in recent years.

\subsection{Data analysis}

This study employed a triangulation mixed methods design and the data analysis included both quantitative data and qualitative data. Creswell (2008) argues that the purpose of a triangulated mixed methods research design is to simultaneously collect both quantitative and qualitative data, merge the data, and use the results to understand a research problem. Hatch (2002) states that "analysis means organizing and interrogating data in the way that allow researchers to see patterns, identify themes, discover relationships, develop explanations, make interpretations, mount critique, or generate theories" (p. 148). Data analysis in this study was conducted in two phases: questionnaire analysis and interview analysis. The researcher analysed the questionnaires for quantitative and qualitative data. Qualitative data drawn from the interviews was analysed separately. Then, the researcher integrated and compared the findings from the analysis of both datasets, and developed an interpretation in order to consider whether the results supported each other or contradicted each other. According to Creswell (2008), this direct comparison of two data sets by the researcher provides a "triangulation" of data sources.

This study also followed a grounded theory design. According to Strauss and Corbin (1998), data analysis in grounded theory includes three steps: open coding, axial coding, and selective coding. As discussed earlier in this chapter, in open coding, the researcher forms initial categories of information about the phenomena being studied by segmenting information or breaking it down into smaller sets (Creswell, 2008). Open coding in this research was based on the interpretation of quantitative and qualitative data analysis of the themes. These themes were identified as follows: international students' academic expectations and level of satisfaction with their experiences of studying at An Giang University; their perceptions and experiences of the effects of linguistic differences on their teacher-student relationships and their academic performance; their perceptions and 
experiences of the effect of cultural differences on their teacher-student relationships and their academic performance; and teacher-student relationships and academic satisfaction.

The second step is axial coding in which the researcher selects one category from open coding and positions it at the centre of the process being explored and relates other categories to it (Creswell, 2008). Accordingly, I selected the term international students from the open coding phase as the core category in the axial coding. Then, I drew a diagram of the relationships between this core category with other categories identified during the open coding phase. The final step of grounded theory design is selective coding in which the researcher generates a theory correlating the categories identified in the axial coding phase (Creswell, 2008). Finally, I developed a theory about the role of teacherstudent relationships in relation to international students' academic performance in the linguistic and cultural context of a higher education institution in Vietnam. The data analysis process of this study is illustrated in Firgure 3.2 (p. 55).

\subsubsection{Questionnaire analysis}

Once the questionnaires data had been collected, data was coded and entered into Excel and SPSS programs. Pallant (2010) recommends the SPSS program for analysing questionnaire data in order to identify the correlation between categories. From the data entered into SPSS, I was able to conduct a frequency analysis and consider the correlation between categories (Denscombe, 2001). The SPSS program was also used in analysing the data of the questionnaires in this research in order to examine students' academic experiences at An Giang University, and the correlation between categories. In order to make sense of the open-ended questions in the questionnaires, I made use of open coding (Strauss \& Corbin, 1998) and developed categories of emergent themes relating to students' experiences of language, culture, relationships with Vietnamese teachers, and the impact of these factors on their academic outcomes.

The response rates to quantitative questions were collated within this research so that I could give a related percentage. The presentation of the numerical values and related percentages helped me to build a clear description of Laotian and Cambodian students' experiences. 


\subsubsection{Interview analysis}

I used elements of grounded theory design for data analysis as mentioned above. Data was transcribed and every interview was coded then translated, and analysed for themes and categories using open coding system to identify ideas that related to research questions and discover insights from each particular case (Strauss \& Corbin, 1998; Creswell, 2008). According to Strauss and Corbin (1998), “open coding is the interpretive process by which data are broken analytically... events/actions/interactions are compared with others for similarities and differences" (p.12). Accordingly, I used an open coding and axial coding process for the initial analysis process. During the process, conceptual labels are given, that are then grouped to form categories/sub-categories. Strauss \& Corbin (1998) argue that "in axial coding, categories are related to their subcategories, and the relationships tested against data" (p.12). Therefore, during analysis process, categories were related to other categories and sub-categories were identified, then relationships were tested against data. Constant comparison was used in both analysis processes.

\subsubsection{The integration of findings from questionnaires and interviews}

After administrating data from questionnaires and interviews, I integrated and compared findings from questionnaires and interviews for common themes in open coding. A core category was selected for axial coding. Finally, I analysed the way the various categories interrelated with each other in selective coding.

\subsubsection{Open coding}

The initial codes were grouped by similarities or by dissimilarities. When the initial codes were developed, I kept a record of them. Some examples of the initial concepts that reflected particular factors and had an impact on Laotian and Cambodian students' experiences of language, culture, relationships with Vietnamese teachers, and their academic performance emerged as communication, rules, learning, constraints, policies, expectation, etc. 
Through a process of constant comparison, these provisional concepts developed into categories as a result of the open coding process. Not all concepts became categories however. For example, some respondents noted that they preferred studying in groups with Vietnamese friends because it improved their proficiency in Vietnamese and helped them to understand the lesson better. Others preferred studying by themselves and sought help from Vietnamese teachers because they did not think that Vietnamese friends would be helpful to them. After a careful comparison of these responses, I started to group the instances where participants reported about studying in groups with Vietnamese friends and labelled this as "group study". Then I identified cases where participants preferred to study on their own and I labelled these responses as "self-study".

During the analysis process, Strauss and Corbin (1998) suggest that analysis becomes more focused on "filling those categories and verifying relationships" (p. 70) because grounded theory meanings are constructed in identifying where the subcategories stand in relation to each other through the coding of conditions, context, strategies, and sequences.

\subsubsection{Axial coding}

When conducting the axial coding process, I reassembled the themes that were formed during the open coding process. Strauss and Corbin (1998) define axial coding as "the process of relating categories to their subcategories, termed 'axial' because coding occurs around the axis of a category, linking categories at level of properties and dimension" (p.123). One category of the open coding was selected as the core category, and then I related other categories to this core category in order to identify the relationships between them.

\subsubsection{Selective coding.}

In grounded theory, theory is generated through the selective coding process (Strauss \& Corbin, 1998). Therefore, in selective coding, I considered the interrelationships between the various categories identified in the axial coding phase. Then, I was able to construct a theory about the importance of the role of teacher-student relationships in helping 
international students to overcome linguistic and cultural barriers and satisfaction with their academic life at AGU.

\subsection{Reliability and validity}

Reliability refers to the consistency or stability of the data. Validity refers to the accuracy of the inferences or interpretation the researcher makes from the data (Johnson \& Christensen, 2012). According to Johnson and Christensen (2012), reliability and validity are the two most important psychometric properties to consider in using a test or assessment procedure. Reliability and validity of this research were addressed to assure the quality of this research.

\subsubsection{Reliability}

Reliability refers to the extent to which researchers' findings are dependable (Merriam, 1988). This means research is reliable if the data collected makes sense and is consistent. In this study, several steps were taken to ensure the research findings were consistent and dependable. First, I checked the translated transcripts to make sure no significant mistakes made during transcription and translation from Vietnamese into English (Gibbs, 2007). Second, when analysing the data, efforts were made to ensure that codes were defined correctly by repeatedly comparing data with the codes (Creswell, 2008). Furthermore, detailed description of the researcher's position, and data analysis, were provided so that an audit of the study could take place (Merriam, 1988).

\subsubsection{Validity}

Internal and external validity were addressed in this mixed research.

\subsubsection{Internal validity}

Internal validity is related to issues pertaining to the congruency of the findings with reality (Merriam \& Simpson, 2000). Merriam and Simpson (2000) suggest using a number of strategies to ensure internal validity including triangulation, member checks, peer or 
colleague examination, including statement about the researcher's experiences and biases, and submersion or engagement in the research institution. In this study, I triangulated literature on the topic of international student experiences. I also triangulated data from questionnaires and interviews for themes in the open coding phase. Member checking was conducted in this study by checking the transcripts and the data to assess whether the interpretation was appropriate. Supervisor's feedback on all things related to the research during the research period helped to adjust my thinking and actions (this is also considered to be a form of member checking). Peer examination was included in this study through the support I received from my thesis supervisor and a particular student learning adviser who has helped me a great deal in my studies. This student learning adviser has supported me from the beginning right through to the end of this research project and has always reviewed my work and given me feedback on my writings.

Content validity was used to address validity of the questionnaires and interview questions. The questionnaires and interview questions were reviewed and feedback for comprehension and content coverage was provided by two learning advisors, my thesis supervisor, and the Ethics Committee of Victoria University of Wellington. A pilot was conducted with six international students in New Zealand before collecting data in Vietnam.

\subsubsection{External validity}

External validity is concerned with the generalizability of findings from one study to other situations, and from a sample to the population. The researcher ensured generalizability by selecting a range of diverse cases and included all international students at AGU in the questionnaires. According to Merriam, a reader of the study will define how generalizable or applicable the findings of this study can be to other situations. Merriam (1988) suggests a number of strategies to address the concerns of external validity such as rich description, multi-site designs, modal comparison, and random sampling. Johnson and Christensen (2012) suggest including the total research population for sampling purposes if the population is small as this allows for strong generalizability. This study included all of the international students enrolled at An Giang University in the quantitative data phase. In this study, measures were taken to enhance external validity. First, a detailed description of the research context, procedures, analysis, and assumptions central to the research were 
provided so that those who are interested in applying the findings will have adequate information for the judgement - thick description (Merriam, 1988). This study also provided a detailed description of the research problem, the research context, the research participants, the data collection and analysis procedure in order to give the readers a clear view of the issues involved with this research.

\subsection{Ethical considerations}

Ethical approval for this study was given the Victoria University of Wellington Faculty of Education Human Research Ethics Committee. It conformed to the ethical guidelines of the New Zealand Association for Research in Education (NZARE, 2010). In Vietnam, there is no formal university regulation of research ethics; however, the Ministry of Education of Vietnam was informed about my activities, and formal permission was sought to conduct the research from the university's Rector Board and the relevant Heads of school at An Giang University. I also sought approval from the Head of Research Department of An Giang University before collecting data. Most importantly, the participants were fully informed about the research purpose and procedures. Consent forms were obtained before data collection took place. In addition, Johnson and Christensen (2012) state that "educational research has historically engaged in research that imposes either minimal or no risk to the participants and has enjoyed a special status with respect to formal ethical oversight" (p.118). For this reason, during the data collection process, the psychological and physical safety and convenience of participants were respected. The participants have the right to withdraw from a study at any time (Johnson \& Christensen, 2012). The identity of participants was protected at all stages, and any information about the participants acquired during the research process was kept confidential. The data collection was not disclosed to anyone except for the researcher and the supervisor.

\subsection{Conclusion}

This chapter has described the methodological and grounded theory approach taken in this study. The mixed method research design that combined quantitative and qualitative data has been discussed. I have also explained how the data was collected and analysed, and discussed the ethical considerations involved. 


\section{CHAPTER FOUR \\ THE STUDY FINDINGS}

\subsection{Introduction}

The study findings are presented in this chapter. The findings from the questionnaires are presented first and include: (a) background information about the international students who participated in this study; (b) the participants' perceptions and experiences of the effect of language barriers on their relationships with Vietnamese teachers and their academic performance; (c) the participants' perceptions and experiences of the effect of cultural differences on teacher-student relationships and their academic performance; and, (d) the participants' levels of satisfaction with their academic performance and academic experiences while studying in Vietnam.

The interview findings include the following information: (a) a discussion about the characteristics of the interviewees; (b) international students' expectations, educational experiences, and recommendations for improving the international students' experiences at the University; (c) the effect of language barriers that Laotian and Cambodian students experienced in the course of their studies and how these affected their relationships with Vietnamese teachers; (d) the impact of cultural differences on their studies; and, (e) the quality of teacher-student relationships and students' academic performance.

\subsection{Questionnaire findings}

In this section, I present the findings from the questionnaires I administered to participants at the outset of the study. The questionnaire provided background information about the international students who were studying at An Giang University at the time the study took place. It gave an overview of their perceptions about their relationships with their teachers; their experience of studying in the cultural and linguistic context of a Vietnamese university and the effect of these factors on their academic performance and their level of satisfaction with their academic performance at An Giang University. 


\subsubsection{The participants' background information}

Twenty-four international students filled in the questionnaires. This represents the total number of international students who were enrolled in the programmes under discussion at the time. In this section, I provide an overview of the Laotian and Cambodian students' responses relating to nationality, age, duration of study in Vietnam, length of academic experience at An Giang University, and their study programmes at An Giang University.

In this study, $70.8 \%$ of the participants were Laotian (17/24) and 29.2\% were Cambodian (7/24). Participants had studied at An Giang University (which conducts its teaching in the Vietnamese language) for different periods of time. Half of the participants (12/24) had been students at An Giang University for about five years (including a nine-month Vietnamese language proficiency course and a four-year undergraduate degree). Just under half of the students (11/24) were enrolled in the Vietnamese language course and most of them had been in residence at the University for six months. This group of participants was scheduled to begin their undergraduate degrees in October of the same year although one participant had been enrolled in the Vietnamese language course for only four months at the time the questionnaire was administered.

The participants were drawn from two particular programs of study offered by An Giang University. These were an undergraduate degree program and a Vietnamese language proficiency course. International students usually need to complete a nine-month long Vietnamese language proficiency course before they start their undergraduate degrees. The purpose of the course is to prepare them to do their studies in a degree program where the language of instruction is Vietnamese. Half the participants involved with this study (12/24) had begun the Vietnamese language proficiency program in January 2011. The rest of the participants (12/24) had begun their undergraduate studies at the University in 2007. These students had graduated from their undergraduate program at the University in June 2011.

Table 4.1 illustrates the participants' ages range. The participants' ages ranged from 18 years to 40 years of age. The majority of international students $(11 / 24)$ were in the 18 to 22 
age range; five students were in the 23 to 27 age range $(5 / 24)$, seven students were in the 28 to more than 32 years old (7/24), and one student was 40 years old.

Table 4.1: The age range of the participants.

\begin{tabular}{|l|c|c|c|}
\hline \multicolumn{1}{|c|}{} & Frequency & Percent \\
\hline Valid & $18-22$ & 11 & 45.8 \\
\cline { 2 - 4 } & $23-27$ & 5 & 20.8 \\
\cline { 2 - 4 } & $28-32$ & 7 & 29.2 \\
\cline { 2 - 4 } & Other & 1 & 4.2 \\
\cline { 2 - 4 } & Total & 24 & 100.0 \\
\hline
\end{tabular}

\subsubsection{The participants' perceptions and experiences of the effect of language barriers on their relationships with Vietnamese teachers and their academic performance while studying at An Giang University.}

Responses from the Laotian and Cambodian participants showed that studying in a foreign language might not only cause difficulties for them in establishing good relationships with their Vietnamese teachers but also result in some unexpected academic outcomes. I discuss these further below.

\subsubsection{International students' perceptions of the connection between learning in a foreign language and their teacher-student relationships and their academic performance.}

Data analysis of international students' perceptions illustrates how international students think about language barriers that may affect their teacher-student relationships and their academic performance. 


\subsection{International students' perceptions of establishing good relationships with their Vietnamese teachers.}

A majority of the study participants lacked confidence in their level of proficiency in the Vietnamese language. Most of these participants also indicated that they had experienced difficulties in establishing good relationships with their teachers and they believed that this was partly due to the language barriers they experienced in the classroom.

The table 4.2 below shows that most of the participants lacked confidence in their level of fluency in the Vietnamese language. Most participants disagreed or strongly disagreed that they felt confident about their proficiency in Vietnamese (19/24). The remaining five students felt confident about their level of competence in the Vietnamese language $(5 / 24)$.

Table 4.2: Students' confidence in their Vietnamese proficiency

\begin{tabular}{|c|c|c|c|}
\hline \multicolumn{4}{|c|}{$\begin{array}{l}\text { You are self confident with your Vietnamese language competence when } \\
\text { you are studying at AGU. }\end{array}$} \\
\hline & & Frequency & Percent \\
\hline \multirow[t]{4}{*}{ Valid } & Agree & 5 & 20.8 \\
\hline & Disagree & 17 & 70.8 \\
\hline & Strongly disagree & 2 & 8.3 \\
\hline & Total & 24 & 100.0 \\
\hline
\end{tabular}

Most of the participants believed that their level of competence in Vietnamese had affected their relationships with their Vietnamese teachers. Table 4.3 shows that a significant number $(22 / 24$ or $91.7 \%)$ responded "yes" to a question about their perception of the effect of their fluency in Vietnamese on their teacher-student relationships. Most of those students who answered "yes" to this question explained that they believed that relationships are built on clear communication and mutual understanding. Consequently, they felt that their limited fluency in Vietnamese had limited their ability to communicate effectively with their Vietnamese teachers; hence, they believed that there were gaps in their understanding of each other. Only two international students $(8.3 \%)$ answered "no" to this question. The students who answered "no" to this question explained that their Vietnamese 
teachers had always tried to communicate well with international students and had made an effort to understand their situation. Another student was confident that he could communicate very well with his Vietnamese teachers and this had enabled him to build a good relationship with them.

\section{Table 4.3: $\quad$ Students' perceptions of the impact of linguistic barrier on their relationships with their Vietnamese teachers.}

\begin{tabular}{|l|c|c|c|}
\hline \multicolumn{3}{|c|}{$\begin{array}{c}\text { Do you think your Vietnamese competence will affect your } \\
\text { relationships with Vietnamese teachers? }\end{array}$} \\
\hline \multirow{2}{*}{} & Frequency & Percent \\
\hline Valid & Yes & 22 & 91.7 \\
\cline { 2 - 4 } & No & 2 & 8.3 \\
\cline { 2 - 4 } & Total & 24 & 100.0 \\
\hline
\end{tabular}

\subsection{International students' perceptions of the relationship between Vietnamese language proficiency and academic outcomes.}

It is significant that all of the international students involved with this study believed that there is a strong relationship between their level of fluency in the Vietnamese language and their academic outcomes. When asked about their perceptions of the effect of language barriers or language difficulties on their academic performance, all of the participants (24/24) believed that competence in the Vietnamese language plays an important role in their academic performance. More than half the participants (15/24) reported that their lack of competence in Vietnamese slowed them down when following their teachers' instructions. They found it difficult to take notes and consequently they did not have enough notes to review lectures after class. Seven of these students said that they did not feel confident about speaking Vietnamese in class. They admitted that they felt too shy to ask for additional help from teachers when they had not kept pace with their teachers' instructions. As a result, they found it difficult to do some of the in-class exercises. They found it even more difficult when they had to deal with that kind of knowledge in the examination. Two of these students noted their feelings of stress and anxiety when they had to spend much of their study time looking up words in the dictionary. These participants 
said that because of this, they found it difficult to arrange time for relaxing or socializing with friends. It was noted that going out with Vietnamese friends was very necessary for them to improve their Vietnamese language proficiency as well as to get academic help from their Vietnamese friends.

\subsubsection{International students' experiences of the link between Vietnamese language proficiency, their teacher-student relationships, and their academic performance.}

The majority of participants noted that they had experienced difficulties communicating with Vietnamese teachers due to their low levels of fluency in Vietnamese. The rest of the participants did not experience difficulties in communicating with Vietnamese teachers because their teachers had shown them kindness and had taken a supportive approach with them. Although several participants had difficulties in communicating with their Vietnamese teachers, they all reported that they had good relationships with their teachers. However, they believed that their limited grasp of Vietnamese had a negative effect on their academic performance and the students were very aware of this.

\subsection{International students' experiences of language difficulties in establishing relationships with their teachers.}

- Communication in Vietnamese

\section{Table 4.4: Students' difficulties in communicating in Vietnamese}

\begin{tabular}{|}
\hline \multicolumn{3}{|c|}{ Do you have any difficulties in communicating with your } \\
Vietnamese teachers? \\
\hline \multirow{2}{*}{} & Frequency & Percent \\
\hline Valid & Yes & 15 & 62.5 \\
\cline { 2 - 4 } & No & 9 & 37.5 \\
\cline { 2 - 4 } & Total & 24 & 100.0 \\
\hline
\end{tabular}


Table 4.4 illustrates how difficult international students found communicating with their Vietnamese teachers. The participants noted that there was a strong correlation between their level of fluency in Vietnamese and the level of communication they were able to have with their teachers. A majority of the participants (15/24 or 62.5\%) reported difficulties in communicating with their Vietnamese teachers because of their low level of fluency in Vietnamese. Some typical comments are given below:

"My Vietnamese competency is not good enough to communicate with teachers."

"I cannot understand teachers' questions in Vietnamese and cannot answer them and communicate with teachers."

"I cannot communicate well with Vietnamese teachers and cannot fully understand them."

"I hardly talk to Vietnamese teachers because of my poor Vietnamese language ability.”

"My poor Vietnamese language competence caused too much embarrassment in communicating with Vietnamese teachers."

"Sometimes, I asked a non-standard Vietnamese question and it took time for my teacher trying to understand my questions. It caused embarrassment for both of us and it was time-consuming. Later, I tended to avoid communicate with my teachers. "

Meanwhile, only nine of the participants (9/24 or 37.5\%) experienced little or no difficulty communicating with Vietnamese teachers. These students explained that although their Vietnamese language competence was not very good, Vietnamese teachers had been very friendly, helpful, and supportive of them, and this has encouraged them to try and communicate with these teachers whenever they had difficulties in their studies or even in their daily lives. 
- International students' experiences of establishing relationships with their teachers using the medium of the Vietnamese language.

Table 4.5: Students' relationships with their Vietnamese teachers

\begin{tabular}{|l|c|c|c|}
\hline \multicolumn{3}{|c|}{ You have established good relationships with Vietnamese } \\
teachers. \\
\hline \multirow{2}{*}{ Valid } & Frequency & Percent \\
\cline { 2 - 4 } & Strongly agree & 20 & 83.3 \\
\cline { 2 - 4 } & Agree & 4 & 16.7 \\
\cline { 2 - 4 } & Total & 24 & 100.0 \\
\hline
\end{tabular}

Table 4.5 shows how international students experienced relationships with Vietnamese teachers. Although most of the participants believed that their low level of proficiency in Vietnamese had hampered their relationships with their Vietnamese teachers, they all reported that they had good relationships with their teachers. A majority of the international students (20/24 or $83.3 \%$ ) strongly agreed that they have had good relationships with their Vietnamese teachers. Meanwhile, 4/24 (16.7\%) international students agreed that they have good relationships with their teachers. All of the participants reported that Vietnamese teachers are friendly and helpful. However, only a few of them (4/24) stated that they thought that Vietnamese teachers are skilled at teaching international students.

\subsection{International students' experiences about the link between having limited proficiency in the Vietnamese language and academic performance.}

Table 4.6: Students' difficulties in participating in class activities

\begin{tabular}{|c|c|c|c|}
\hline \multicolumn{2}{|c|}{ Do you have any difficulties in participating in classes at An Giang } \\
University? \\
\hline \multirow{2}{*}{} & Frequency & Percent \\
\hline \multirow{2}{*}{ Valid } & yes & 23 & 95.8 \\
\cline { 2 - 5 } & no & 1 & 4.2 \\
\cline { 2 - 4 } & Total & 24 & 100.0 \\
\hline
\end{tabular}


Table 4.6 shows that almost all international students had experienced difficulties in participating fully in classes. The questionnaire results showed that 23/24 (95.8\%) of the international students had experienced language barriers that limited their participation in classroom activities and only one student (1/24 or $4.2 \%)$ indicated that he had not experienced any difficulties participating in classroom activities. It is surprising that this respondent was a Laotian student who had been enrolled in the Vietnamese language proficiency course for only six months. Meanwhile, almost all the international students stated that they usually encountered difficulties during group-work activities and class discussions. Many participants explained that their levels of competence in Vietnamese had deterred them from discussing class material with Vietnamese classmates. Some typical comments from participants who had experienced difficulties in participating in classroom activities are given below:

"My listening skills are not good enough to fully understand all knowledge taught in class."

"I could not understand all activities in class and it was hard for me to participate in classroom activities."

"I could not follow all the teacher's instructions in class."

"I could not fully express my ideas in class."

"When I did not understand the teacher's explanation in Vietnamese, the teachers could not explain the lesson for me in the Laotian language.”

"It was hard and time-consuming for me to revise the lessons at home so I could prepare for classroom activities, therefore, I could not perform well in class."

"My poor Vietnamese language competence made me reluctant to answer teachers' questions or eagerly take part in discussions. " 


\subsubsection{The participants' perceptions and experiences of the effect of cultural differences on teacher-student relationships and academic performance}

\subsubsection{International students' perceptions of the effect of cultural differences on teacher-student relationships and academic performance.}

International students reckoned that cultural differences did not affect their academic performance and their relationships with Vietnamese teachers.

\subsection{International students' perceptions of the effect of cultural differences on their academic performance.}

\section{Table 4.7: Students' perceptions of the impact of cultural differences on their} academic performance.

\begin{tabular}{|c|c|c|c|}
\hline \multicolumn{3}{|c|}{ Do you think cultural differences will negatively affect your academic performance? } \\
\hline & & Frequency & Percent \\
\hline Valid & no & 24 & 100.0 \\
\hline
\end{tabular}

Table 4.7 shows that none of the participants $(24 / 24$ or $100 \%)$ reckoned that cultural differences negatively affect their academic performance. Some typical explanations are listed as follows:

"Studying is not affected by culture."

"Teachers try to help me understand the differences between Laotian culture and Vietnamese culture and are always there to help me overcome uncomfortable feelings."

"The two cultures are very similar and there is few differences that might affect the relationship or progress in my studies."

"The learning styles of Vietnamese cultures and mine are similar to each other."

\subsection{International students' perceptions of the effect of different} cultures on their teacher-student relationships. 
Table 4.8: Students' perceptions of the impact of cultural differences on their relationships with Vietnamese teachers.

\begin{tabular}{|c|c|c|c|}
\hline \multicolumn{2}{|c|}{ Do you think cultural differences may affect your relationships with Vietnamese teacher? } \\
\hline \multirow{2}{*}{} & Frequency & Percent \\
\hline \multirow{2}{*}{ Valid } & no & 21 & 87.5 \\
\cline { 2 - 4 } & yes & 3 & 12.5 \\
\cline { 2 - 4 } & Total & 24 & 100.0 \\
\hline
\end{tabular}

Table 4.8 illustrates that a majority of the international students did not believe that differences in cultures may negatively affect teacher-student relationships. Most of the participants $(87.5 \%)$ responded "no" to the question "Do you think cultural differences may affect your relationships with Vietnamese teachers?" Only 3/24 or $12.5 \%$ international students responded "yes" to this question.

\subsubsection{International students' experiences of the effect of different cultures on their teacher-student relationships and academic performance.}

\subsection{International students' experiences of the effect of cultural differences on their teacher-student relationships.}

\section{Table 4.9: Vietnamese teachers' helpfulness in helping international students understand cultural differences.}

\begin{tabular}{|}
\hline \multicolumn{2}{|c|}{ Vietnamese teachers help you to understand the differences between your culture and Vietnamese } \\
culture. \\
\hline \multirow{2}{*}{ Valid } & Strongly agree & Frequency & Percent \\
\cline { 2 - 4 } & Agree & 18 & 75.0 \\
\cline { 2 - 4 } & Total & 6 & 25.0 \\
\hline
\end{tabular}

Table 4.9 shows that a majority of the international students learnt about Vietnamese culture from their Vietnamese teachers and from lessons that were taught in their classes. Three-quarters of the participants (18/24 or $75 \%)$ strongly agreed that Vietnamese teachers 
had helped them to understand Vietnamese culture. The other participants (6/24 or 25\%) also agreed that Vietnamese teachers helped them understand Vietnamese culture.

All of the participants agreed that the differences between Vietnamese culture and their own culture did not affect their relationships with their teachers. All of the students (24/24 or $100 \%$ ) responded "no" when asked whether they had experienced any difficulties in establishing relationships with Vietnamese teachers.

\subsection{International students' experiences of the effect of different culture on their academic performance.}

Table 4.10: Students' difficulties in adapting to Vietnamese culture.

\begin{tabular}{|c|c|c|c|}
\hline \multicolumn{3}{|c|}{ Have you had any difficulties in adapting to Vietnamese culture while you have been } \\
studying at AGU?
\end{tabular}

Table 4.10 shows that most of the participants $(22 / 24$ or $91.7 \%)$ reported that they had adapted to Vietnamese culture easily during their time at An Giang University. Many of these students gave explanations as follows:

"Laotian culture and Vietnamese culture is not very different."

"Laotian and Vietnamese cultures are very much the same."

"Studying is not affected by cultural differences."

"It is not hard to adapt to Vietnamese culture because I already knew that

Vietnamese and Cambodian culture is not very different."

"I can learn Vietnamese culture from my teachers and in the lessons." 
Only $2 / 24$ or $8.3 \%$ of the international students had experienced difficulties in adapting to Vietnamese culture while they were studying at An Giang University. Some typical explanations are as follows:

"My Vietnamese language competence is not good enough to communicate with other Vietnamese to know more and to understand the differences in cultures between the two countries."

"Significant cultural differences are cooking styles and modes of transport. It is too crowded in Vietnam."

In conclusion, these findings show that the participants did not believe that cultural differences had a negative effect on their learning, their academic performance, or their teacher-student relationships. Similarly, international students experienced no difficulty in adapting to Vietnamese culture. In addition, they also experienced that cultural differences did not negatively affect their academic performance and their relationships wit Vietnamese teachers. This was not only due to the perception that there are many similarities between Vietnamese, Laotian, and Cambodian cultures but the efforts of Vietnamese teachers to help and support international students become familiar with Vietnamese culture was also a significant factor.

\subsubsection{The participants' experiences of their academic performance and satisfaction levels with the academic experiences while studying in Vietnam.}

The last section of the questionnaire elicited data about participants' experiences of their academic performance and their levels of satisfaction with their academic performance while studying at the University. 
Table 4.11: Students' academic grades

\begin{tabular}{|c|c|c|c|}
\hline \multicolumn{2}{|c|}{ How would you describe your academic achievement based on the report of grades? } \\
\hline \multirow{2}{*}{ Valid } & A- to A+ & Frequency & Percent \\
\cline { 2 - 4 } & B- to B+ & 2 & 8.3 \\
\cline { 2 - 4 } & C to C+ & 7 & 29.2 \\
\cline { 2 - 4 } & Other & 13 & 54.2 \\
\hline & Total & 2 & 8.3 \\
\hline
\end{tabular}

Table 4.11 illustrates international students' academic grades. A majority of international students at An Giang University (13/24 or 54.2\%) had attained C to C+ grade averages in their most recent academic reports. Specifically, only two participants (2/24 or $8.3 \%$ ) had received grades in the $\mathrm{A}-\mathrm{A}+\mathrm{A}$ range. A few students $(7 / 24$ or $29.2 \%)$ had achieved grades in the $\mathrm{B}-\mathrm{-B}+$ range. Two of international students $(8.3 \%)$ checked the "other" option in their responses which indicated that their grade had fallen below a $\mathrm{C}$.

Table 4.12: Students' self-evaluation of their academic performance.

\begin{tabular}{|c|c|c|c|}
\hline \multicolumn{2}{|c|}{ How would you describe your academic achievement based on your self-evaluation? } \\
\hline \multirow{3}{*}{ Valid } & Good & Frequency & Percent \\
\cline { 2 - 4 } & Average & 3 & 12.5 \\
\cline { 2 - 4 } & Other & 20 & 83.3 \\
\cline { 2 - 4 } & Total & 1 & 4.2 \\
\hline
\end{tabular}

Table 4.12 shows students' self-evaluation of their academic performance. The international students' estimation of their academic performance was not similar to their real achievement. Most of the participants (20/24 or 83.3\%) estimated themselves as having average academic performance. Only a small number (3/24 or $12.5 \%)$ estimated themselves as having good academic achievement. Only one student (1/24 or $4.2 \%)$ estimated himself/herself as having below average academic performance. 
Table 4.13: Students' satisfaction with their academic performance.

\begin{tabular}{|c|c|c|c|}
\hline \multicolumn{3}{|c|}{ Are you satisfied with your academic achievement at AGU? } \\
\hline \multirow{2}{*}{} & Frequency & Percent \\
\hline \multirow{2}{*}{ Valid } & yes & 21 & 87.5 \\
\cline { 2 - 4 } & no & 3 & 12.5 \\
\cline { 2 - 4 } & Total & 24 & 100.0 \\
\hline
\end{tabular}

The participants' levels of satisfaction with their academic performance at An Giang University was shown in table 4.13. Almost all participants (21/24 or 87.5\%) were satisfied with their academic performance. These students provided explanations for their academic satisfaction which also included their levels of satisfaction of having improved levels of Vietnamese language proficiency; good friendships with Vietnamese people; help and support from Vietnamese teachers, friends, and administrators; and completing their undergraduate degree on time. Some common explanations are listed in the following table:

Table 4.14: Students' explanations for their academic satisfaction levels

\begin{tabular}{|c|c|c|c|}
\hline \multicolumn{4}{|c|}{ Why are you satisfied with your academic achievement at AGU? } \\
\hline & & Frequency & Percent \\
\hline \multirow[t]{13}{*}{ Valid } & & 3 & 12.5 \\
\hline & My Vietnamese language competency has improved, & 1 & 4.2 \\
\hline & Vietnamese teachers are friendly and devoted to teaching & 2 & 8.3 \\
\hline & I can communicate in Vietnamese well & 1 & 4.2 \\
\hline & I can finish homework on my own & 1 & 4.2 \\
\hline & I will finish undergraduate program on time & 2 & 8.3 \\
\hline & I can graduate on time and go home & 1 & 4.2 \\
\hline & I can make a lot of Vietnamese friends at AGU and they help me a lot & 1 & 4.2 \\
\hline & I try my best and my grades exactly reflect my ability & 1 & 4.2 \\
\hline & My grade reflect accurately my ability & 1 & 4.2 \\
\hline & $\begin{array}{l}\text { My Vietnamese language competency has improved and I will finish } \\
\text { my undergraduate degree on time }\end{array}$ & 1 & 4.2 \\
\hline & $\begin{array}{l}\text { My Vietnamese language competency has improved, I can communicate } \\
\text { in Vietnamese well }\end{array}$ & 1 & 4.2 \\
\hline & $\begin{array}{l}\text { My Vietnamese language competency is improved, I know that } \\
\text { Vietnamese culture is not very much different from Laotian culture }\end{array}$ & 2 & 8.3 \\
\hline
\end{tabular}




\begin{tabular}{|l|l|c|}
\hline $\begin{array}{l}\text { Teachers and staff are very helpful, the Rector Board gave international } \\
\text { students great support }\end{array}$ & 2 & 8.3 \\
\begin{tabular}{|l|c|} 
Teachers, staff and my Vietnamese classmates helped me a lot during \\
the time I was studying at AGU
\end{tabular} & 1 & 4.2 \\
\hline $\begin{array}{l}\text { The Rector Board and staff gave us a lot of support to help us overcome } \\
\text { difficulties during the time }\end{array}$ & 1 & 4.2 \\
\hline $\begin{array}{l}\text { Teachers are helpful to international students } \\
\text { Teachers are friendly and supportive }\end{array}$ & 1 & 4.2 \\
\hline Total & 24 & 100.0 \\
\hline
\end{tabular}

Most of the participants (18/24) explained that their satisfaction with their grades lay with their belief that their grades accurately reflected their ability. The rest of them (6/24) reported that their Vietnamese language competence was improved by doing the intensive language course.

Figure 4.1 shows students' preferences for seeking help. The participants noted that they often preferred to seek help from their Vietnamese friends when they had difficulties in their studies and their academic lives at An Giang University. The findings show that $45.83 \%$ of the international students sought help from their Vietnamese friends. The second preferred source of help $(29.17 \%)$ was listed as Vietnamese teachers. The third preferred source of help was listed as other Cambodian student (12.50\% of international students said they would seek help from this source). Only $8.33 \%$ of respondents said they would seek help from Laotian students. Only one respondent (4.17\%) said they would seek help from 'other people'. 

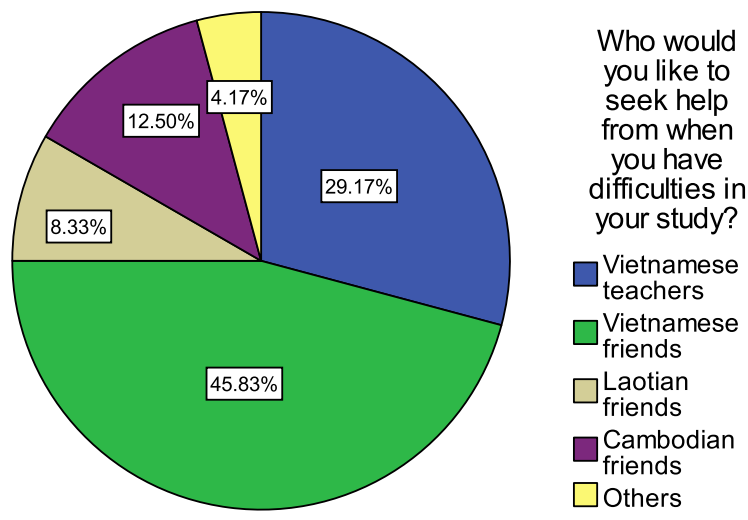

\section{Figure 4.1: Students' preferences for seeking help}

Figure 4.2 illustrates where students found help from during their study in Vietnam. Overall, the participants said that Vietnamese teachers and Vietnamese students were most helpful to them. Indeed, just over half the participants $(54.17 \%)$ reported that Vietnamese teachers were most helpful to them. Just under half the participants (41.67\%) believed that Vietnamese friends were most helpful to them. Only $4.17 \%$ of the respondents chose "other" as the most helpful person to him/her. When participants noted "Other" in their responses, they noted that this included "administration staff".

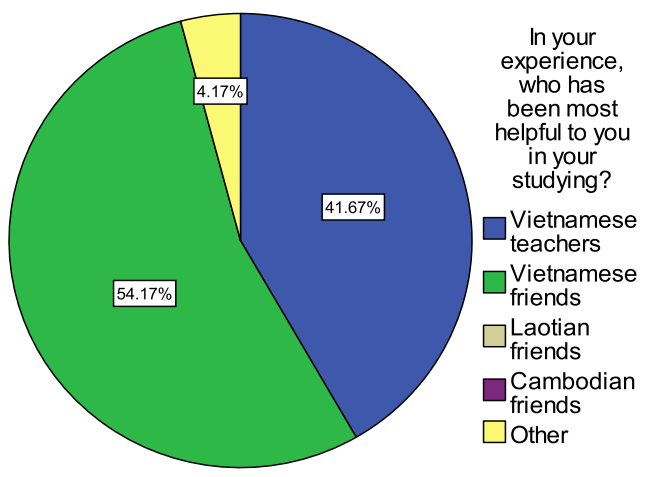

\section{Figure 4.2: Where students found help during their study in Vietnam}

The participants were asked to rank five factors that affect their academic performance from 1-most important to 5-less important. Figure 4.3 shows that a majority of the students (70.83\%) believed that fluency in the Vietnamese language was the most important factor affecting their academic performance. Having good teacher-student relationships was ranked second by $54.17 \%$ of the participants. Independent study skills were ranked third by 
$50 \%$ of the students. Interest in the subject was placed fourth by $58.33 \%$ of the students. Readily adapting to the cultural context of Vietnam was placed fifth by $37.50 \%$ of the students.

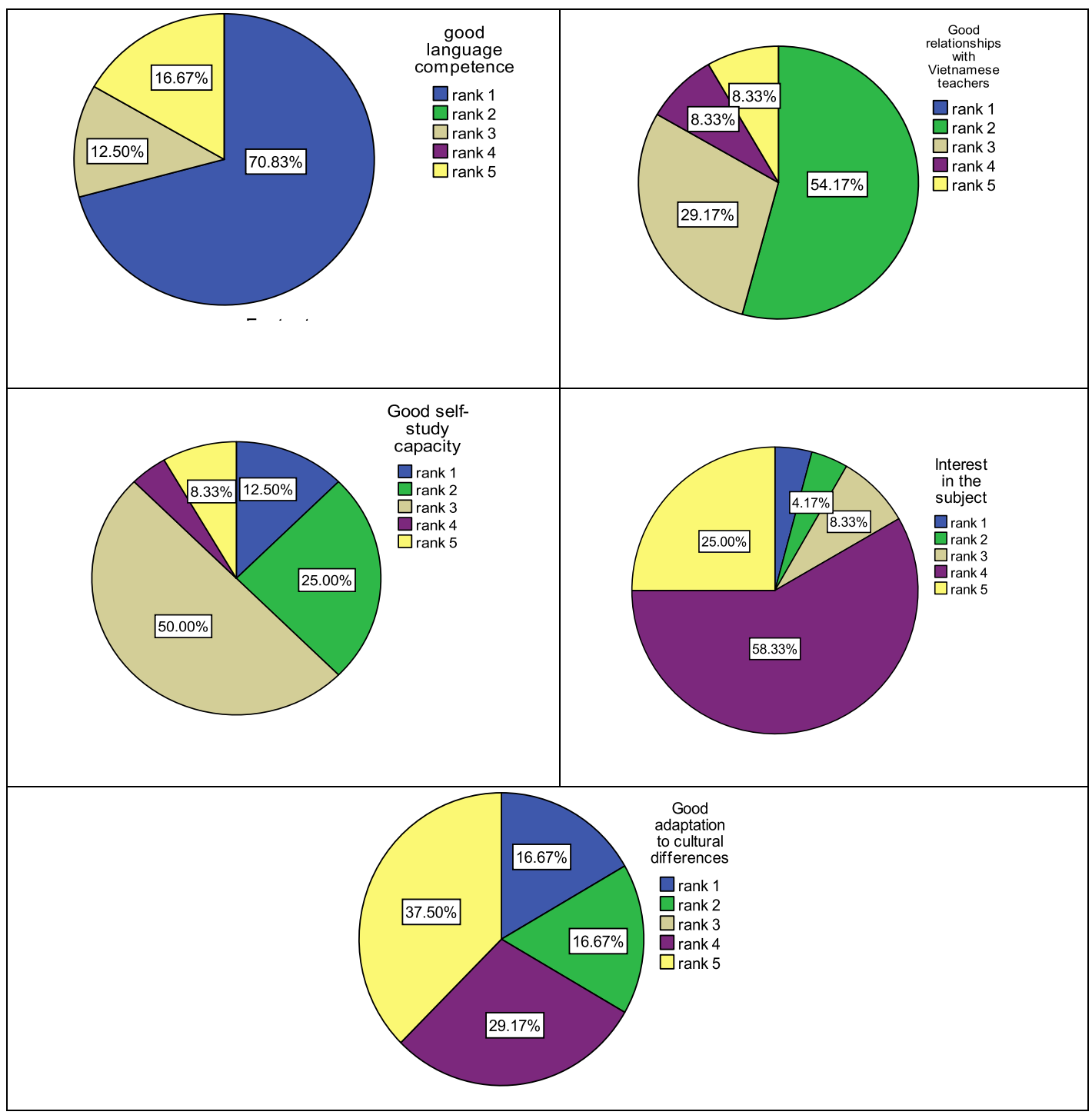

Figure 4.3: Students' ranking of the important factors contributing to their academic achievement.

\subsubsection{Conclusion of questionnaire findings}

In conclusion, the participants believed that language difficulties significantly affected both their academic performance and their relationships with Vietnamese teachers. At the same time, they felt that cultural differences had little or no effect on their academic performance 
and their teacher-student relationships. They reported that while they faced some difficulties relating to low levels of proficiency in the Vietnamese language and a few minor cultural differences, their Vietnamese teachers were always supportive. Vietnamese teachers are described as being friendly, supportive, and sympathetic. This created a strong perception that good relationships existed between Vietnamese teachers and international students at the university. Fluency in the Vietnamese language was reported to be the most important factor for achieving a good academic performance by $70.83 \%$ of international students. This was followed in importance by good teacher-student relationships; good independent study skills; interest in the subject; and ready adaptation to cultural differences. International students' academic performances were self-reported and grades fell mainly in the $\mathrm{C}$ to $\mathrm{B}+$ range. However, almost all the international students were satisfied with their academic performance during the time they were studying at An Giang University.

\subsection{Interview findings}

In this section, I provide information about the academic characteristics of the six interview participants and present the findings from my interviews with them. The characteristics of the interviewees given below are presented in no particular order.

\subsubsection{Characteristics of the interviewees}

\subsubsection{Interviewee A}

Interviewee $\mathrm{A}$ is a 29-year-old Laotian student who had worked for the Ministry of Agriculture in Laos before beginning his studies in Vietnam. He is married with two children and at the time the interview took place, he was enrolled in the nine-month intensive Vietnamese language course. When he completes the course, he plans to do an undergraduate degree at An Giang University and then return to his job at the Ministry of Agriculture in Laos after graduation. Although he was eager to participate in the research, he worried that his limited fluency in Vietnamese might prove to be a problem. In light of this, I tried my best to encourage him and understand his anxieties. As a result, the interview took a little longer than the other interviews. 
The data from this participant show that he was partially satisfied with the academic environment at An Giang University. He did not think that cultural differences had any negative effect on his academic performance although his fluency in Vietnamese language was a major concern for him. He said that he found it difficult to communicate with his Vietnamese teachers and he sometimes had difficulty understanding what they were saying. Nevertheless, he reported that he has received good support from them and has established good relationships with them.

\subsubsection{Interviewee $B$}

The second interview was carried out with a 23-year-old Cambodian student who had just graduated as a cultivation scientist with an undergraduate degree from the Agriculture and Natural Resources Faculty at An Giang University. He had enrolled in the undergraduate degree directly after graduating from high school. This Cambodian student had been in a relationship with a Vietnamese girlfriend for two years at the time the interview took place. He planned to return to Cambodia and work for the Cambodian government after his graduation ceremony. He spoke Vietnamese fluently.

This participant had enjoyed his academic experience at An Giang University. He had actively participated in sporting events at the university and he regularly spoke in Vietnamese with his friends outside the classroom. Although this participant had completed an undergraduate degree with a B grade average, he had found it difficult to participate in class discussions. However, he acknowledged that good teacher-student relationships had played an important role in his academic life, but he seldom asked teachers questions because he lacked confidence in his level of fluency in Vietnamese. Despite avoiding speaking directly to his teachers in class, this student said that he had established good relationships with them. He said that cultural differences had not negatively affected his study at An Giang University but he did feel that the Vietnamese language course for international students should be longer than nine months before they started their undergraduate degrees. 


\subsubsection{Interviewee $C$}

This interviewee is a 23-year-old female student from Cambodia. She had graduated as a cultivation scientist from the Agriculture and Natural Resources Faculty at An Giang University in June of the year that the interview took place. Initially, this student was shy but later in the interview she became more forthcoming. She had a reasonable level of fluency in Vietnamese and was able to understand the interviewer and express her opinions well although she still lacked confidence in her level of fluency in Vietnamese. After graduating, she plans to return to Cambodia and work for the Cambodian government.

This interviewee was happy that she had finished her undergraduate degree in good time. She felt that good relationships with her teachers had been an important factor in her academic performance. In spite of her lack of self-confidence in her level of fluency in Vietnamese, she felt that her relationships with her Vietnamese teachers had been good ones. She did not think that cultural differences had negatively affected her academic experience at An Giang University.

\subsubsection{Interviewee $D$}

This interviewee is a 40-year-old Laotian student who had worked as an officer at a provincial Agriculture Department in Laos before he enrolled at An Giang University four years earlier. He had just graduated with his undergraduate degree in June as a cultivation scientist. He is married but his wife and daughter are living in Laos. The participant was happy that he had completed his study and would shortly be reunited with his family. He plans to continue his work at the provincial Agriculture Department when he returns to Laos.

Being in his forties, this student was the oldest participant in this study. He was partially satisfied with his academic outcomes but reported that the experience of living in a different country and cultural context had limited his degree of social contact with Vietnamese locals. At the time the interview took place, he was able to communicate well in Vietnamese, but he said that achieving the level of proficiency in Vietnamese that he needed in order to manage his studies had been a challenge for him. He said that whenever 
he had difficulties in study or in his personal life he would always talk to the international students' administrator.

\subsubsection{Interviewee $E$}

This interviewee was a Laotian male who had just graduated with his undergraduate degree as an aquaculture scientist from the Agriculture and Natural Resources Faculty at An Giang University. He was 35 years old and had a wife and a son living in Laos. This participant had worked for a provincial Agriculture Department in Laos before he had enrolled in the An Giang undergraduate degree program. After his graduation, he planned to return to Laos and work for his provincial Agriculture Department at a higher level of seniority. This interviewee was fluent in the Vietnamese language and he was able to provide plenty of information during the interview.

The participant had several expectations of his study. He had aimed to complete an undergraduate degree, get a promotion, and acquire a good level of proficiency in the Vietnamese language. He also wished to learn more about Vietnamese culture. He felt these aspirations had been met. Cultural differences had no negative effect on his study or on his relationships with Vietnamese teachers. He acknowledged that, thanks to support from his friends, teachers, and from administrative staff at the University, he had managed to resolve any difficulties he encountered during his studies and in his personal life. Due to his high level of proficiency in Vietnamese, this student had been elected as the representative of Laotian students at the University. Whenever his Laotian friends had difficulties, he accompanied them to meetings with teachers or administrative staff. According to this participant, good independent study skills were the most important factor that had contributed to his academic performance at An Giang University.

\subsubsection{Interviewee $F$}

This interviewee was a female Laotian student. She was married and had a son who was living in Laos. She was enrolled in the Vietnamese language class at An Giang University at the time the interview took place. After she finished the nine-month long Vietnamese 
language course in October 2011, she planned to begin postgraduate studies at another university in Vietnam.

The participant had only been enrolled in the Vietnamese language course for four months at the time the interview took place and her level of proficiency was not strong. However, she tried to speak Vietnamese as often as possible in order to improve her fluency. The participant had observed many similarities and differences between Vietnamese culture and Laotian culture but she did not feel that cultural differences had had a negative impact on her academic experience. Although she was still gaining fluency in Vietnamese, she maintained regular and frequent communication with her Vietnamese teachers. She was a lecturer of industrial herbs in a Laotian university before her enrolment at An Giang University. As a lecturer, she believed that teachers should always welcome and appreciate students' questions. In her opinion, teachers need to be willing to help their students out of difficulties. Despite her limited Vietnamese language proficiency, she actively asked teachers for help in her studies at An Giang University. During the interview, she suggested that library access is important for building independent study skills but that she had not yet had the chance to visit the University library due to the intensive schedule of her Vietnamese language class. This interviewee considered independent study skills as the most important factor for academic success. In addition, she also acknowledged that a high level of proficiency in the Vietnamese language was an important factor for her as she pursued her postgraduate studies in Vietnam.

\subsubsection{Interview analysis}

The interview analysis focuses on the four main themes of this thesis, as follows: (a) international students' academic expectations, level of satisfaction with their academic experience and recommendations for improving the student experience at An Giang University; (b) international students' perceptions and experiences of being in a new cultural context during their studies at An Giang University; (c) international students' perceptions and experiences of language barriers in the university classroom; and (d) international students' experiences and perceptions of teacher-student relationships. 


\subsubsection{International students' expectations, educational experiences and recommendations.}

Several of the interviewees reported a series of commonly held expectations for their studies at An Giang University. These international students' expectations focused on obtaining undergraduate credentials in Vietnamese, improving their levels of Vietnamese language proficiency, learning about the Vietnamese culture, and getting career promotions after graduation. All the interviewees expected to complete their undergraduate degrees at An Giang University in a reasonable period of time. Two interviewees who were enrolled in the Vietnamese language class aimed to improve their Vietnamese language proficiency as quickly as possible so that they could access more academic literature in their disciplinary areas. They hoped the Vietnamese language course would make it easier for them to undertake undergraduate study. Only one of the six interviewees aimed to contribute to the strengthening of political, economic and cultural relationships between Vietnam and the participant's home country. The Laotian student who expressed these sentiments also hoped that the Vietnamese government would grant more scholarships to Laotian learners in his province to study agricultural techniques at An Giang University. Three out of the six interviewees said that they would recommend that the stipends need to be increased.

According to these expectations, international students' satisfactions were partly met. Four graduates were satisfied with their academic outcomes. They stated that although they experienced difficulties at the beginning of their studies, they found it easier to get help from Vietnamese teachers, Vietnamese friends, and the administrators as time went by. One of the graduates said that

"It was a really hard time at the beginning when I had to translate
almost every word in the lesson. It took me an enormous time for
translating, then understanding and completing homework and
appointed tasks"

Details of each interviewee's academic expectations, levels of satisfaction and recommendations, supported by extracts from the six interviews, are as follows: 


\title{
- Interview 1
}

This Laotian student expected to learn the Vietnamese language, Vietnamese culture, and finish his undergraduate degree in good time.

$\begin{array}{ll}\text { Researcher } & : \text { What did you expect from studying at An Giang } \\ & \text { University? } \\ \text { Interviewee 1 } & : \text { I expected to learn the Vietnamese language, } \\ & \text { Vietnamese culture, and finish my undergraduate } \\ & \text { degree in good time. }\end{array}$

He felt that his expectations had been partly met in this respect, as follows:

\author{
Researcher : :Have your expectations been met? \\ Interviewee $1 \quad$ : Yes, my Vietnamese proficiency is improving. Actually, I \\ can communicate in Vietnamese better than before.
}

This student was comfortable with the academic environment of the University. He described the Vietnamese teachers as being friendly and approachable with international students.

$\begin{array}{ll}\text { Researcher } & : \text { What do you like most when you are studying at An } \\ & \text { Giang University? } \\ \text { Interviewee 1 } & \text { : I like the teachers. Vietnamese teachers are friendly and } \\ & \text { very kind. We traveled to Unclce Tôn's historic house } \\ & \text { with Mrs. Nhiệm and Mr. Tùng. We played football with } \\ & \text { teacher Tùng. Vietnamese teachers always listen to our } \\ & \text { needs and expectations. }\end{array}$

Although this student said that he was satisfied with his academic life at An Giang University, he still felt pressured with the intensive study schedule. He also wished that the stipend could be increased to meet his cost of living needs. 


\begin{abstract}
Researcher : What would you suggest to improve your academic life at An Giang University?

Interviewee 1 : Uhm, at the moment, I have to go to class too much. I have classes both morning and afternoon. Some evenings, we have to go to class to do exercises with teachers' help. With an intensive schedule, I cannot go out with friends. I also wished to have more money from the scholarship provider. Currently, the stipend is not enough for us. I also need a television in my dormitory to practice my Vietnamese language competence.
\end{abstract}

\title{
- Interview 2
}

This Cambodian undergraduate did not have many expectations when he decided to study at An Giang University. He had chosen to study at An Giang University because his parents had encouraged him to do this. He was pleased to complete the undergraduate program on schedule.

$\begin{array}{ll}\text { Researcher } & : \text { What did you expect when you decided to study at An } \\ & \text { Giang University? } \\ \text { Interviewee } 2 & : \text { My parents wanted me to take the chance to study for an } \\ & \text { undergraduate degree at An Giang University with } \\ & \text { financial support from the People's Committee of An } \\ & \text { Giang Province. It is good that I can study overseas and } \\ & \text { know some Vietnamese. }\end{array}$

The participant's grade average was not high but he was happy to complete his studies on schedule.

$\begin{array}{ll}\text { Researcher } & \text { : Have your expectations been met? } \\ \text { Interviewee } 2 & : \text { Well, it is good enough that I can finish my } \\ & \text { undergraduate degree in time. Some of my friends still } \\ & \text { need to take examination again for several courses. }\end{array}$


According to this participant, Vietnamese friends and the administrative staff of An Giang University were helpful to him.

$\begin{array}{ll}\text { Researcher } & \text { : What do you like most about studying at An Giang } \\ & \text { University? } \\ \text { Interviewee } 2 & : \text { I like Vietnamese friends and administrative staff. } \\ & \text { Whenever I had a problem, I talked to my international } \\ & \text { student assistant. They would try their best to help me } \\ & \text { out. When I had problem in studying, I also talked to her, } \\ & \text { she would have helpful recommendations for my teachers } \\ & \text { to make studying easier for me. }\end{array}$

This interviewee pointed out that it is very difficult for international students to study philosophy in the Vietnamese language, and he would like the Vietnamese language course to be extended so that the international students would feel more confident when they started their undergraduate degrees.

$\begin{array}{ll}\text { Researcher } & \text { : What would you like to recommend An Giang University } \\ & \text { to improve your academic life? } \\ \text { Interviewee } 2 & \text { : Nothing, Vietnamese teachers are good. However, I } \\ & \text { found it extremely difficult with some of the philosophy } \\ & \text { credits. It is very hard for us to study such subjects with } \\ & \text { limited Vietnamese language proficiency. Well, if } \\ & \text { possible, I would like to learn Vietnamese language } \\ & \text { competence about a year before I started my } \\ & \text { undergraduate degree at An Giang University. I think it is } \\ & \text { better if I have good Vietnamese language proficiency to } \\ & \text { be more confident in academic life here. }\end{array}$




\section{- Interviewee 3}

This Cambodian student had few expectations when she began her studies at An Giang University. She enrolled at the University because her parents wanted her to have a scholarship from An Giang province that would allow her to study abroad. She could complete her undergraduate degree in good time and her expectation was met.

$\begin{array}{ll}\text { Researcher } & \text { : What did you expect from studying at An Giang } \\ & \text { University? } \\ \text { Interviewee 3 } & : \text { I only wanted an undergraduate degree. My parents } \\ & \text { advised me to take the scholarship from An Giang } \\ & \text { People's Committee to study at An Giang University. I } \\ & \text { had just graduated from high school at that time and I } \\ & \text { just took my parents'advice. } \\ \text { Researcher } & : \text { Have your expectations been met? } \\ \text { Interviewee } 3 & : \text { Yes, luckily I could finish my undergraduate degree in } \\ & \text { time (smiles). }\end{array}$

Vietnamese teachers were reported to be helpful to students. However, this student had some dissatisfaction with academic life at An Giang University and these centered mostly on her limited number of friendships with Vietnamese people.

$\begin{array}{ll}\text { Researcher } & : \text { What do you like most about studying at An Giang } \\ & \text { University? } \\ \text { Interviewee } 3 \quad & : \text { The thing I like most is knowing a foreign language, } \\ & \text { Vietnamese language. } \\ \text { Researcher } & : \text { How about Vietnamese friends and Vietnamese } \\ & \text { teachers? } \\ \text { Interviewee } 3 & : \text { Well, Vietnamese teachers were kind but always busy. I } \\ & \text { did not have many Vietnamese friends. At the dormitory, I } \\ & \text { shared room with a Laotian female student but there was } \\ & \text { a difference in our ages; therefore, we did not have } \\ & \text { similar interests for sharing. }\end{array}$


She had hoped that she might share a room with Vietnamese students so that she could practise her Vietnamese and establish some friendships with local people.

$\begin{array}{ll}\text { Researcher } & : \text { What would you like to recommend for An Giang } \\ & \text { University in order to improve your academic life? } \\ \text { Interviewee } 3 & : \text { It is better if I can share a room with some Vietnamese } \\ & \text { friends. If so, I can use more Vietnamese language in my } \\ & \text { daily life and have some more Vietnamese friends. }\end{array}$

\section{- Interviewee 4}

Being an officer of a provincial Agriculture Department in Laos, this student's expectations centered on completing an undergraduate degree, learning the Vietnamese language, understanding more about Vietnamese culture, and contributing to the strengthening of relationships between Laos and Vietnam. His expectations were partially met. He also recommended that stipend from the scholarship provider should be increased.

$\begin{array}{ll}\text { Researcher } & : \text { What did you expect when you studied at An Giang } \\ & \text { University? } \\ \text { Interviewee } 4 \quad: \text { I expected to earn an undergraduate degree, study } \\ & \text { Vietnamese language, understand Vietnamese culture, } \\ & \text { and the relationship between Vietnam and Laos will be } \\ & \text { closer. }\end{array}$

His expectations were partly met. He was happy that he could finish his study on schedule after a difficult time studying in a foreign language.

$\begin{array}{ll}\text { Researcher } & : \text { Have your expectations been met? } \\ \text { Interviewee } 4 & : \text { Yes, it is good that I could finish my undergraduate } \\ & \text { degree in time. It was a hard time for us. I did not believe } \\ & \text { that I could do that. } \\ \text { Researcher } & : \text { What do you mean? }\end{array}$


Interviewee $4 \quad$ : Well, I and other international students faced language difficulties in the first two years. We failed several courses due to our poor Vietnamese language competence. Some of us had to take the third exam until we passed the courses. It was a hard time. Then it was better and now we graduated (smiles).

This participant experienced financial difficulties during his studies because his stipend was not sufficient for his living costs. Therefore, he recommended better stipend from the scholarship provider.

$\begin{array}{ll}\text { Researcher } & : \text { What would you recommend for An Giang University to } \\ & \text { improve your academic life? } \\ \text { Interviewee } 4 & : \text { I did not have enough money living here. The living cost } \\ & \text { was high and stipend from the scholarship was not } \\ & \text { enough. It is better if the scholarship provider provide } \\ & \text { better stipend so that we would not worry about the } \\ & \text { financial issues and focus well on our study. }\end{array}$

This student also felt that the Vietnamese language course needed to be extended for students who were going to go on to study for an undergraduate degree.

$\begin{array}{ll}\text { Researcher } & : \text { What do you suggest to improve your academic } \\ & \text { performance at An Giang University? } \\ \text { Interviewee } 4 & : \text { Well, it is better if I could study Vietnamese longer and } \\ & \text { be proficient at Vietnamese language so that I would be } \\ & \text { more confident to exchange knowledge with my } \\ & \text { classmates. We (Laotian students) seemed very passive in } \\ & \text { class. We just listen and rarely contribute in class } \\ & \text { discussions. }\end{array}$




\section{- Interviewee 5}

As an officer at a provincial Agriculture Department in Laos, this Laotian student hoped to complete the undergraduate degree and master the Vietnamese language to enhance his career promotion prospects when he returned to Laos. He was also interested in learning about Vietnamese culture and people. He did find, however, that the University Library was not very helpful for his study. In addition, according to this student, the scholarship stipend was not sufficient to cover international students' basic living costs. He recommended an increase in the stipend from the scholarship provider.

$\begin{array}{ll}\text { Researcher } & : \text { What did you expect from studying at An Giang } \\ & \text { University? } \\ \text { Interviewee 5 } & : \text { I expected to achieve an undergraduate degree, learn } \\ & \text { Vietnamese language, Vietnamese culture and know more } \\ & \text { about Vietnamese people. I also expected to have } \\ & \text { sufficient financial support from the scholarship provider. }\end{array}$

He was happy that his expectations were partly met. He had finished his study on schedule and had improved his Vietnamese language proficiency.

$\begin{array}{ll}\text { Researcher } & : \text { Have your expectations been met? } \\ \text { Interviewee } 5 & : \text { Yes, finally I could finish the undergraduate degree as } \\ & \text { expected. In addition, my Vietnamese language } \\ & \text { competence is better than it was before. }\end{array}$

This student recommended that international students should obtain a good level of Vietnamese language proficiency before they begin their studies in Vietnam. He also suggested that the scholarship provider should increase the stipend for international students. 


\begin{abstract}
Researcher : Do you have any recommendations for An Giang University that would improve your academic life?

Interviewee $5 \quad:$ Well, all international students faced extreme difficulties with Vietnamese language proficiency. It is unavoidable. All of us had studied Vietnamese language for just nine months before we started our undergraduate degree in Vietnam. I also recommend that the scholarship provider should provide a better stipend for us to assure our basic needs while we are studying here.
\end{abstract}

He did suggest that having a television in each international student's room would allow them to listen to the local news and hear Vietnamese being spoken more often.

\begin{tabular}{|c|c|}
\hline Interviewee 5 & $\begin{array}{l}\therefore . . . I \text { also recommend having a television in each } \\
\text { international student's room at the dormitory so that we }\end{array}$ \\
\hline & $\begin{array}{l}\text { can watch local news and practise the Vietnamese } \\
\text { language. }\end{array}$ \\
\hline
\end{tabular}

\title{
- $\quad$ Interviewee 6
}

This female Laotian student wished to improve her Vietnamese language competence as quickly as possible so that she could start her postgraduate studies in another university in Vietnam. Her Vietnamese language proficiency had gradually improved since her arrival at An Giang University, however, she worried that she would not be sufficiently fluent in Vietnamese to manage her postgraduate studies. She said that she found the demands of the intensive Vietnamese language course very tiring, although she also acknowledged that it would put her in good stead to handle her postgraduate program in the near future. However, it seemed that in some respects, the Vietnamese language class was too intensive and this caused additional stress for some of the international students. In some cases, they did not even have time to go to the University library or socialize with friends. 


$\begin{array}{ll}\text { Researcher } & : \text { What did you expect from studying at An Giang } \\ & \text { University? } \\ \text { Interviewee 6 } & : \text { I wished to improve my Vietnamese language } \\ & \text { competence for my postgraduate studies in Vietnam. }\end{array}$

This student expressed anxiety about the intensive schedule of the language course as follows:

$\begin{array}{ll}\text { Researcher } & \text { : Did you ever feel uncomfortable during your studies at } \\ & \text { An Giang University? } \\ \text { Interviewee 6 } & : \text { We have to study very intensively; we have classes all } \\ & \text { the time, morning, afternoon, and even evening. We come } \\ & \text { home at 9pm. and we are always tired. We did not have } \\ & \text { time to go out with friends or go to the library to read } \\ & \text { books in Vietnamese. }\end{array}$

She recommended that Vietnamese teachers should elicit ideas from all international students in class, not only the ones who are good at Vietnamese. In that way, she believed, more of the international students would participate more actively in class activities.

$\begin{array}{ll}\text { Researcher } & \text { : What would you suggest to improve your academic life } \\ & \text { at An Giang University? } \\ \text { Interviewee 6 } & \text { : Nothing, I just have a short time to study Vietnamese } \\ & \text { language competence before starting my postgraduate } \\ & \text { study in Vietnamese at Tay Nguyen University (a } \\ & \text { university in Vietnam). I have to try my best to keep peace } \\ & \text { with my friends. Other Laotian students in this } \\ & \text { Vietnamese language class started their study in January. } \\ & \text { I just started this class in April. Therefore, I am slower } \\ & \text { than the others. At first, I could not understand or say } \\ & \text { anything in Vietnamese, my friends and teachers helped } \\ & \text { me a lot. Vietnamese teachers should elicit answers from }\end{array}$ 
all international students in class. This may help all international actively participate in class activities.

\subsubsection{Language barriers}

The interviewees reported their lack of confidence in their proficiency in the Vietnamese language. Although these participants were able to finish their undergraduate program, only two of the four graduates felt confident about their level of fluency in the Vietnamese language. The other two graduates worried that when they went back to their country, they would not have many opportunities to speak Vietnamese regularly. All the interviewees stated that they believed that frequent, ongoing communication in Vietnamese would improve their Vietnamese language proficiency. However, the problem for many participants was that they had no time to make friends or communicate with Vietnamese friends outside of class. Most of their time was taken up with attending class and consulting dictionaries so that they could understand the lessons.

All of the students in the Vietnamese language class were Laotian. Although the administrators of the dormitory at An Giang University had purposely arranged for Vietnamese students to share rooms with three of the international students in order to help them improve their conversational Vietnamese, these Vietnamese students did not seem to be very helpful to international students. The international students said that this was because their Vietnamese roommates had different study schedules and were not often around to establish friendships. The international students themselves also did not have much time for communicating with Vietnamese students.

"An Giang University arranged for Vietnamese students to share rooms in the dormitory with three other international students to help the international students to improve their Vietnamese proficiency and understand local knowledge. However, one Vietnamese student usually came home very late when everyone was tired and was going to bed. At the weekends, the Vietnamese student usually went back his hometown. Although we had a Vietnamese roommate, we had very little communication with him." 
Although An Giang University administrators had intended to help international students to improve their language competence, the dormitory arrangements were not as beneficial for international students as the administrators hoped and these international students did not get sufficient support from their Vietnamese roommates.

The international students considered that having a good level of proficiency in the Vietnamese language was the most important factor in their academic success. Five out of the six interviewees reported that they recognized the need to communicate well in the Vietnamese language if they were going to succeed in their studies. Only one language student said that independent study skills were the most important consideration for him.

"With independent study skills, I could improve my Vietnamese language competence. Later, with good Vietnamese language competence, I would get through my undergraduate study at An Giang University.”

The following section provides information about the interviewee's level of confidence about their proficiency in the Vietnamese language with extracts from the interview data.

\section{- Interviewee 1}

This student believed that fluency in the Vietnamese language was very important for his academic achievement but he lacked confidence in his level of proficiency.

Researcher

Interviewee 1
: Are you self-confident in your academic Vietnamese language competence now you are studying at An Giang University?

: No, I am not self-confident in my academic Vietnamese language competence. I only know conversational vocabularies. I do not know a lot about vocabularies in agriculture. Now, we just study vocabularies used in daily life or everyday Vietnamese culture. 


Researcher $\quad$ What are the main factors that would contribute to
your academic success?
Interviewee $1 \quad:$ I need to have good language proficiency to understand
the lessons in my undergraduate study program. Without
good language competence, I cannot follow the teachers
instructions.

His lack of confidence in the Vietnamese language competence prevented him from approaching his Vietnamese teachers for help with his work.

$\begin{array}{ll}\text { Researcher } & \text { : Do you usually seek help from teachers when you have } \\ & \text { difficulties in class? } \\ \text { Interviewee } 1 & \text { : No, my Laotian friends in class will explain things to me } \\ & \text { and help me to pose questions to the teachers. I seldom } \\ & \text { raise questions with my teachers because I am afraid that } \\ & \text { my poor speaking of Vietnamese would take up too much } \\ & \text { class time. }\end{array}$

In class, he sought help from his Laotian classmates and this was helpful for him. However, the way he was given assistance could ultimately hinder his progress in Vietnamese.

$\begin{array}{ll}\text { Researcher } & : \text { Have you ever felt uncomfortable when you are in } \\ & \text { classes at An Giang University? } \\ \text { Interviewee 1 } & : \text { No, all of my classmates are Laotian. If I have } \\ & \text { difficulties in understanding the teacher, my friends will } \\ & \text { translate for me. Whenever I cannot express my ideas to } \\ & \text { teachers, my Laotian friends are also helpful at that time. }\end{array}$

\section{- Interviewee 2}

The interviewee 2 also reported his lack of confidence in his level of fluency in the Vietnamese language which meant that he communicated only very infrequently with his Vietnamese teachers. When he did not understand the lesson, he sought help from 
Vietnamese friends rather than asking the teachers. Moreover, his limited fluency in the Vietnamese language prevented him from participating in class discussions. He felt uncomfortable during class discussions. However, he also acknowledged the necessity of being a proficient speaker of Vietnamese if he intended to further his undergraduate studies at An Giang University. This Cambodian participant noted that he frequently communicates in Vietnamese with his friends outside of class.

According to this participant, Vietnamese teachers were helpful to international students, however, they (international students) lacked confidence in their proficiency in speaking Vietnamese. Consequently, international students often did not feel comfortable about asking for help from their teachers.

$\begin{array}{ll}\text { Researcher } & : \text { What do you think about Vietnamese teachers? } \\ \text { Interviewee 2 } & : \text { Ah, yes, they are always friendly and helpful. } \\ & \text { However, they were always busy. I seldom saw them } \\ & \text { after classes. } \\ \text { Researcher } & : \text { Did you usually ask teachers for more explanation } \\ & \text { when you did not understand the lesson? } \\ \text { Interviewee 2 } & : \text { Not usually, I mainly asked my friends first. } \\ \text { Researcher } & : \text { Why did not you ask your teachers for explanation? } \\ \text { Interviewee 2 } & : \text { I was not confident that my teachers would understand } \\ & \text { my questions right away. It usually took time for me to } \\ & \text { ask questions and understand the teachers } \\ & \text { explanations. }\end{array}$

This participant felt uncomfortable when he participated in class discussions due to his lack of fluency in Vietnamese.

$\begin{array}{ll}\text { Researcher } & : \text { Did you ever feel uncomfortable when you were in } \\ & \text { classes at An Giang University? } \\ \text { Interviewee } 2 & : \text { Yes, due to my poor linguistic ability, class discussions } \\ & \text { made me feel the most uncomfortable. Sometimes, my } \\ & \text { Vietnamese friends were very kind, they kept the }\end{array}$


discussion as slow as they could so that I could follow and contribute my ideas. However, usually, I could not keep pace with what my friends were talking about.

He believed that fluency in the Vietnamese language would help international students from feeling uncomfortable in the classroom.

$\begin{array}{ll}\text { Researcher } & \text { : Do you have any recommendations for your teachers so } \\ & \text { that discussions might be more comfortable for you and } \\ & \text { other international students? } \\ \text { Interviewee 2 } & \text { I do not know. Maybe international students should } \\ & \text { have very good Vietnam language competence before } \\ & \text { studying for an undergraduate degree at An Giang } \\ & \text { University. }\end{array}$

In fact, this participant had studied Vietnamese language for only nine months before he began his undergraduate degree at An Giang University. However, international students usually continue Vietnamese language classes at night during the first two years of their undergraduate study programme at An Giang University.

Researcher $\quad$ How long did you study Vietnamese language before
you began the undergraduate degree at An Giang
University?
Interviewee $2 \quad$ I had just learnt Vietnamese language for about nine
months before I started the undergraduate degree here.
At that time, I was very worried that my Vietnamese
language competence would not enough for me to study
for the undergraduate degree. However, we still had
Vietnamese language competence classes at night
during the first two years of my undergraduate study.
That was good for me to obtain sufficient Vietnamese
language competence for my study.


This participant established some strategies to improve his Vietnamese language proficiency. For example, he frequently talked to his friends in Vietnamese and he regularly participated in sporting events with other Vietnamese friends. He also had a Vietnamese girlfriend, who was always happy to help him improve his Vietnamese language.

$\begin{array}{ll}\text { Researcher } & \text { : Do you have any strategies to improve your Vietnamese } \\ & \text { language competence? } \\ \text { Interviewee } 2 & \text { : Well, I speak Vietnamese language with my friends } \\ & \text { outside of the classes. I and other Cambodian students } \\ & \text { always actively participate in sport events of the } \\ & \text { university. We played football with other Vietnamese } \\ & \text { friends and we could speak many Vietnamese. Also, I } \\ & \text { have a Vietnamese girlfriend; she is very keen and patient } \\ & \text { to help me improve my Vietnamese day by day. }\end{array}$

The participant believed that fluency in the Vietnamese language was the most important factor that contributes to his academic success at An Giang University.

\begin{abstract}
Researcher : What are the main factors that contribute to your academic performance at An Giang University?

Interviewee 2 : Vietnamese language competence is very important to my academic life at An Giang University. If I have good Vietnamese language competence, I will be able to follow teachers' lectures in classes, effectively discuss and contribute to group discussions. Moreover, I will be able to communicate well with Vietnamese friends and teachers.
\end{abstract}

\title{
- Interviewee 3
}

This Cambodian student was not confident in her academic Vietnamese language fluency. Although she could communicate well with her Vietnamese friends, it was hard to participate effectively in class discussions. The University administrators had arranged for her to share a room with a Laotian female student and hoped she would have an opportunity 
for them to speak Vietnamese together. She identified fluency in the Vietnamese language proficiency as being the most important factor that affected her academic performance.

$\begin{array}{ll}\text { Researcher } & : \text { Are you confident about your academic Vietnamese } \\ & \text { language competence? } \\ \text { Interviewee } 3 & : \text { No, I am not. I can communicate with Vietnamese } \\ & \text { friends, and Laotian friends in Vietnamese but it is not } \\ & \text { easy to participate in class discussions. }\end{array}$

Class discussions were uncomfortable for this student. She lacked confidence in presenting her opinions. She was also afraid of spending too much class time on expressing her ideas.

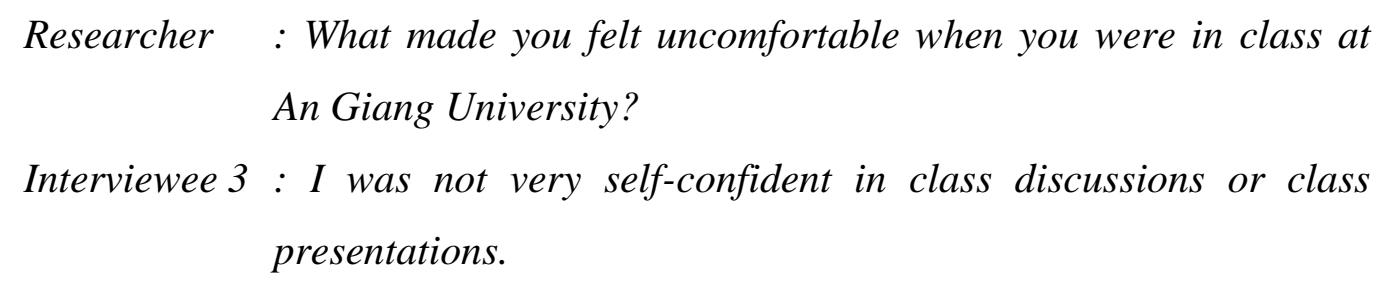

She also hoped to improve her fluency in the Vietnamese language before she started her undergraduate degree so that she would feel more confident about participating in classroom activities.

$\begin{array}{ll}\text { Researcher } & : \text { What might you suggest to improve the situation? } \\ \text { Interviewee } 3 & : \text { We should have good Vietnamese language competence } \\ & \text { before we begin our undergraduate degrees so that we } \\ & \text { can be more confident about participating in class } \\ & \text { discussions. }\end{array}$

To improve her Vietnamese language competence, she tried to speak to her friends in Vietnamese as frequently as possible. However, she did not have many Vietnamese friends during her four years studying at An Giang University. 


$\begin{array}{ll}\text { Researcher } & : \text { What did you do to improve your Vietnamese language } \\ & \text { competence? } \\ \text { Interviewee } 3 & : \text { My Laotian roommate and I tried to speak Vietnamese } \\ & \text { to each other a lot. We hope that we can improve our } \\ & \text { Vietnamese competence. However, the Laotian roommate } \\ & \text { is much older than me. Therefore, we did not have much } \\ & \text { in common and our conversation was not very interesting. } \\ \text { Researcher } & : \text { Did you have many Vietnamese friends? } \\ \text { Interviewee } 3 & : \text { No, not many, I just had some Vietnamese friends in my } \\ & \text { study group. }\end{array}$

She believed that good Vietnamese language proficiency contributes to successful academic outcomes.

$\begin{array}{ll}\text { Researcher } & : \text { What are the main factors that contribute to your } \\ & \text { academic success at An Giang University? } \\ \text { Interviewee } 3 & : \text { It is necessary to be proficient in Vietnamese language } \\ & \text { to study here. }\end{array}$

\section{- Interviewee 4}

After dealing with language difficulties particularly in his first two years of study, this student was able to get through all his courses. He was grateful that the administrators were very helpful and supportive to international students because that encouraged them to try their best to complete their courses as well as they can. Although he can communicate well in Vietnamese, he was not quite confident about participating in classroom discussions or activities. He recognized that Vietnamese language proficiency was the most important factor in his academic life at An Giang University. 


$$
\begin{array}{ll}
\text { Researcher } & : \text { Are you confident in your academic Vietnamese } \\
& \text { language competence when you are studying at An Giang } \\
& \text { University? } \\
\text { Interviewee } 4 \quad \text { I can communicate well in Vietnamese but studying in } \\
\text { Vietnamese is another story. I am not self-confident in my } \\
\text { Vietnamese language proficiency. }
\end{array}
$$

He said that Vietnamese friends seemed to be friendly and helpful to international students and this encouraged international students to work in study groups with Vietnamese students.

$\begin{array}{ll}\text { Researcher } & \text { : What did you do to overcome difficulties and keep peace } \\ & \text { with your classmates? } \\ \text { Interviewee } 4 & : \text { Sometimes, I borrowed notes from my Vietnamese } \\ & \text { friends. Vietnamese friends in my study group were of } \\ & \text { great help for us. They lent me notes and they were eager } \\ & \text { to explain more information about the lessons for us. } \\ & : \text { Were you comfortable about working with your study } \\ & \text { group? } \\ & : \text { I preferred working with my study group to class } \\ & \text { discussion. My group understood me and they always } \\ & \text { gave me a chance to speak when we were in discussion. }\end{array}$

According to this student, good Vietnamese language proficiency is the most important factor to achieve good academic performance at AGU.

$\begin{array}{ll}\text { Researcher } & \text { : What are the main factors that contribute to your } \\ & \text { academic performance at An Giang University? } \\ \text { Interviewee } 4 & : \text { Vietnamese language proficiency is necessary for a } \\ & \text { successful academic performance. Good Vietnamese } \\ & \text { competence will help international students become more } \\ & \text { confident and achieve a better academic performance. If I } \\ & \text { have good Vietnamese proficiency, I could take notes of }\end{array}$


teachers' lectures to review at home. Based on these notes, I could do homework or revise for the examinations. It is quite hard to take notes in class if international students are not proficient Vietnamese speakers.

\section{- Interviewee 5}

Before this participant came to An Giang University, he had already studied Vietnamese language for nine months. He was considered the most proficient Vietnamese speaker in the participant sample group. According to him, international students, especially Laotian students are very quiet in classes not only because they lack confidence in speaking their Vietnamese but also because they are, on average, older than most of the Cambodian and Vietnamese students. He considered that independent study skill was the most important factor in improving Vietnamese language proficiency and academic performance. Unlike several other participants, this student was comfortable with his level of fluency in Vietnamese when he participated in class discussions.

$\begin{array}{ll}\text { Researcher } & : \text { Were you confident in your academic Vietnamese } \\ & \text { language proficiency when you were studying at An } \\ & \text { Giang University? } \\ \text { Interviewee 5 } & : \text { Well, my Vietnamese language competence was not too } \\ & \text { bad. I can communicate well in Vietnamese and I was the } \\ & \text { representative for Laotian students to talk to } \\ & \text { administrative staff about our difficulties. }\end{array}$

This participant was confident about participating in class discussions and presentations. He said that he was often quiet in class not because he was embarrassed about his fluency in Vietnamese but because he is a quiet person. 


\begin{abstract}
Researcher : :How about in the classroom, were you confident in class discussions?

Interviewee $5 \quad$ : Well, I was able to participate in discussion rather well and present in front of the class. However, normally, I just kept quiet in class, we are older than other young Vietnamese students and we think quite differently.
\end{abstract}

This participant believed that independent study skill was the most important factor in improving his proficiency in Vietnamese and achieving a good academic performance.

$\begin{array}{ll}\text { Researcher } & : \text { What are the most important factors that contribute to } \\ & \text { your academic performance? } \\ \text { Interviewee 5 } & : \text { I think independent study skill is the most important } \\ & \text { factor. With good independent study skill, I can improve } \\ & \text { my Vietnamese language competence as well as my } \\ & \text { academic performance. }\end{array}$

Unlike several other participants, this student did not feel anxious or uncomfortable about his level of fluency in Vietnamese when he participated in class activities.

$\begin{array}{ll}\text { Researcher } & : \text { Have you ever felt uncomfortable when studying at An } \\ & \text { Giang University? } \\ \text { Interviewee 5 } & : \text { Yes, when I heard some bad news from my family in } \\ & \text { Laos, I felt very sad and uncomfortable. } \\ \text { Researcher } & : \text { How did you feel when you participated in class } \\ & \text { discussion and oral presentation? } \\ \text { Interviewee 5 } & : \text { It is ok, I could participate in discussion and confidently } \\ & \text { present in front of the class. }\end{array}$




\section{- Interviewee 6}

This interviewee had limited fluency in the Vietnamese language, however, her Laotian friends gave her a lot of support and this helped her in class. She was very active in improving her Vietnamese language independently and took every possible opportunity to talk to Vietnamese teachers and get help from them both inside and outside of class. She believed that good independent study skill and fluency in Vietnamese would be the most important factors in her postgraduate study in Vietnam.

$\begin{array}{ll}\text { Researcher } & : \text { Are you confident in your academic Vietnamese } \\ & \text { language competence? } \\ \text { Interviewee 6 } & \text { : No, my Vietnamese language competence is not good. } \\ & \text { However, it has improved after four months studying } \\ & \text { Vietnamese. When I first came here, I could not } \\ & \text { communicate in Vietnamese. Now, it is better; however, I } \\ & \text { do not know much academic Vietnamese for my study in } \\ & \text { the future. Studying for a postgraduate degree will be } \\ & \text { very difficult. } \\ & \text { : Do you have any difficulty in participating in class? } \\ \text { Researcher } & \text { Interviewee } 6 \\ & \text { understand the teachers, my friends will help me by } \\ & \text { explaining in Laotian. Teachers are always kind and } \\ & \text { supportive to us. Teachers know we are not good at } \\ & \text { Vietnamese; therefore, they (Vietnamese teachers) keep } \\ & \text { talking very slowly in class. }\end{array}$

Being a lecturer at a university in Laos, this participant knew how to take advantage of the help and support offered by her teachers.

$\begin{array}{ll}\text { Researcher } & : \text { What did you do to overcome challenges of studying } \\ & \text { foreign language? } \\ \text { Interviewee } 6 & : \text { I took every chance to talk to my Vietnamese teachers, } \\ & \text { in class and outside of the class. Sometimes, I visited Mrs. }\end{array}$


Nguyên (a Vietnamese teacher) at her house and asked her things I did not understand or asked for her advice about how to improve my academic performance.

This participant considered that independent study skill was the most important factor in improving her fluency in Vietnamese and achieving a good academic performance in her future postgraduate studies.

$\begin{array}{ll}\text { Researcher } & : \text { What are the main factors that contribute to your study } \\ & \text { in Vietnam? } \\ \text { Interviewee 6 } & : \text { I need to have good independent study skills and good } \\ & \text { Vietnamese language proficiency in order to study for my } \\ & \text { postgraduate degree in Vietnam. It is not good if I speak } \\ & \text { Vietnamese well but I do not have good independent study } \\ & \text { skills as well. }\end{array}$

\subsubsection{Cultural issues}

International students felt satisfied with their improved levels of understanding and engagement with Vietnamese culture. Each of them commented that they felt there were more similarities than differences between Vietnamese culture and their own cultures. For that reason, they did not experience a high degree of cultural isolation during their studies at An Giang University.

Cultural differences were not therefore identified as having a negative effect on their academic achievement or on their relationships with Vietnamese teachers. Most of the cultural differences that the interviewees reported related to different national festivals, means of transportation, regional cuisine, and wedding ceremonies. The interviewees also confirmed that the way Vietnamese teachers and students interact is very similar to pedagogical interactions in their own cultures. Consequently, the participants experienced few problems in relation to cultural differences. Lessons in the Vietnamese language course included discussions and information about Vietnamese culture and lifestyles and the students found that this laid a good foundation for their later undergraduate studies. 


\section{- Interviewee 1}

Interviewee 1 perceived few major cultural differences between Vietnam and Laos and said that none of these had negatively affected his academic performance or his relationships with his Vietnamese teachers.

$\begin{array}{ll}\text { Researcher } & \text { : What are the significant differences between Vietnamese } \\ & \text { culture and your culture? } \\ \text { Interviewee } 1 \quad & \text { : Vietnamese culture and Laotian culture are very similar } \\ & \text { to each other. Some minor differences between two } \\ & \text { cultures are food and clothing but these cultural } \\ & \text { differences do not negatively affect my academic } \\ & \text { performance. } \\ & : \text { Did cultural differences affect your relationships with } \\ \text { Researcher } & \text { Vietnamese teachers? } \\ & \text { Interviewee } 1 \\ & \text { lessons involving cultural issues. It was good to learn } \\ & \text { about Vietnamese culture when we had just arrived. The } \\ & \text { Vietnamese teachers always explained cultural } \\ & \text { differences to international students. }\end{array}$

\section{- Interviewee 2}

Like Interviewee 1, Interviewee 2 also perceived few major cultural differences between Vietnam and Cambodia. In addition, this student had a Vietnamese girlfriend and this gave him insights into aspects of Vietnamese culture. He also observed that there were different kinds of cultural festivals and regional cuisines but overall, none of the cultural differences he identified had a negative impact on his academic performance or his relationships with his Vietnamese teachers. 


$\begin{array}{ll}\text { Researcher } & \text { : What are some of the significant differences between } \\ & \text { Vietnamese culture and yours? } \\ \text { Interviewee } 2 & : \text { When I came here, at first, I was worried that there } \\ & \text { might be cultural differences between Vietnamese culture } \\ & \text { and Cambodian culture and I might face difficulties } \\ & \text { adapting to life in Vietnam. However, my Vietnamese } \\ & \text { girlfriend told me a lot about Vietnamese culture. Then I } \\ & \text { recognized that cultural differences were not a big } \\ & \text { problem when I studied at An Giang University. } \\ & \text { : Did cultural differences negatively affect your academic } \\ \text { Researcher } & \text { performance? } \\ \text { Interviewee 2 } & \text { No, cultural differences did not negatively affect my } \\ & \text { academic performance. } \\ \text { Researcher } & \text { : Did cultural differences affect your relationships with } \\ \text { Interviewee 2 } & \text { :ietnamese teachers? } \\ & \text { students. They talk to international students slowly so that }\end{array}$

\section{- Interviewee 3}

Like Interviewees 1 and 2, Interviewee 3 mentioned that Cambodia and Vietnam have different kinds of cultural festivals but that there were no major cultural differences that negatively affected her academic performance or her relationships with Vietnamese teachers. This participant also identified a number of similarities between Cambodian culture and Vietnamese culture such as the value placed on showing respect for teachers and the elderly.

$\begin{array}{ll}\text { Researcher } & : \text { What are some significant cultural differences between } \\ & \text { Vietnamese culture and yours? } \\ \text { Interviewee } 3 \quad & : \text { Vietnamese culture and Cambodian culture is not very } \\ & \text { different. There are some differences in the festivals. } \\ & \text { There are many festivals in Cambodia. Vietnamese }\end{array}$


culture is similar to Cambodian culture in the way young people respect the elderly or students should respect and follow the teachers' instructions.

Researcher

: Did these cultural differences negatively affect your academic performance?

Interviewee $3 \quad:$ No, it is very similar to my culture.

Researcher : Did these cultural differences affect your relationships with Vietnamese teachers?

Interviewee $3 \quad:$ No, Vietnamese teachers were considerate to their international students. They always explain cultural differences to avoid upsetting international students.

\section{- Interviewee 4}

Interviewee 4 also reported that there were no major cultural barriers that negatively affected his academic performance or his teacher-student relationships. He enjoyed learning about Vietnamese culture and Vietnamese people and he also appreciated the way Vietnamese teachers looked after their international students.

$\begin{array}{ll}\text { Researcher } & \text { What are some significant cultural differences } \\ & \text { between your culture and Vietnamese culture? } \\ \text { Interviewee } 4 & \text { : There are not many cultural differences between the } \\ & \text { two cultures. Some noticeable cultural differences are } \\ & \text { festivals and cooking. Laos has some festivals that are } \\ & \text { the same to which of the Thai and the Cambodian. } \\ & \text { Meanwhile, my friends told me that Vietnamese festivals } \\ & \text { are similar to Chinese festivals. For example, the Tet } \\ & \text { festival in Vietnam was originated from China. Also, } \\ & \text { Laotian food is as spicy as Thai food but Vietnamese } \\ & \text { food is salty and oily. } \\ & \text { : Do these cultural differences negatively affect or } \\ & \text { positively affect your academic life? }\end{array}$




\begin{abstract}
Interviewee $4 \quad$ : These cultural differences had no major effect on my academic life. It was good to learn more about Vietnamese culture. In the future, I may do business with the Vietnamese and I will be able to behave appropriately.

Researcher : Do these cultural differences affect your relationships with Vietnamese teachers?

Interviewee $4 \quad$ : No, Vietnamese teachers are considerate towards their international students. In class, they always paid a lot of attention to international students to make sure we understood the lessons (smiles).
\end{abstract}

\title{
- Interviewee 5
}

Like the other participants, Interviewee 5 said that there were no major cultural barriers that negatively affected his academic experiences at the University. This Laotian participant noted many cultural similarities between Vietnamese culture and Laotian culture, and as a result, he felt that he had no difficulty in understanding culturally appropriate ways of interacting with his Vietnamese teachers.

$\begin{array}{ll}\text { Researcher } & : \text { What are the significant differences between Vietnamese } \\ & \text { culture and yours? } \\ \text { Interviewee 5 } & : \text { There are not many differences, but there are } \\ & \text { similarities between Vietnamese culture and my culture in } \\ & \text { the way the younger respect elders or students respect } \\ & \text { teachers. I can see some cultural differences in the way } \\ & \text { Vietnamese women and Laotian women clothe themselves } \\ & \text { and atwedding ceremonies. } \\ \text { Researcher } & : \text { Did these cultural differences negatively affect your } \\ & \text { academic performance? } \\ \text { Interviewee } 5 & : \text { No, it was good to know about some of the cultural } \\ & \text { differences between Laotian culture and Vietnamese }\end{array}$


culture. I interacted with others quite comfortably due to our cultural similarities.

$\begin{array}{ll}\text { Researcher } & : \text { Did cultural differences negatively affect your } \\ & \text { relationships with Vietnamese teachers? } \\ \text { Interviewee 5 } & : \text { No, Vietnamese teachers always appreciated our } \\ & \text { nationality. They were kind to us and they rarely did } \\ & \text { anything that might upset us about our nationality. }\end{array}$

\section{- Interviewee 6}

This interviewee was interested in the similarities between Vietnamese culture and Laotian culture but she had also noticed a few cultural differences. However, these differences, such as regional cuisine and cultural festivals, had not negatively affected her study or teacherstudent relationships.

$\begin{array}{ll}\text { Researcher } & \text { : What are some similarities and differences between } \\ \text { Vietnamese culture and Laotian culture? } & \text { : Ah, Vietnamese culture and Laotian culture are similar. } \\ \text { For example, there are many pagodas in Laos. It is the } \\ \text { same here in Vietnam. The way the young people respect } \\ \text { their elders and students respect teachers; the ways } \\ \text { people greet each other are similar. Some of the } \\ \text { differences between Vietnamese culture and Laotian } \\ \text { culture are cooking, festivals, and different means of } \\ \text { transportation. Vietnamese food is very oily, Laotian food } \\ \text { is spicy. Festivals are quite different between Laos and } \\ \text { Vietnam. Laos has many festivals during the year. Means } \\ \text { of transportation are also different. In Laos, people } \\ \text { mainly use cars for transport and it is not very crowded. } \\ \text { Meanwhile, there are too many motorcycles on the streets } \\ \text { here in Vietnam. Vietnamese are very diligent while, } \\ \text { Laotians seem more relaxed. }\end{array}$




$\begin{array}{ll}\text { Researcher } & : \text { Do these cultural differences negatively affect your } \\ & \text { academic performance? } \\ \text { Interviewee 6 } & : \text { No, it is good to know more about Vietnamese culture. } \\ \text { Researcher } & : \text { Do cultural differences negatively affect your } \\ & \text { relationships with Vietnamese teachers? } \\ \text { Interviewee 6 } & : \text { No, Vietnamese teachers always explain cultural } \\ & \text { differences to international students. Lessons in my } \\ & \text { Vietnamese competence class always involve Vietnamese } \\ & \text { culture and Vietnamese lifestyle. }\end{array}$

\subsubsection{Teacher-student relationships and academic performance.}

All the interviewees reported that they had good relationships with their Vietnamese teachers. Vietnamese teachers encouraged them to speak up in class and this helped the students to feel comfortable and gave them a sense of belonging to the class. One interviewee said that:

"Vietnamese teachers always encourage me to talk to them. They do not wait for students to volunteer to answer the questions but they often ask for answers from the quietest students in class so every student has the chance to speak in class. I believe that in this way, students can be more active and supported in their studies."

This statement shows that Vietnamese teachers are seen as being helpful and supportive towards their international students. Also, the Vietnamese teachers use teaching strategies that encourage international students to contribute their opinions in class discussions.

None of the interviewees had any suggestions for improving their relationships with Vietnamese teachers because they said that they already had good relationships with them.

"Vietnamese teachers were very considerate to international students. They traveled with us to Vietnamese festivals and told us about Vietnamese culture." 
The graduates added that An Giang University funds sightseeing tours every school year for international students so that they can get to know Vietnam better. On these occasions, An Giang University staff and teachers accompanied the students and they had a great time together. These class trips gave the international students an opportunity to socialize with teachers and other University staff.

Although international students had good relationships with Vietnamese teachers, almost all of them preferred to seek help from Vietnamese friends when they had difficulties with

their studies. Their explanation for this was that they felt more comfortable about approaching their Vietnamese friends whenever they wanted.

"It was easier to seek help from Vietnamese friends about the lesson.

Vietnamese friends were helpful and eager to help international students."

Only one interviewee preferred to seek help from his Vietnamese teachers because he felt that Vietnamese students were less approachable.

"I do not like Vietnamese friends, they always laugh at my speaking

Vietnamese, and they are not good friends at all."

Analysis of each interview is presented in details as follows.

\section{- Interviewee 1}

Interviewee 1 was clear that having good teacher-student relationships positively affected his academic performance, yet he frequently avoided communicating with his Vietnamese teachers in class because he lacked confidence in his level of fluency in Vietnamese. Instead, he chose to seek help from his Laotian friends. 


$\begin{array}{ll}\text { Researcher } & : \text { Do you think teacher-student relationships affects } \\ & \text { student's academic performance? } \\ \text { Interviewee 1 } & : \text { Yes, it does. If students have good relationships with } \\ & \text { teachers, students can comfortably ask questions about } \\ & \text { the lessons. Teachers will be eager to explain more for } \\ & \text { these students. } \\ \text { Researcher } & : \text { Do you usually talk to your teachers? } \\ \text { Interviewee 1 } & : \text { No, I do not. My Vietnamese proficiency is not good, I } \\ & \text { do not understand teachers and sometimes, I cannot } \\ & \text { express my ideas to teachers. It is quite embarrassing. } \\ \text { Researcher } & : \text { How about when you have difficulties understanding the } \\ & \text { lesson, do you ask your teachers for explanations? } \\ & : \text { No, not really, I usually ask my Laotian friends who are } \\ & \text { good at Vietnamese to ask teachers for me, then, they } \\ & \text { translate the teachers' explanation into Laotian for me. }\end{array}$

\section{- Interviewee 2}

Like the first interviewee, Interviewee 2 said that good teacher-student relationships are important. Despite the fact that the Vietnamese teachers were always helpful and supportive to him, he was not confident enough to ask teachers for help when he had difficulties. This student suggested that an extended period of Vietnamese language study would be a good idea for students to embark on an undergraduate degree.

\footnotetext{
Researcher : Do you think teacher-student relationships affect a student's academic performance?

Interviewee $2 \quad$ :Yes, I think so. If students have good relationships with teachers, they will feel more comfortable about asking teachers for more explanations or help. If students do not have good relationships with teachers, they avoid asking questions and communicating with teachers.
} 
This participant believed that if international students spoke Vietnamese fluently, they would feel more confident about communicating with their Vietnamese teachers and this would help to establish good teacher-student relationships.

$\begin{array}{ll}\text { Researcher } & : \text { What do you think is important for establishing good } \\ & \text { relationships with Vietnamese teachers? } \\ \text { Interviewee } 2 & : \text { I think Vietnamese teachers are good. It is because of } \\ & \text { international students feelings of being ashamed of their } \\ & \text { poor Vietnamese language competence; therefore, they } \\ & \text { (international students) do not dare to communicate } \\ & \text { frequently with their teachers. }\end{array}$

\section{- Interviewee 3}

Like the other participants, Interviewee 3 acknowledged the importance of good teacherstudent relationships and their role in her academic performance. Like some of the other participants, she noted that the Vietnamese teachers seemed to be very helpful but she had not actively worked on establishing good relationships with her teachers. This was because she saw that Vietnamese teachers are very busy with heavy teaching schedules and she felt that they did not have enough time to give a lot of support to international students.

$\begin{array}{ll}\text { Researcher } & \text { : Do you think teacher-student relationships will affect } \\ & \text { students' academic performance? } \\ \text { Interviewee } 3 & \text { : Yes, I think if I kept up regular communications with my } \\ & \text { teachers, I could establish good relationships with them. } \\ & \text { Then the teachers would give me more study advice. } \\ \text { Researcher } & \text { : Do you usually talk to your teachers when you have } \\ & \text { difficulties in your study? } \\ & \text { : Seldom, and it is not usual to ask questions in class, } \\ & \text { some of my friends made appointments with teachers } \\ & \text { after class. They (the teachers) may not have time to } \\ & \text { assist only international students. However, in discussion } \\ & \text { sections, some Vietnamese teachers paid more attention }\end{array}$


to international students, they approached us and asked whether we had difficulties and tried to help us.

\author{
Researcher : What should you do to get more help from Vietnamese \\ teachers? \\ Interviewee $3 \quad$ : I think I should have better Vietnamese language \\ competence so that I can be more confident about talking \\ to my teachers.
}

\title{
- Interviewee 4
}

According to this interviewee, good teacher-student relationships have a positive effect on academic performance and frequent contact is a good way to keep teachers informed about his needs and difficulties. He felt that his teachers provided him with appropriate advice and help. However, the reality was that he sought help more often from the international students' administrators and from Vietnamese friends when he had difficulties with his studies or with his personal life.

$\begin{array}{ll}\text { Researcher } & \text { : Do you think teacher-student relationships might affect } \\ & \text { a student's academic performance? } \\ \text { Interviewee } 4 & : \text { Yes, I think so } \\ \text { Researcher } & : \text { Why do you think so? } \\ \text { Interviewee } 4 & : \text { Well, if students have good relationships with teachers, } \\ & \text { teachers will understand students' needs and difficulties. } \\ & \text { In that way, teachers can provide students with } \\ & \text { appropriate advice and help. That would help students } \\ & \text { feel more confident in their studies. } \\ & : \text { How can students establish good relationships with } \\ \text { Researcher } & \text { teachers? } \\ \text { Interviewee } 4 & : \text { I think keeping in frequent contact or asking questions } \\ & \text { will help. } \\ \text { Interviewee } 4 & \text { : In practice, did you have frequent contact with your } \\ & \text { teachers or ask them many questions? }\end{array}$




\begin{abstract}
Interviewee $4 \quad$ : No, I rarely asked the teachers any question. I just asked friends in my study-group and got help from the international students' administrators. They were all very helpful to me.

Researcher $\quad:$ Why did not you ask the teacher for help?

Interviewee $4 \quad$ : It was very crowded in classes and it was not usual that students asked questions in class. Some of my friends might see teachers after class if teachers had time for them.
\end{abstract}

\title{
- Interviewee 5
}

This Laotian participant also acknowledged the importance of teacher-student relationships on his academic performance and he had good relationships with his teachers. His fluency in the Vietnamese language gave him confidence to approach the Vietnamese teachers. Moreover, he was very helpful to Vietnamese teachers. Whenever other Laotian students did not understand something, he helped the teachers by explaining in the Laotian language what the teacher said. When he had difficulties in his study, he was confident about seeking help from his teachers.

$\begin{array}{ll}\text { Researcher } & \text { : Do you think that teacher-student relationships have an } \\ & \text { effect on your academic performance? Why (not)? } \\ \text { Interviewee 5 } & \text { : Yes, teacher-student relationships can affect academic } \\ & \text { performance. If students and teachers can establish good } \\ & \text { relationships, teaching and learning will be more } \\ & \text { effective. Students trust teachers and teachers understand } \\ & \text { students. This is very important in teaching and learning. } \\ & : \text { Do you have good relationships with Vietnamese } \\ \text { Researcher } & \text { teachers? } \\ \text { Interviewee 5 } & \text { and hell, Vietnamese teachers are nice. They are friendly } \\ & \text { international students go with teachers on a sightseeing } \\ & \text { trip, traveling or playing football. After all these }\end{array}$


activities, international students may feel more comfortable about approaching their teachers. That may encourage them (international students) to talk to teachers more. In class, I usually asked teachers whenever I did not understand something, and teachers replied kindly. Sometimes, my Laotian friends did not understand the lessons and I would help them to ask teachers for further explanations and then translated teachers' explanations back into the Laotian language for them.

\section{- Interviewee 6}

Being a lecturer, this interviewee acknowledged the importance of teachers' helpfulness to students. In spite of her limited fluency in Vietnamese, she frequently sought help from Vietnamese teachers when she had difficulties in her study or in her life at the University. According to her, Laotian friends in her Vietnamese language class were often too shy to ask teachers for further explanations. This was because they did not want to tell teachers that they were having difficulties in learning from them.

$\begin{array}{ll}\text { Researcher } & \text { : Do you think teacher-student relationships affect } \\ & \text { academic performance? } \\ \text { Interviewee 6 } & : \text { Yes, I think so. Good teacher-student relationships will } \\ & \text { result in effective teaching and learning. Teachers and } \\ & \text { students get closer, understand each other's needs and } \\ & \text { expectations; therefore, they will appropriately address } \\ & \text { each other's needs. If students and teachers do not have } \\ & \text { good relationships, students may not dare to seek help or } \\ & \text { askfor further explanation from teachers. } \\ & : \text { What should you do to establish good relationship with } \\ \text { Researcher } & \text { teachers? } \\ & \text { Interviewee } 6 \\ & \text { frequently and share with me their interests and }\end{array}$


difficulties. In that way, I can understand them better and I can address their needs appropriately. It is the reason why I always seek help from Vietnamese teachers so that teachers will know my needs and difficulties and they can provide me with appropriate help. However, my other Laotian friends in the Vietnamese language class do not raise their questions with teachers. They do not tell teachers what is not clear to them. It is not good. It is better if students tell teachers what is not clear to them. Knowing that, teachers may make further explanations.

\subsubsection{Conclusion of interview findings.}

In conclusion, the findings from interviews illustrate some of the common themes that occurred across the six interviewees. These themes include international students' expectations, satisfaction levels, and recommendations; international students' experiences of language barriers in the classroom; international students' experiences of cultural differences; and, students' experiences about the connection between teacher-student relationships and academic outcomes. Generally speaking, international students' greatest expectations while studying at An Giang University were that they would complete their undergraduate degrees and learn as much as they could about Vietnamese language and culture because this would increase their promotion prospects in the future. Some of Laotian students recommended better stipend from the scholarship provider.

Their expectations were partly met. The undergraduate students could complete their studies in good time. International students in the Vietnamese language class could improve their Vietnamese language proficiency. However, most of them still reported a lack of confidence in studying in the Vietnamese language. They also commented that Vietnamese culture has many similarities with their own cultures. All of them wished that they had acquired a greater degree of fluency in the Vietnamese language before they started their undergraduate studies in Vietnam. This, they believed, would have increased their level of confidence in their academic lives. 
The international students who participated in this study felt that they were able to adapt quickly and easily to Vietnamese culture. They did not feel that cultural differences had negatively affected their studies or their relationships with Vietnamese teachers. Finally, while they all believed that good teacher-student relationships positively affected academic outcomes; many of them lacked confidence in their ability to communicate effectively in Vietnamese. As a result, most of them avoided communicating directly with their Vietnamese teachers, participating in class discussions, or asking their teachers for further explanation when they did not understand something that was said in class.

\subsection{Conclusion}

This chapter presents findings from questionnaires and interviews with international students at An Giang University. Findings from questionnaires and interviews show that almost all international students faced language barriers while studying at An Giang University. Language barriers might cause embarrassment in students' communicating with Vietnamese teachers and in class activities. Meanwhile, all international students at An Giang University reported that it was easy for them to adapt to the Vietnamese culture. Therefore, cultural differences did not negatively affect their academic performance and relationships with Vietnamese teachers. All international students at AGU reported good relationships with Vietnamese teachers. It is noticeable that teacher-student relationships were reported to have a significant impact on international students' academic performance and satisfaction levels while studying at An Giang University. 


\section{CHAPTER FIVE \\ INTEGRATION, DISCUSSION, AND RECOMMENDATION}

\section{$5.1 \quad$ Introduction}

This chapter integrates the literature with the key findings of this research. The first section summarizes the findings for each of the key research questions. Section two integrates these findings with a selection of the literature concerned with those factors thought to impact on international students' academic experiences at An Giang University and their relationships with Vietnamese teachers. Section three looks at the implications of this research for both theory and practice. In section four, I consider future research opportunities. Section five presents a paradigm model of international students' academic satisfaction. Finally, section six concludes the chapter.

\subsection{Summary of the findings}

\subsubsection{Findings from questionnaires and interviews of international students'} responses on question 1 - “What are Laotian and Cambodian students' perceptions and experiences of linguistic and cultural differences when they are studying at An Giang University?

Data from questionnaires and interviews showed that almost all the Laotian and Cambodian students had experienced difficulties learning a new language while studying at An Giang University. On the other hand, cultural differences presented fewer challenges for these students.

\subsubsection{Linguistic issues}

\subsection{Linguistic confidence}

Language difficulties were acknowledged as a major challenge for the Laotian and Cambodian participants. Over $80 \%$ of the participants lacked confidence in their level of Vietnamese language proficiency. The following graph shows that the international 
students enrolled in the University's intensive Vietnamese language course either strongly disagreed or disagreed that they felt confident about their level of proficiency in the Vietnamese language. Meanwhile, only some of the study participants who were enrolled in an undergraduate degree programme felt confident about their level of Vietnamese language proficiency.

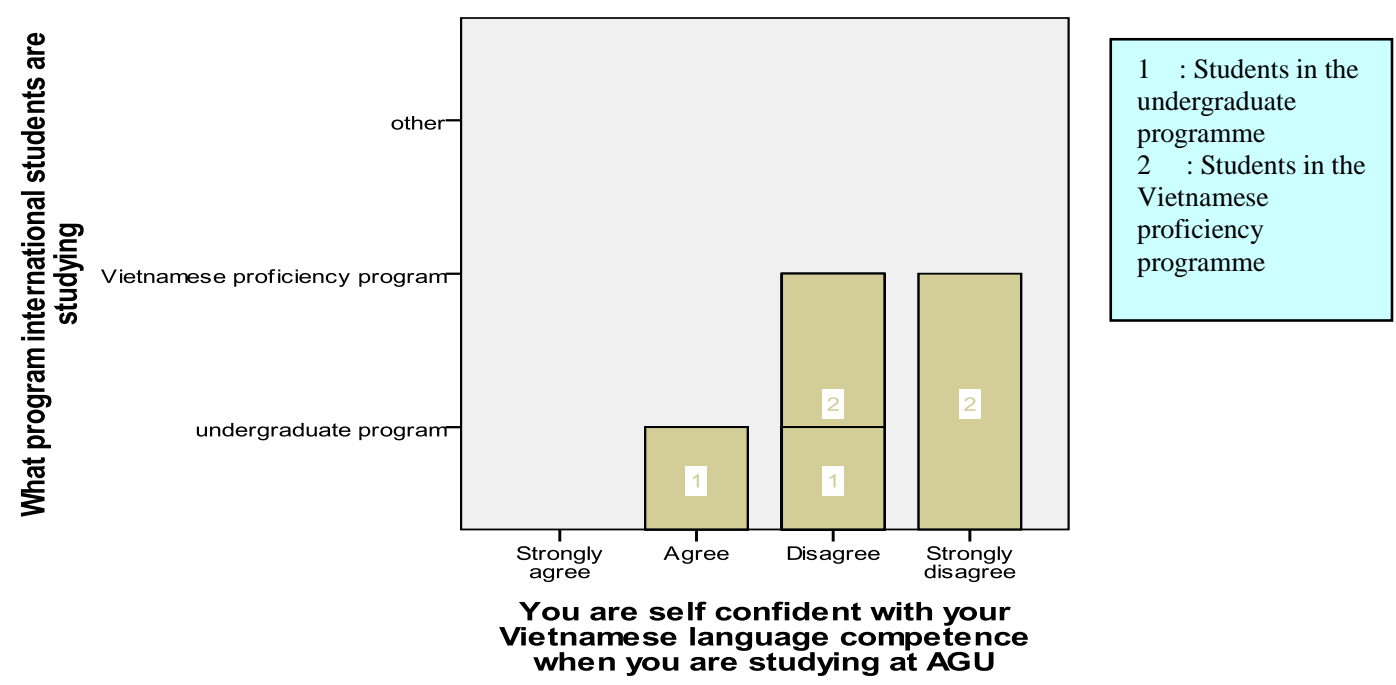

Figure 5.1: The correlation between students' levels of study and students' confidence in Vietnamese language proficiency.

Five out of six of the interviewees reported a lack of self-confidence in their level of proficiency in Vietnamese. Only one interviewee reported that he felt confident about his level of proficiency in the Vietnamese language. However, this participant had completed a nine-month Vietnamese language course in Laos before coming to An Giang University. For the most part, many of the undergraduates who participated in this study reported that they lacked confidence in their level of proficiency in Vietnamese even though they had done their studies in classrooms where the medium of instruction is Vietnamese and had done so for more than four years. This may be due to the fact that they were studying with other Vietnamese students and these international undergraduates may have been comparing their own level of fluency in Vietnamese with that of native Vietnamese speakers. Consequently, they felt that their fluency in Vietnamese was not as good as that of the Vietnamese students.

The interviewees felt that, for international students, having a good level of fluency in Vietnamese is the most important factor in maintaining a strong academic performance. 
Specifically, $70.8 \%$ of the participants ranked having good Vietnamese language skills as the most important factor in achieving academic success at the University. This was followed by having a good relationship with teachers which $54.2 \%$ of intentional students ranked as the second most important factor. Half (50\%) of the participants ranked good independent study skills as being the third most important factor in a successful academic performance. Interest in the subject was ranked fourth in importance by $58.3 \%$ of international students. Finally, 37.5\% of the interviewees ranked adapting to Vietnamese culture as being least important compared to other factors.

\subsection{Difficulties in participating in class activities.}

Almost all the participants $(95.8 \%)$ indicated in the questionnaire that they had difficulty participating fully in class activities. Only one language student responded that he did not have difficulties in participating in class activities. However, five out of six of the interviewees reported feeling uncomfortable about contributing to class activities such as class discussions or oral presentations. Only one interviewee who had attended the Vietnamese language proficiency course had not experienced difficulties with participating in activities in his language class. Despite that, he rarely spoke in class unless the teachers asked him a direct question.

\subsection{Language competence and academic performance.}

All the participants involved with this study believed that their level of proficiency in Vietnamese had affected their academic performance. Similarly, all six interviewees perceived a link between their level of Vietnamese language proficiency and their academic performance. These interviewees reported that some of their academic difficulties related to language problems such as taking notes, following teachers' instructions, participating in oral presentations and class discussions, and sitting examinations. 


\subsection{Language difficulties and relationships with Vietnamese teachers.}

My findings from the questionnaires show that although $62.5 \%$ of international students had difficulties communicating with Vietnamese teachers, $91.7 \%$ of them believed that their degree of fluency in Vietnamese had affected their relationships with their Vietnamese teachers. All of them thought that good relationships were based on clear communication, and mutual understanding and sympathy. Hence, they believed that low levels of Vietnamese language proficiency had blocked their relationships with their Vietnamese teachers. However all the participants reported that they had established good relationships with Vietnamese teachers.

Responses from interviewees therefore generated widely held views about their relationships with their teachers. For example, although four out of the six interviewees stated that they rarely asked their Vietnamese teachers for additional explanations because of their embarrassment about their level of fluency in Vietnamese, they each reported that they had good relationships with their Vietnamese teachers.

\subsubsection{Cultural issues}

It seems that international students at An Giang University do not have significant cultural problems relating to learning in the Vietnamese context. Almost all international students $(91.7 \%)$ stated that they had no difficulties adapting to Vietnamese culture when they were studying at An Giang University. In addition, $100 \%$ of the participants strongly agreed or agreed that Vietnamese teachers had helped them to understand about cultural differences between Vietnamese culture and their own cultures. Vietnamese teachers did this in the language course during their lessons about culture and Vietnamese life-styles. Similarly, all six interviewees said that they saw no significant differences between Vietnamese culture and their own cultures. Some minor cultural differences were reported, such as cuisine, transportation, and cultural festivals, but these were not seen as problematic. This is interesting because $\mathrm{Tu}$ (1993) has argued that Vietnamese culture is heavily influenced by Chinese culture, for example the commemoration of the Lunar New Year. Laotian, Cambodian and Thai cultures are more influenced by Indian culture. 
It is also noticeable that while $87.5 \%$ international students thought that cultural differences had not affected their relationships with their Vietnamese teachers, $100 \%$ of them experienced good relationships with Vietnamese teachers despite some minor cultural differences.

\subsubsection{Findings from questionnaires and interviews of international students' responses on the research question 2 - "How do teacher-student relationships affect international students' academic performance in different language and cultures?"}

Although almost all the participants thought that competency in Vietnamese and cultural differences would affect their relationships with Vietnamese teachers and their academic performance, all of them had experienced good relationships with their Vietnamese teachers. Despite that, while most of the participants $(79.2 \%)$ either strongly disagreed or disagreed that they felt self-confident about their proficiency in Vietnamese, all of them experienced good relationships with their Vietnamese teachers. They indicated that this was a result of the helpfulness and approachability of Vietnamese teachers towards international students. The participants described their Vietnamese teachers as helpful, sympathetic, friendly, and approachable. In addition, the Vietnamese teachers seemed to be sympathetic to international students' language difficulties and cultural differences.

Although international students indicated that they had good relationships with their Vietnamese teachers, only $29.2 \%$ of international students said they would be willing to seek extra help and advice from Vietnamese teachers when they had difficulties in their academic lives. Indeed, while $41.7 \%$ of them found Vietnamese teachers were most helpful to them in their study, a higher percentage of the participants (54.2\%) believed that Vietnamese friends were the most helpful to them in their study. This group of respondents said they preferred seeking help from Vietnamese friends to Vietnamese teachers because Vietnamese teachers were always busy. Moreover, although Vietnamese teachers were thought to be approachable, international students were very shy about asking teachers for extra help because they lacked confidence in their level of fluency in Vietnamese. Meanwhile, Vietnamese friends were seen as always helpful and available whenever help or advice was needed. 


\subsubsection{Findings from questionnaires and interviews of international students' responses on the research question 3 - "What are international students' expectation, satisfaction levels, and recommendation when they are studying at An Giang University?"}

Due to the close international relationships between Vietnam, Laos, and Cambodia, most of the participants wished to learn the Vietnamese language and upgrade their qualifications to strengthen their career promotion prospects in the future.

Although not all of the participants had received very high grades in the course of their studies, they seemed satisfied with their academic life at An Giang University. The questionnaires showed that a majority of the international student participants $(54.2 \%)$ received grade averages in the $\mathrm{C}$ to $\mathrm{C}+$ range and only $8.3 \%$ of the participants were in the A- to A+ grade range. Meanwhile, $87.5 \%$ of the participants reported that they were satisfied with their level of academic achievement while they were studying at the University. Most of them explained that some of their satisfaction was due to the helpfulness of Vietnamese teachers as well as the opportunity for them to improve their Vietnamese language skills. Similarly, all the interviewees stated that their Vietnamese teachers had encouraged them a lot in their study and this had helped them to overcome language barriers and also motivated them to try their best in their studies.

In conclusion, while cultural differences did not significantly affect the participants' academic performance or relationships with their teachers, they thought that their level of proficiency in Vietnamese language had affected both their academic performance and their relationships with Vietnamese teachers. However, Vietnamese teachers and Vietnamese friends' friendliness, helpfulness, and encouragement helped them to overcome some of their difficulties with language as well as establish good relationships with Vietnamese teachers. In addition, almost all the participants were satisfied with their academic performance although their academic reports were mostly in the $\mathrm{C}$ and $\mathrm{C}+$ grade range. It seems that the most important expectation of these international students was not high academic reports but rather, completing an undergraduate certificate and improving their Vietnamese language skills. 


\subsection{Integration of findings with the literature.}

This section summarizes the similarities and differences between key findings of this research with a range of literature as detailed in Chapter 2.

\subsubsection{Linguistic barriers}

The most significant issue for the participants in this study was the language difficulties they experienced during their time at An Giang University. Almost all the international students who participated in the study indicated that they lacked confidence in their ability to communicate effectively in class activities. This finding reflects findings from other studies which emphasize that language barriers need to be addressed with international students (Bradley \& Bradley, 1984; Sakthivel, 2003; Hellsten \& Prescott, 2004; Marr, 2005; Dao \& Le, 2007; Zhang \& Mi, 2009; and Unyapho, 2011). Interestingly, almost all the undergraduates in my study who expressed a lack of confidence in their Vietnamese language proficiency had also attended a nine-month Vietnamese language competence course before they started their undergraduate degrees at An Giang University and had been enrolled in an undergraduate degree at An Giang University in Vietnamese for four years.

These students also reported that they had good relationships with their Vietnamese teachers and were satisfied with their academic outcomes despite their lack of fluency in Vietnamese. These findings differ from those of Dao \& Le (2007) and Campbell \& Li (2008) who found that international students with high levels of fluency in the language of instruction were more likely to establish good relationships with teachers and be satisfied with their academic experience. The findings from my study are more similar to Hullena (2008) who found that teachers' care and appreciation towards their students can be a powerful catalyst for building teacher-student rapport and increasing students' levels of academic satisfaction. In my study, I found that even though international students at the University lacked confidence in their level of fluency in Vietnamese and avoided communicating with Vietnamese teachers as a result, they reported that Vietnamese teachers were very helpful and considerate towards them. Hall \& Kidman (2004) also argue that teacher-student rapport is essential in maintaining an effective teaching and learning 
process. Similarly, international students reported that their satisfaction studying at An Giang University was enhanced by having good relationships with Vietnamese teachers.

The participants in my study who lacked confidence in their ability to communicate well in Vietnamese felt uncomfortable participating in class discussions and oral presentations and this reflects Ramburruth and Birkett's (2000) argument that "poor language and communication skills [are] a major problem in group assignments" (p. 186). In addition, several participants in this study reported that they did not actively seek help from Vietnamese teachers because they felt that their Vietnamese was not fluent enough. Aida (1994) argues that language difficulties can lead to poor oral performance in learning situations. Furthermore, Ryan (2000) argues that students who study in a second language are often afraid to speak in class or seek help because of a lack of confidence in their ability to communicate and fear of embarrassing themselves or their teachers.

The participants in my study found it difficult to follow teachers' instructions, take notes and do well in examinations as a result of the language barriers they experienced. This reflects Campbell \& Li's (2008) contention that language barriers can prevent international students from listening to lectures, following instructions, understanding assessment criteria and procedures, completing assignments, and doing well in exams and tests.

Lack of proficiency in Vietnamese also deterred the participants in my study from asking Vietnamese teachers for additional help with their learning. This finding is similar to Kim (2007) who found that international students' lack of English language proficiency was the most challenging barrier to their efforts at exchanging ideas with their advisors. Their learning seemed to be very passive and they did not seek frequent communication with their teachers. Freire (2000) also argues that "without dialogue, there is no communication, and without communication, there can be no true education" (p. 81).

\subsubsection{Cultural differences}

While language barriers are identified here as a significant challenge for international students and their ability to establish relationships with Vietnamese teachers, cultural differences were reported as being less important. 
Some of the findings from this study support the existing literature on cultural diversity in educational contexts. For example, Averill (2009) states that cultural differences can be a challenge for both teachers and students in achieving successful academic outcomes. Although it seems that there are few major differences between Vietnamese culture and Laotian and Cambodian cultures; international students at An Giang University also acknowledge a sense of being foreigners compared with the Vietnamese students in their classes. This might deter international students from active in-class participation and they may appear to be more quiet and passive in their classes than they really are. In addition, Campbell \& Li (2008) argue that students' satisfaction with their learning experience is related to the degree to which they have adapted to the cultural environments of their classrooms. They argue that the better they (international students) adapt to the new environment, the more positive their learning experience is. Similarly, although the international students in my study had experienced language difficulties, their positive engagement with Vietnamese culture had enhanced their academic experiences at An Giang University. My participants reported that Vietnamese teachers had helped them to understand Vietnamese culture better. Moreover, Vietnamese teachers had actively helped the international students to engage with Vietnamese culture by accompanying them to activities outside of classes and also on some short class trips. Brown (2009) argues that teachers play an important role in communicating cultural differences to students and preventing cultural misunderstanding. My study supports this view.

Although the participants in my study lacked confidence in their level of proficiency in the Vietnamese language, $91.7 \%$ of these students said that they had not experienced difficulties in adapting to Vietnamese culture. This finding is different from the arguments of Holmes, 2005; Brown, 2008; and Unyapho, 2011 who have argued that difficulties in communicating in the English language affects the level of cultural engagement that many international students have with American academic culture. Findings from my study may result from the fact that Vietnamese teachers are very aware of the need to actively help international students understand more about Vietnamese language and culture. 


\subsubsection{International students' expectations and satisfaction levels.}

A clear result from my study was that although the participants found it difficult to maintain frequent communication with their Vietnamese teachers due to their lack of proficiency in Vietnamese, they still felt that they had good rapport with their teachers and were satisfied with their academic performance. This finding differs from that of Unyapho (2011) who found that language proficiency is an important factor in the level of satisfaction that international students have with their academic experiences abroad. On the other hand, my findings support the view of Hullena (2008) who concluded that teacherstudent rapport is an important influence in students' satisfaction with their academic performance. In addition, the findings from my study also support the view of Campbell \& Li (2008) who have identified a link between adapting readily to a new cultural environment and students' satisfaction with their international study experience.

\subsection{Implications and recommendations for practice}

In this study, I have investigated some of the challenges that face international students in the course of their studies. I have found that strong teacher-student rapport is a powerful factor in establishing a good learning environment for this group of students. The findings of my study show that language proficiency has an effect on academic performance but when a good rapport is established between teachers and students, students are more likely to strive to overcome these difficulties and find satisfaction in their studies.

The findings of this study have several implications for future practice in the Vietnamese university context. Firstly, in order to help international students with their academic performance, it would be helpful if they have a good level of Vietnamese language proficiency before enrolling in Vietnamese higher education institutions. Evidence from the literature shows that being able to communicate effectively in the language of instruction is essential for students who are studying abroad. In particular, proficiency in the language of instruction helps international students to maintain a good academic performance,

participate in class activities with confidence, communicate effectively with friends and teachers, and engage more fully with the new cultural environment. 
Secondly, it would be helpful to have a standard Vietnamese language test, similar to IELTS, TOELF, or EPP, that measures the level of competency in the Vietnamese language. If such a measure was available, Vietnamese universities and international students attending higher education in Vietnam would have some indication about the level of support that would be required once students were enrolled in a higher education programme.

Thirdly, university administrations need a sustained focus on the importance of building rapport with international students and understanding the challenges they confront in the course of their studies. It was shown very clearly in the findings of this study that international students greatly value teachers' friendliness and helpfulness as important factors that help them to overcome the challenges of studying in a new language and culture. Moreover, teachers' approachability needs to be reinforced in order for international students to feel more at ease about seeking help and advice from their teachers. On the other hand, however, it was also clear that the international students did not always actively communicate with their Vietnamese teachers due to their perception that they did not speak Vietnamese well. These perceptions may create additional barriers to establishing rapport between teachers and students and this may have a flow-on effect on students' learning. For that reason, it is important that teachers find ways of letting international students know that their questions and contributions in class are always welcomed and appreciated. In this respect, teachers should encourage questions and oral contributions from international students in order to ensure that effective teaching and learning is taking place.

Fourthly, some international students recommended a better stipend from the scholarship provider. While international students may face many difficulties in a new language and culture environment, it would be better if the scholarship provider considers a better stipend granted to the scholarship receivers in order to help international students with financial difficulties. It is believed that with a better stipend, international students would be more comfortable with their academic lives abroad.

Finally, it is also important to involve international students in the extracurricular activities of the university so that they feel they are an important part of the community. In addition, 
participating in the extracurricular programmes of the university is likely to help international students further improve their Vietnamese language proficiency, build their confidence in themselves and their ability to do well academically, and widen their relationships with others. This would also help international students to be more active in their study as well as encouraging them to seek help from friends and teachers more often.

\subsection{Implications and recommendations for future research}

Data for this study was collected from international students in only one university in Vietnam. While, the findings can be generalized within the international student body at An Giang University, it may not be appropriate for international students studying at other universities in Vietnam. Future research in this area should explore the academic experience of international students at other universities in order to gain a more thorough insight into their experiences in Vietnam generally. Moreover, while this study explored the importance of the rapport between teachers and international students, data was only collected from international students. Future studies should aim to collect data from both teachers and students so that the findings provide more detailed insights.

This study focuses on the language and cultural challenges that international students face in the course of their studies. It concludes that good teacher-student rapport is a primary factor in improving the academic performance of international students. It would be beneficial if future research explored other factors that present challenges for international students and which negatively affect their academic performance in higher education in Vietnam. It would also be helpful if strategies were identified that would help international students overcome other kinds of difficulties that have not been explored in this study.

The findings from this study were drawn from two different groups of international students; namely, undergraduate students and students enrolled in an intensive Vietnamese language course. International students in different programmes or enrolled in different levels of study may well have very different experiences to those of the students who were involved with this study. Future researchers might make a comparison of the similarities and differences in the academic experience of these two groups in order to identify specific strategies for each group. 


\subsection{The paradigm of international students' academic experiences at a higher education institution in Vietnam.}

A paradigm model can be used to explain the level of satisfaction students have with their academic experiences at a higher education institution in Vietnam, particularly in relation to language difficulties and cultural differences, teacher-student relationships, expectation, and satisfaction levels. Strauss \& Corbin (1998) argue that developing a paradigm model is fundamental to grounded theory studies. They contend that a good paradigm is made by creating a story line that connects each of the various themes that have emerged from the data (Strauss \& Corbin, 1998). Therefore, the story line for this study is as follows: Laotian and Cambodian students expect to obtain undergraduate degrees and increase their proficiency in Vietnamese. They hope that this will enhance their career promotion prospects in the future. These students face language difficulties in their study abroad. Cultural differences do not, however, have any significant or negative effect on their academic life in Vietnam. Good relationships with Vietnamese teachers inspire and encourage these students to overcome language difficulties and increase their feelings of achievement and satisfaction with their academic outcomes. The findings of this study emphasize the importance of building teacher-student rapport in the teaching and learning environment and this supports the views of Hall \& Kidman (2004), Hullena (2008), and Averill (2009) who argue that teacher-student rapport is an important part of their learning experience. The paradigm model I have developed from this storyline is presented in the diagram below. 


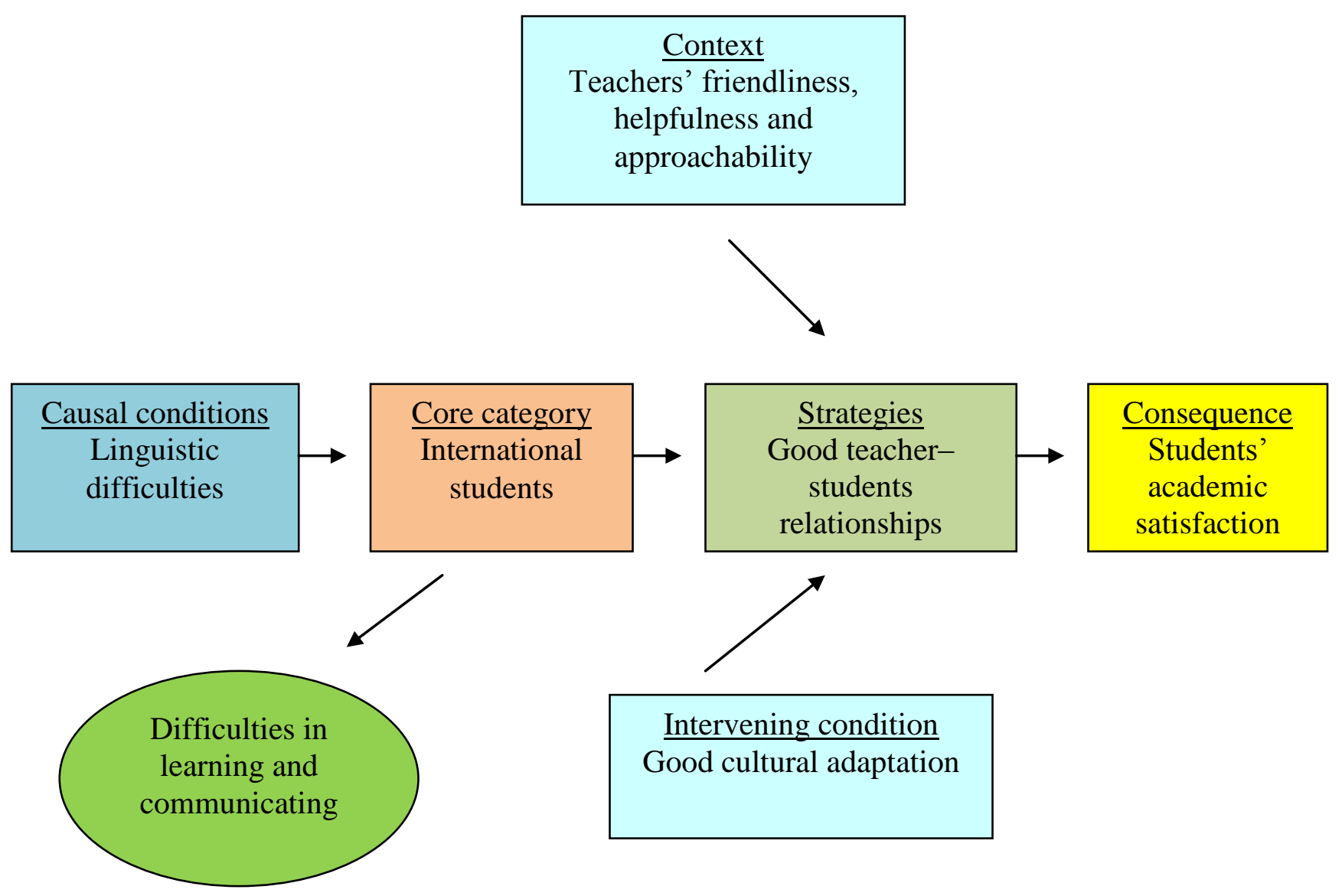

Figure 5.2: The paradigm of international students' academic experiences at a higher education in Vietnam.

\subsection{Conclusion}

This chapter has summarized the findings of the questionnaires and the interviews conducted with international students at An Giang University. The main findings show that international students at An Giang University face linguistic difficulties in their studies; however, cultural differences did not negatively affect their academic performance or their relationships with Vietnamese teachers. While language difficulties deterred them from communicating frequently or openly with their teachers, they reported that they had good relationships with their Vietnamese teachers. It was these relationships that helped them to feel satisfied with their academic outcomes.

This chapter has integrated the findings with a range of the literature. There are similarities and differences between findings of this study and literature. Significantly, most of the 
existing literature identifies a strong relationship between linguistic proficiency and international students' satisfaction. The findings from this study show that although international students at An Giang University lacked confidence in their levels of Vietnamese language proficiency, they were satisfied with their academic outcomes. The literature also indicates that international students face cultural shocks when they are studying abroad, however, this study found that international students at An Giang University did not have these difficulties in adapting to the Vietnamese cultural context. Recommendations and implementations for practice and future research have also been included in this chapter.

A paradigm of international students' academic satisfaction in a university in Vietnam has also been introduced in this chapter. This paradigm shows that language difficulties can be overcome more readily for international students' academic satisfaction when good rapport exists between teachers and students and students adapt easily to culture of the host country. 


\section{CHAPTER SIX CONCLUSION}

While little is known about international students' experiences in higher education institutions in Vietnam, this study has explored the experiences of Laotian and Cambodian students at An Giang University in relation to language barriers, cultural differences, and teacher-student rapport. It has emphasized the importance of building rapport between teachers and students in helping international students to establish a sense of belonging within the institutional environment of a foreign university. In light of this, the findings of this study have answered three guiding research questions using a mixed methods research methodology. Quantitative and qualitative data in the form of questionnaires was collected from all international students $(\mathrm{N}=24)$ at An Giang University. This data was supplemented with qualitative data drawn from six subsequent in-depth interviews with six international students who were purposively selected from the groups of students based on their academic reports. In examining this data, it is clear that the international students who were involved in this study, experienced many challenges in the course of their study as they found strategies for learning in a foreign language context. On the other hand, however, the students did not feel that cultural differences had negatively affected their academic experiences or outcomes, nor did they feel these were problematic in their relationships with their Vietnamese teachers. It was significant, however, that while international students lacked confidence in their Vietnamese language proficiency, they reported having good relationships with their Vietnamese teachers. This rapport with their teachers helped them to strive to overcome the language difficulties they were facing and increased their level of satisfaction with their academic outcomes (despite the fact that most of them did not achieve high grades). Findings from this study also illustrate that international students need the scholarships offered by the Vietnamese government if they are going to be able to study for undergraduate degrees in Vietnam. These international students hope to become proficient in Vietnamese so that they can use Vietnamese language in their future careers and this is also a way for them to get career promotions. Findings from this study also reveal that these expectations were partly met; they were able to complete undergraduate degrees in Vietnam. However, they still lacked confidence in 
their level of Vietnamese language proficiency after graduating with an undergraduate degree. The most important aspect of study for this group of students was the value they accorded to the rapport they experienced with their Vietnamese teachers. In light of this, I argue that rapport between teachers and international students needs to be a focus for An Giang University in the future so that international students are not only confident about their academic lives but are also able to overcome language difficulties more readily and with a greater level of institutional support while they are studying abroad. 


\section{REFERENCES}

Adam, D., Geok, H. K., \& Lin, L. (2001). Linking research, policy and strategic planning to education development in Lao People's Democratic Republic. Comparative Education Review. 45(2), 220-241.

Aida, Y. (1994). Examination of Horwitz, Horwitz, and Cope's construct of foreign language anxiety: The case of students of Japanese. The Modern Language Journal, 78(2), 155-168.

Apfelthaler, G., Hansen, K., Keuchel, S., Mueller, C., Neubauer, M., Ong, H. S., \& Tapachai, N. (2007). Cross-cultural differences in learning and education: stereotypes, Myths and realities. In D. Palfreyman \& L. D. McBride (Eds.), Learning and teaching across cultures in higher education (pp. 15-35). New York: Palgrave Macmillan.

Averill, R. (2009). Teacher-student relationships in diverse New Zealand year 10 mathematics classrooms: Teacher care. Unpublished PhD thesis. Victoria University of Wellington, New Zealand.

Banks, J. A. (1985). Multicultural education. In T. Husen \& T. N. Postlethwaite (Eds.), The international encyclopaedia of education. Oxford: Pergamon Press.

Banks, J. A. (1995). Multicultural education: Historical developments, dimensions, and practice. In J. A. Banks \& C. M. Banks (Eds.), Handbook of research on multicultural education. (pp.3-34). New York: Macmillan.

Banks, J. A. (2004). Diversity and citizenship education. San Francisco: Jossey-Bass.

Bishop, R., Berryman, M., Tiakiwai, S., \& Richardson, C. (2003). Kotahitanga: The experiences of year 9 and 10 Maori students in mainstream classrooms. Wellington: Ministry of Education. 
Bradley, D. \& Bradley, M. (1984). Problems of Asian students in Australia: Language, culture, and education. Canberra, ACT: Australia Government Publishing Service.

Brown, A., \& Reushle, E. S. (2010). People, pedagogy and the power of connection. Studies in Learning, Evaluation, Innovation and Development, 7(3), 37-48.

Brown, L. (2008). Language and anxiety: An ethnographic study of international postgraduate students. Evaluation and Research in Education, 21(2), 75-95.

Brown, L. (2008). The incidence of study-related stress in international students in the initial stage of the international sojourn. Journal of Studies in International Education, 12(1), 5-28.

Brown, L. (2009). A failure of communication on a cross-cultural campus. Journal of Studies in International Education, 13(4), 439-454.

Campbell, J., \& Li, M. (2008). Asian students' voices: An empirical study of Asian students' learning experiences at a New Zealand University. Journal of Studies in International Education, 12(4), 375-396.

Chansopheak, K. (2009). Basic education in Cambodia: Quality and equity. In Y. Hirosato \& Y. Kitamura (Eds.), The political economy of educational reforms and capacity development in Southeast Asia: Cases of Cambodia, Laos and Vietnam, (pp. 131152). Tokyo, Japan: Springer.

Chapman, W. D. (2009). Education reform and capacity development in basic education: Illustrations from Indochina. In Y. Hirosato \& Y. Kitamura (Eds.), The political economy of educational reforms and capacity development in Southeast Asia: Cases of Cambodia, Laos and Vietnam, (pp. 75-89). Tokyo, Japan: Springer.

Charlesworth, Z. (2007). Educating international hospitality students and managers: The role of culture. International Journal of Contemporary Hospitality Management, $19(2), 133-145$.

Charmaz, K. (2006). Constructing grounded theory: A practical guide through qualitative analysis. Thousand Oaks, CA: Sage. 
Chealy, C. (2009). Higher education in Cambodia. In Y. Hirosato \& Y. Kitamura (Eds.), The political economy of educational reforms and capacity development in Southeast Asia: Cases of Cambodia, Laos and Vietnam, (pp. 153-165). Tokyo, Japan: Springer.

Chen, C. (1999). Common stressors among international college students: Research and counseling implications. Journal of College Counseling, 2(1), 49-65.

Cheng, X. (2000). Asian students' reticence revisited. System, 28, 435-446.

Chhing, S., \& Dy, S. S. (2009). Education reform context and process in Cambodia. In Y. Hirosato \& Y. Kitamura (Eds.), The political economy of educational reforms and capacity development in Southeast Asia: Cases of Cambodia, Laos and Vietnam, (pp. 113-129). Tokyo, Japan: Springer.

Cô có đánh con không (Did I beat you?). (2011). Retrieved December 29, 2011 from http://dantri.com.vn/c25/s25-551895/co-co-danh-con-khong.htm

Cohen, D. (2003). Australia has become the academic destination for much of Asia. Can it handle the influx? Chronicle of Higher Education, 49(21), 1-40.

Corbin, J. A., \& Strauss, A. (2008). Basics of qualitative research ( $3^{\text {rd }}$ Ed.). Thousand Oaks, CA: Sage Publications.

Cothran, D., \& Ennis, C. (2000). Building bridges to students' engagement: Communicating respect and care for students in urban high schools. Journal of Research and Development in Education, 33(2), 106-117.

Cothran, D., Kulinna, P., \& Garrahy, A. (2003). "This is kind of giving a secret away": Students' perspectives on effective class management. Teaching and Teacher Education, 19, 435-444.

Creswell, J. W. (2008). Educational research (3 ${ }^{\text {rd }}$ Ed.). New Jersey: Pearson Education Ltd.

Creswell, J. W. (2009). Research design: Qualitative, quantitative, and mixed methods approach ( $3^{\text {rd }}$ Ed.). Los Angeles, London: Sage. 
Crose, B. (2011). Internationalization of the higher education classroom: Strategies to facilitate intercultural learning and academic success. International Journal of Teaching and Learning in Higher Education, 23(3), 388-395.

Crosnoe, R., Johnson, M., \& Elder, G. (2004). International bonding in school: behavioural and contextual correlates of student-teacher relationship. Sociology of Education, 77, $60-81$.

Dai, N. D. (2006). "Vietnam” in higher education in Southeast Asia. Bangkok: Bangkok UNESCO 2006, 219-250.

Đại học Việt nam thêm hấp dẫn với sinh viên ngoại (Higher education in Vietnam gradually more attractive to international students). (2011). Retrieved February 7, 2012, from http://hoinguoiviet.ru/news/Giao-duc/Dai-hoc-Viet-Nam-them-hap-danvoi-sinh-vien-ngoai-1509/

Danh sách quốc gia theo số dân (Lists of countries according to the population). (2011). $\begin{array}{llll}\text { Retrieved } \quad \text { February } & \text { 2012, from }\end{array}$ http://vi.wikipedia.org/wiki/Danh_s\%C3\%A1ch_qu\%E1\%BB\%91c_gia_theo_s\%E1 $\%$ BB\%91_d\%C3\%A2n

Dao, D. Q. (2003). Firmly holding to the socialist orientation. Retrieved 7 February, 2012 from from http://www.cpv.org.vn/cpv/Modules/News/NewsDetail.aspx?co_id=30107\&cn_id=14 4322\#

Đẩy mạnh hợp tác Việt - Lào phát triển nguồn nhân lực chất lượng cao (Strengthening the cooperation of Viet - Laos for the human resources development). (2010). Retrieved July 13, 2011, from http://gdtd.vn/channel/3005/201107/Day-mang-hop-tac-phattrien-nguon-nhan-luc-chat-luong-cao-Viet--Lao-1949540/

Đến Việt Nam du học (Study abroad in Vietnam). (2011). Retrieved September 13, 2011, from http://www.mangduhoc.com.vn/du-hoc-hoc-bong/news/Cau-chuyen-duhoc/Den-Viet-Nam-du-hoc-6814/ 
Denscombe, M. (2001). The good research guide. Buckingham: Oxford University Press.

Denzin, N. K., \& Lincoln, Y. K. (2000). Handbook of qualitative research (2 ${ }^{\text {nd }}$ Ed.). Thousand Oaks, CA: Sage Publications.

Denzin, N. K. (2009). The research act: A theoretical introduction to sociological methods. Piscataway, NJ: Aldine Transactions Publishers.

Duanmu, L. J., \& Chen, W. (2009). Determinants of international students' academic performance: A comparison between Chinese and other international students. Journal of Studies in International Education, 20(10), 1-17.

Duff, A., Boyle, E., Dunleavy, K., \& Ferguson, J. (2004). The relationship between personality: An approach to learning and academic performance. Personality and Individual Differences, 36, 1907-1920.

Elson-Green, J. (2007). Looking beyond the western perspective. Campus Review, 7.

Flick, U. (1992). Triangulation revisited: Strategy of validation or alternative. Journal for the Theory of Social Behaviour, 22(2), 175-197.

Flick, U. (2009). An introduction to qualitative research. London: Sage Publications.

Freire, P. (2000). Pedagogy of the oppressed, 30 ${ }^{\text {th }}$ anniversary edition. New York: Continuum Publishing Company.

Fry, W. G. (2009). Higher education in Vietnam. In Y. Hirosato \& Y. Kitamura (Eds.), The political economy of educational reforms and capacity development in Southeast Asia: Cases of Cambodia, Laos and Vietnam, (pp. 237-261). Tokyo, Japan: Springer.

Furnham, A. (2004). Foreign students' education and culture shock. The Psychologist, $17(1), 16-19$.

Gall, M. D., Borg, W. R., \& Gall, J. P. (1996). Educational research (6 ${ }^{\text {th }}$ Ed.). White Plains: Longman. 
Gibbs, G. R. (2007). Analysing qualitative data. (Book 6 of the Sage qualitative research kit). London: Sage.

Glaser, B. (1992). Basics of grounded theory analysis. Mill Valley, CA: Sociology Press.

Glaser, B., \& Strauss, A. (1967). The discovery of grounded theory: Strategies for qualitative research. Chicago: Aldine Pub. Co.

Gonzalez, N., Moll, L., \& Amanti, C. (2005). Funds of knowledge: Theorizing practices in households and classrooms. Mahwah, NJ: Lawrence Erbaum.

Grant, C., \& Sleeter, C. (1986). Race, class and gender in education research: An argument for integrative analysis. Review of Education Research, 56, 195-211.

Gu, Q., Schweisfurth, M., \& Day, C. (2009). Learning and growing in a 'foreign' context: Intercultural experiences of international students. Compare: A Journal of Comparative and International Education, 40(1), 7-23.

Hall, C., \& Kidman, J. (2004). Teaching and Learning: Mapping the contextual influences. International Higher Education, 5(3), 331-343.

Hamre, B. K., \& Pianta, R. (2001). Early teacher-child relationships and the trajectory of children's school outcomes through eighth grade. Child Development, 72(2), 625638.

Hamre, B. K., Pianta, R. C., Downer, J. T., \& Mashburn, A. J. (2008). Teachers' perceptions of conflict with young students: Looking beyond problem behaviours. Social Development, 17(1), 115-136.

Hatch, J. A. (2002). Doing qualitative research in education settings. Albany. New York: SUNY Press.

Hayden, M., \& Lam, Q. T. (2007). Institutional autonomy for higher education in Vietnam. Higher Education Research \& Development, 26(1), 73-85. 
Hellison, D. (2003). Teaching responsibility through physical education. Champaign, IL: Human Kinetics.

Hellsten, M., \& Prescott, A. (2004). Learning at university: The international students' experience. International Education Journal, 5, 344-351.

Hill, J., \& Hawk, K. (2000). Making a difference in the classroom: Effective teaching practice in low decile, multicultural schools. Wellington: Ministry of Education.

Hirosato, Y. \& Kitamura, Y. (2009). An integrated framework for analyzing education reforms and capacity development in developing countries: why, how, and for whom? In Y. Hirosato \& Y. Kitamura (Eds.), The political economy of educational reforms and capacity development in Southeast Asia: Cases of Cambodia, Laos and Vietnam, (pp. 7-21). Tokyo, Japan: Springer.

Holmes, P. (2005). Ethnic Chinese students' communication with cultural others in a New Zealand university. Communication Education, 54(4), 289-311.

Hơn 1.100 sinh viên Campuchia đang học tập tại Việt Nam (Over 1,100 Cambodian students studying in Vietnam). (2011). Retrieved February 7, 2012, from http://www.baomoi.com/Hon-1100-luu-hoc-sinh-Campuchia-hoc-tap-tai-VietNam/107/5395380.epi

Hullena, T. (2008). Student-teacher relationships/rapport in physical education: A perspective from New Zealand secondary schools. Unpublished Master of Education thesis. Victoria University of Wellington, New Zealand.

Hullena, T., \& Hullena, V. (2010). Student-teacher relationships: A pathway for at risk youth. In V., Green \& S., Cherrington, (Eds.), Delving into diversity: An international exploration of issues of diversity in education (pp. 9-20). Nova Science Publisher: New York.

Johnson, B., \& Christensen, L. (2008). Educational research: Quantitative, qualitative, and mixed approaches $\left(3^{\text {rd }}\right.$ Ed.). Thousand Oaks, CA: Sage Publications. 
Johnson, B., \& Christensen, L. (2012). Educational research ( $4^{\text {th }}$ Ed.). Thousand Oaks, CA: Sage Publications.

Kamibeppu, T. (2009). Education reform context and process in Vietnam. In Y. Hirosato \& Y. Kitamura (Eds.), The political economy of educational reforms and capacity development in Southeast Asia: Cases of Cambodia, Laos and Vietnam, (pp. 169189). Tokyo, Japan: Springer.

Keng, C. (2009). Basic education in Cambodia. In Y. Hirosato \& Y. Kitamura (Eds.), The political economy of educational reforms and capacity development in Southeast Asia: Cases of Cambodia, Laos and Vietnam, (pp. 131-152). Tokyo, Japan: Springer

Kidman, J. (1994). Dialogues with students: Some learning experiences of Maori Undergraduate students at Victoria University. Wellington: Victoria University of Wellington.

Kim, Y. (2007). Difficulties in quality doctoral academic advising: Experiences of Korean students. Journal of Research in International Education, 6(2), 171-193.

Knight, J. (2007). Internationalization: Concepts, complexities and challenges. International Handbook of Higher Education, 207-227.

Lam, Q. T. (2004). Vietnam. In Handbook on diplomas, degrees and other certificates in higher education in Asian and Pacific ( $2^{\text {nd }}$ Ed.). Bangkok: UNESCO.

Le, P. H. H. (2004). A socio-cultural analysis of learning English in unassisted and assisted peer group at university in Vietnam. Unpublished PhD thesis. Victoria University of Wellington, New Zealand.

Lee, E. L. (2002). Self-perceived language competence and East Asian students' oral participation in American university classrooms. Unpublished Master's thesis. Western Michigan University, Michigan.

Lee, E. L. (2007). Linguistic and cultural factors in East Asian students' oral participation in U.S. university classrooms. International Education, 36(2), 27-47. 
Lee, J., \& Rice, C. (2005). Welcome to America? International perceptions of discrimination. Higher Education, 53(3), 381-409.

Liên Hiệp Các Tổ Chức Hữu Nghị Việt Nam (The Vietnam Union of Friendships Organization). (2010). Hội nghị sinh viên Lào 2009-2010 (Annual meeting of Laotian students in Vietnam). Retrieved February 7, 2012, from http://www.vietpeace.org.vn/express/express_detail_v.aspx?id1=7\&id2=35\&id3=126 1

Luong, H. V. (2003). Postwar Vietnam: Dynamics of a transforming society. Oxford and Singapore: Bowman \& Lichfield, Institute of Southeast Asian Studies.

Luu, T. H. (2011). Hạ thấp Đại học (Universities downgraded). Retrieved October 14, 2011, from http://tuoitre.vn/Giao-duc/460354/Ha-thap-dai-hoc.html

Marr, T. (2005). Language and the capital: A case study of English "Language shock among Chinese students in London. Language Awareness, 14, 239-253.

May, T. (2001). Social research: Issues, methods and process ( $2^{\text {nd }} E d$.). Buckingham: Open University Press.

Merriam, S. B. (1988). Case study research in education: A qualitative approach. San Francisco: Jossey - Bass Publishers.

Merriam, S. B., \& Simpson, E. L. (2000). A guide to research for educators and trainers of adults. Mabalar, Fla: Krieger Pub.

Ministry of Education \& Training. (2006). Educational Laws of Vietnam 2005. Retrieved February 7, 2012, from http://www.moet.gov.vn/?page=6.3\&type=documents $\&$ view $=2741$

Ministry of Education \& Training. (2010). Annual report of the education statistics in Vietnam 2010-2011. Retrieved June 30, 2011, from http://www.moet.gov.vn/?page=11.10\&view=3544. 
Ministry of Foreign Affairs of Vietnam. (2007). Foreign Policy. Retrieved February 7, 2012, from http://www.mofa.gov.vn/en/cs_doingoai/

Ministry of Foreign Affairs of Vietnam. (2007). List of countries which maintain diplomatic relations with the Socialist Republic of Vietnam (as at April, 2010). Retrieved February 7, 2012, from http://www.mofa.gov.vn/en/cn_vakv

Ministry of Foreign Affairs of Vietnam. (2007). Vietnam and international organizations. Retrieved December 10, 2011, from http://www.mofa.gov.vn/en/ctc_quocte.

Morrison, M., \& Moir, J. (1998). The role of computer software in the analysis of qualitative data: Efficient clerk, research assistant or Trojan horse? Journal of Advanced Nursing, 28 (1), 106-116.

Mức học phí đại học cao nhất 340.000 đồng/ tháng (the highest tuition fee for higher education is 340.000 VND/month). (2010). Retrieved February 7, 2012, from http://dantri.com.vn/c25/s25-396047/muc-hoc-phi-dai-hoc-cao-nhat-la-340000dongthang.htm

Năm trường Đại học, Cao đẳng có vốn đầu tư ở nước ngoài (Five higher education institutions with foreign invested captal. (2010). Retrieved February 7, 2012, from http://www.baomoi.com/Home/DaoTao/hanoimoi.com.vn/5-truong-dai-hoc-caodang-co-von-dau-tu-nuoc-ngoai-tai-Viet-Nam/3858474.epi

Năm 2011, dân số Việt Nam đạt gần 88 triệu người (The population of Vietnam reached nearly 88 million in 2011). (2011). Retrieved December 30, 2011, from http://laodong.com.vn/Tin-Tuc/Nam-2011-dan-so-Viet-Nam-dat-gan-88-trieunguoi/71452

New Zealand Association for Research in Education. (2010). NZARE ethical guidelines 2010. Retrieved February 7, 2012, from http://www.nzare.org.nz/pdfs/NZAREEthicalGuidelines2010.pdf

Nghị dịnh thu về hợp tác giáo dục Việt Nam - Campuchia giai đoạn 2011-2015 (The protocol of cooperation of education between Vietnam and Cambodia 2011-2015) 
(2011). Retrieved April 29, 2011, from http://www.gdtd.vn/channel/3005/201104/Nghi-dinh-thu-ve-hop-tac-GD-Viet-NamCampuchia-giai-doan-20112015-1945259/.

Nguyen, K. D. (2003). International practices in quality assurance for higher education teaching and learning: Prospects and possibilities for Vietnam. Unpublished PhD thesis. The University of Melbourne.

Nguyen, K. V. (1993). Vietnam: A long history. Hanoi: The Gio Publishers.

Nguyen, M. B. (2011). How teachers perceive the on-going influence of a portfolio on a reflection: A case study. Unpublished Master of Education thesis. Victoria University of Wellington, New Zealand.

Nhật Bản - thu hút nhiều du học sinh (Japan attracts many international students). (2011). Retrieved February 7, 2012, from http://treonline.com/news/17/detail/9753/nhat-banthu-hut-nhieu-du-hoc-sinh.aspx

Noddings, N. (1992). Caring: A feminist perspective. In K. Strike \& P. Ternasky (Eds.), Ethics for professionals in education: Perspectives for preparation and practice (pp. 43-53). New York: New York Teachers' College Press.

Nông sản thế giới tháng 4 (Agricultural products all over the word in April). 2011. $\begin{array}{lllll}\text { Retrieved } & \text { April } & 30, & 2012, & \text { from }\end{array}$ http://www.vinanet.com.vn/wce/view_search.aspx?ZoneID=290\&ContentID=190180

Ogawa, K. (2009). Higher education in Lao PRD. In Y. Hirosato \& Y. Kitamura (Eds.), The political economy of educational reforms and capacity development in Southeast Asia: Cases of Cambodia, Laos and Vietnam, (pp. 283-301). Tokyo, Japan: Springer.

Olanira, B. (1993). International students' network patterns and cultural stress. What really counts. Communication Research Reports, 10, 69-83.

Olsen, A. (2008). International mobility of Australia universities students. Journal of Studies in International Education, 12(4), 364-374. 
Onsman, A. (2010). Cross-border teaching and globalization of higher education: Problems of funding, curriculum quality, and international accreditation. New York: The Edwin Mellen Press, Ltd.

Pallant, J. (2007). SPSS Survival manual (3 ${ }^{\text {rd }}$ Ed.). Sydney, Australia: Open University Press.

Pallant, J. (2010). SPSS Survival manual (4 $4^{\text {th }}$ Ed.). Sydney, Australia: Open University Press.

Peguero, A. A., \& Bondy, J. M. (2011). Immigration and students' relationship with teachers. Education and Urban Society, 43(2), 165-183.

Pham, L. H., \& Fry, G. W. (2004). Education and economic, political, and social change in Vietnam. Educational Research for Policy and Practice, 3, 199-222.

Pham, L. H. (2009). Tù Hà Nội đến Viêng xay và Phnôm Pênh hồi kí (Reminiscences on the journey from Hanoi to Phnom Penh). Retrieved December 10, 2011, from http://lichsu.hnue.edu.vn/index.php?option=com_content $\&$ view=article\&id=86:t-hani-n-vieng-xay-va-phnom-penh-hi-ki\&catid=35:tin-khoa-hc $\&$ Itemid=60

Pham, M. H. (1998). Vietnam's education: The current position and future prospect. Hanoi: The Gio Publishers.

Pham, V. K., (2008). Vietnamese agriculture: One year after entering WTO. East Asia Economic Research Group Discussion, Paper No.15, June 2008, School of Economics, The University of Queensland, Brisbane, Australia.

Phetsiriseng, I. (2009). Educational reform context and process in Lao PRD: Focusing on basic education. In Y. Hirosato \& Y. Kitamura (Eds.), The political economy of educational reforms and capacity development in Southeast Asia: Cases of Cambodia, Laos and Vietnam, (pp. 265-282). Tokyo, Japan: Springer.

Pianta, R. (1999). Enhancing relationships between children and teachers. Washington: American Psychological Association. 
Pianta, R. (2006). Classroom management and relationships between children and teachers: Implications for research practice. In C. Evertson \& C. Weistein (Eds.), Handbooks of classroom management (pp. 685-709). London: Lawrence Erlbam.

Ramburuth, P., \& Birkett, W. P. (2000). Language, learning and diversity project. Sydney: Faculty of Commerce and Economics, UNSW.

Ramburuth, P., \& Tani, M. (2009). The impact of culture on learning: Exploring student perceptions. Multicultural Education \& Technology Journal, 3(3), 182-195.

Robert, A., Chou, P., \& Ching, G. (2009). Contemporary trends in East Asian higher education: Dispositions of international students in a Taiwan university. Higher Education, 59, 149-166.

Runckel, C. (2009). The education system in Vietnam. Retrieved February 7, 2012 from http://www.business-in-asia.com/vietnam/education_system_in_vietnam.html

Ryan, J. (2000). A guide to teaching international students. Oxford: Oxford Centre for Staff and Learning Development.

Ryan, J., \& Carol, J. (2005). 'Canaries in the coalmine': International students in Western universities. In J. Carroll \& J. Ryan (Eds.), Teaching international students (pp. 310). London, DC: Routledge.

Sakthivel, T. (2003). Problems faced by overseas research students. Pharmacy Education, $3,217-222$.

Schuitema, J., \& Veugelers, W. (2010). Multicultural contacts in higher education: A case study of an exchange project between different ethnic groups. Educational Studies, 37(1), 101-114.

Schweisfurth, M., \& Gu, Q. (2009). Exploring the experiences of international students in UK higher education: Possibilities and limits of interculturality in university life. Intercultural Education, 20(5), 463-473. 
Seidman, I. (2006). Interviewing as qualitative research: A guideline for researchers in education and the social science. New York: Teachers College Press.

Shank, G. D. (2005). Qualitative Research: A personal skills approach (2 ${ }^{\text {nd }}$ Ed.). Columbus. OH: Merrill/Prentice Hall.

Silverman, D. (2010). Doing qualitative research ( $3^{\text {rd }}$ Ed.). London, England: SAGE Publications Ltd.

Singh, P., \& Doherty, C. (2002). Navigating cultural sensibilities: Respect and provocation as pedagogical partners. Paper presented at the Australian Association for Research in Education Conference, University of Queensland, Brisbane.

Sinh viên Lào sang Việt Nam học ngày càng tăng (The number of Laotian students enrollment in higher education has been increasing). (2008). Retrieved February 7, 2012 from http://www.thanhnien.com.vn/news/Pages/200808/227155.aspx

Sloper, D., \& Le, T. C. (Eds.) (1995). Higher education in Vietnam: Change and response. Singapore: Institute of South East Asian Studies, National University of Singapore.

Smart, D., Volet, S., \& Ang, G. (2000). Fostering social cohesion in universities: Bridging the cultural divide. Canberra: Australian Education Foundation, Department of Education, Training and Youth Affairs.

Smith, J. A. (2008). Qualitative Psychology: A practical guide to research methods. Los Angeles, CA: SAGE Publications.

Strang, K. D. (2008). Quantitative online students profiling to forecast academic outcomes from learning styles using dendrogram decision models. Multicultural Education \& Technology Journal, 2(4), 215-244.

Strang, K. D. (2010). Global culture, learning styles, and outcomes: An interdisciplinary empirical study of international university students. Intercultural Education, 21(3), 519-533. 
Strauss, A., \& Corbin, J. (1998). Basic qualitative research: Techniques and procedures for developing grounded theory. London: Sage publications, Inc.

Strunk, D. R., \& Chang, E. C. (1999). Distinguishing between fundamental dimensions of individualism-collectivism: Relations to socio-political attitudes and beliefs. Personality and Individual Differences, 27, 665-671.

Tarlow, B. (1996). Caring: A negotiated process that varies. In S. Gordon, P. Benner, \& N. Noddings (Eds.), Caregiving: Readings in knowledge, practice, ethics and polictics (pp. 56-82). Philadelphia: University of Pennsylvania.

Tapper, J. (1996). Exchange patterns in the oral discourse of international students in university classrooms. Discourse Processes, 22, 25-55.

Tran, H., \& Ha, A. T. (2000). A brief chronology of Vietnam's history. Hanoi: The Gio Publishers.

Tran, T. L. (2011). Committed, face-value, hybrid or mutual adaptation? The experiences of international students in Australian higher education. Educational Review, 63(1), 79-94.

Tu, W. (1993). Way, learning, and politics: Essays on the Confucian intellectual, Albany, NY: State University of New York.

UNESCO. (2006). Higher education in South East Asian. Bangkok: UNESCO Asian and Pacific Regional Bureau for Education.

Unyapho, P. (2011). A phenomenological study: Educational experiences of international doctoral students of education at Midwestern University. Unpublished $\mathrm{PhD}$ thesis. Southern Illinois University Carbondale, The United States.

USAID. (2005). About Cambodia. Retrieved February 7, 2012, from http://www.equip123.net/equip1/escup/aboutcambodia.htm

Vang, C. T. (2010). An educational psychology of methods in multicultural education. New York: Peter Lang Publishing. 
Vì sao sinh viên nước ngoài tới Việt Nam du học? (Why international students study higher education in Vietnam?). (2011). Retrieved November 7, 2011, from http://www.mangduhoc.com.vn/du-hoc-hoc-bong/news/Cau-chuyen-du-hoc/Vi-saosinh-vien-nuoc-ngoai-toi-Viet-Nam-du-hoc-7073/

Vietnam Business News. Living information and cost in Vietnam. (2010). Retrieved February 7, 2012, from http://vietnambusiness.asia/living-information-and-cost-invietnam/.

Vietnam International Education Development. (2011). The annual report of international students in Vietnam. HaNoi: Nguyen.

Vietnam's quest for role model. (2008). Retrieved February 7, 2012, from http://www.economist.com/node/11041548.?story_id=E1_TTDQTVQR.

Wallace, R. M. (2011). A qualitative examination of how equal opportunity and diversity factors are communicated to African American airmen. Unpublished Master's thesis. University of South Alabama, The United States.

Wentzel, K. (1997). Student motivation in middle school: The role of perceived pedagogical caring. Journal of Education Psychology, 3, 411-419.

Woodside, G. A. (2010). Case study research. United Kingdom: Emaral Group Publishing Limited.

World Desk References. (2004). Cambodian. Retrieved February 7, 2012, from http://dev.prenhall.com/divisions/hss/worldreference/KH/education.html

World Desk References. (2004). Laos. Retrieved February 7, 2012, from http://dev.prenhall.com/divisions/hss/worldreference/LA/introduction.html

World Desk References. (2004). Vietnam. Retrieved on February 7, 2012, from http://dev.prenhall.com/divisions/hss/worldreference/VN/introduction.html 
World Education News and Reviews. (2007). International student mobility: Pattern and trends. $\quad$ Retrieved November $\quad 10, \quad 2011, \quad$ from http://www.wes.org/educators/pdf/StudentMobility.pdf

Zhadko, O. (2011). Experiences of international students using information communication technology in college in the United States. Unpublished $\mathrm{PhD}$ thesis. University of Missouri-St. Louis, the United States.

Zhang, Y., \& Mi, Y. (2010). Another look at the language difficulties of international students. Journal of Studies in International Education, 14(4), 371-388. 


\section{APPENDICES}

\section{Appendix A: Information sheet (Questionnaire)}

\section{TITLE:}

Cambodian and Laotian students' experiences of language barriers, cultural differences, and teacher-student rapport in a university in Vietnam:

A grounded theory approach.

My name is MyNgoc Doan and I am a Master of Education student at Te Kura Māori School, Faculty of Education, Victoria University of Wellington. The topic of my proposed thesis is "Cambodian and Laotian students' experiences of language barriers, cultural differences, and teacher-student rapport in a university in Vietnam: A grounded theory approach". The main aim of this study is to explore the academic experiences of Laotian and Cambodian students. Questionnaires and semi-structured interviews will be used in this research. The researcher will use this research to recommend new approaches aimed at improving the academic experience of Laotian and Cambodian students at An Giang University (AGU). This research has been assessed and approved by Victoria University Faculty of Education Ethics Committee.

I would like to invite you to take part in answering a questionnaire. It will take about ten minutes to complete the questionnaire. This questionnaire is designed to collect information on your background; your expectations, levels of satisfaction, and recommendation; your experiences and perceptions of the effect of different language and culture adaptation capacity on your relationships with teachers and your academic achievement.

Your participation in this project is voluntary. Your decision to participate will not affect your grades in any way. I would like your permission to use the information which you provide in my thesis or in publications that arise from this research. At no time when reporting on the findings of this study will your identity be disclosed. All the information I collect will be kept at a secure location, and will be only available to my supervisor, Dr. Joanna Kidman, and myself. All collected data will be stored securely and destroyed two years after the completion of the thesis. The final thesis will be deposited in the Victoria University of Wellington Library and a conference paper and journal article may be published using the data. 
If you have any questions or would like to receive further information about this study, please do not hesitate to contact me via email: myngoc.doan@vuw.ac.nz or my supervisor, Dr. Joanna Kidman at Joanna.Kidman@vuw.ac.nz, or by mail at Te Kura Māori School, Faculty of Education, Victoria University of Wellington, PO Box 17 - 310, Karori, Wellington 6147.

In case you would like to make a complaint, please contact the Chair of Victoria University Human Ethics Committee, Dr. Allison Kirkman at allison.kirkman@vuw.ac.nz or phone 044635676.

MyNgoc Doan 
Appendix B: Participant consent form (Questionnaire)

\section{TITLE:}

Cambodian and Laotian students' experiences of language barriers, cultural differences, and teacher-student rapport in a university in Vietnam:

A grounded theory approach.

\section{Please tick the boxes if you agree with the following statements:}

․ I have been provided with adequate information relating to the nature and objectives of this research project. I have understood that information and have been given the opportunity to seek further clarification or explanations.

․ I understand that I may withdraw from this study at any time before the analysis of data starts without providing reasons, in which case all the information that I have provided will be destroyed.

․ I understand that any information I provide will be kept at a secure location, and will only be available to the researcher and the supervisor. I give permission for information which I provide to be used in a thesis or any other publications that arise from this research.

․ I understand that my identity will not be disclosed to any person who is not the researcher.

․ I agree to complete the questionnaire.

․ I would be willing to be invited to participate in an one hour interview.

Please indicate your preference for the following statement by ticking one of the options:

I would like to receive a summary of the results of this project when it is completed and therefore I will provide my mailing or e-mail address. $\quad Y_{\square} \quad N_{\square}$

Name

Mailing or E-mail Address

Signature:

Date: 
Appendix C: The questionnaire

\section{TITLE:}

Cambodian and Laotian students' experiences of language barriers, cultural differences, and teacher-student rapport in a university in Vietnam:

A grounded theory approach.

\section{Please choose appropriate answers}

I. This part will elicit the participants' background information.

1. How long have you been studying Vietnamese?
a. One year
b. Two years
c. Three years
d. Other:

2. How long have you been studying at An Giang University (AGU)?
a. One year
b. Two years
c. Three years
d. Other:

3. What programme are you studying at AGU?

a. Undergraduate programme

b. Vietnamese proficiency programme

c. Other:

4. What is your nationality?
a. Laotian
b. Cambodian
c. Other:..................

5. What age range are you in?
a. $18-22$
b. 23-27.
c. $28-32$
d. Other: 
II. This part will elicit the participants' experiences and perceptions of the effect of different language on their relationships with Vietnamese teachers and academic achievement when studying at AGU.

6. You are confident in your Vietnamese language competence when you are studying at AGU.
A. Strongly agree
b. Agree
c. Disagree
d. Strongly disagree

7. Do you have any difficulties in participating in classes at AGU?

a. Yes, what are they?

b. No

8. Do you think your Vietnamese language competence will affect your academic achievement? a. Yes, why?

b. No, why not?

9. Do you have any difficulties in communicating with Vietnamese teachers?

a. Yes, what are they?

b. No

10. Do you think your Vietnamese language competence will affect your relationships with Vietnamese teachers?

a. Yes, why?

b. No, why not? 
11. You have established good relationships with Vietnamese teachers at AGU.
A. Strongly agree
b. Agree
c. Disagree
d. Strongly disagree

III. This part will elicit the participants' experiences and perceptions of the effect of different culture on their relationships with Vietnamese teachers and their academic achievement when studying at AGU.

12. Have you had any difficulties in adapting to Vietnamese culture while you have been studying at AGU?

a.Yes, what are they?

b. No, why not?

13. Vietnamese teachers help you to understand the differences between your culture and Vietnamese culture.
A. Strongly agree
b. Agree
c. Disagree
d. Strongly disagree

14. Do cultural differences affect your relationships with Vietnamese teachers?

a. Yes, why?

b. No

15. Do cultural differences negatively affect your academic achievement?

a. Yes, why?

b. No, why not? 
16. Do you think cultural differences may affect your relationships with Vietnamese teachers?
a. Yes
b. No

IV. This part will elicit the participants' experiences and perceptions of their academic achievement.

17. How would you describe your academic achievement based on the report of grades?
a. $\mathrm{A}^{-}-\mathrm{A}^{+}$
b. $\mathrm{B}^{-}-\mathrm{B}^{+}$
c. $\mathrm{C}-\mathrm{C}^{+}$
d. Other:

18. How would you describe your academic achievement based on your self-evaluation?
a. Excellent
b. Good
c. Fair
d. Other:

19. Are you satisfied with your academic achievement at AGU?

a. Yes, why?

b. No, why not?

20. Who would you like to seek help from when you have difficulties in your study?
a. Vietnamese teachers
b. Vietnamese friends
c. Laotian friends
d. Cambodian friends
e. Other:

21. In your experience, who has been most helpful to you in your studying?

a. Vietnamese teachers

b. Vietnamese friends 

c. Laotian friends
d. Cambodian friends
e. Other:

22. Please range five factors from 1-most important to 5-least important which may affect your academic achievement.

a. Good language competency

b. Good adaptation to cultural differences

c. Good relationships with Vietnamese teachers

d. Good self-study capacity

e. Interest in the subject

23. Is there anything that you would like us to think more about? Please indicate

Thank you for your participation in this study! 
Appendix D: Information sheet (Interview)

\section{TITLE:}

Cambodian and Laotian students' experiences of language barriers, cultural differences, and teacher-student rapport in a university in Vietnam:

A grounded theory approach.

My name is MyNgoc Doan and I am a Master of Education student at Te Kura Māori School, Faculty of Education, Victoria University of Wellington. The topic of my proposed thesis is "Cambodian and Laotian students' experiences of language barriers, cultural differences, and teacher-student rapport in a university in Vietnam: A grounded theory approach". The main aim of this study is to explore the academic experiences of Laotian and Cambodian students. Questionnaires and semi-structured interviews will be used in this research. The researcher will use this research to recommend new approaches aimed at improving the academic experiences of Laotian and Cambodian students at An Giang University (AGU). This research has been assessed and approved by Victoria University Faculty of Education Ethics Committee.

I would like to invite you to take part in an individual interview that will take thirty minutes to an hour to complete. I would like to record the interview with your permission. This interview is designed to collect information on: (a) students' expectation, levels of satisfaction, and recommendations while studying at AGU; (b) students' experiences of different culture and language when studying at AGU; (c) students' experiences and perceptions of the teacher-student relationships and academic achievement.

Your participation in this project is voluntary. Decision to participate will not affect your grades in any way. I would like your permission to use the information which you provide in my thesis or in publications that arise from this research. At no time when reporting on the findings of this study will your identity be disclosed. All the information I collect will be kept at a secure location, and will be only available to my supervisor, Dr. Joanna Kidman, and myself. You will have the opportunity to review interview notes. All interview notes will be stored securely and destroyed two years after the completion of the thesis. The final thesis will be deposited in the Victoria University of Wellington Library and a conference paper and journal article may be published using the data. 
I can provide you with a summary of my research findings at your request. Please indicate your preference in the consent form. You can withdraw at any stage before the process of analyzing collected data starts. I will inform you when this process is about to begin

If you have any questions or would like to receive further information about this study, please do not hesitate to contact me via email: myngoc.doan@vuw.ac.nz or my supervisor, Dr. Joanna Kidman at Joanna.Kidman@vuw.ac.nz, or by mail at Te Kura Māori School, Faculty of Education, Victoria University of Wellington, PO Box 17 - 310, Karori, Wellington 6147.

In case you would like to make a complaint, please contact the Chair of Victoria University Human Ethics Committee, Dr. Allison Kirkman at allison.kirkman@vuw.ac.nz or phone 044635676.

MyNgoc Doan 
Appendix E: Consent to participants in the research (Interview)

\section{TITLE:}

Cambodian and Laotian students' experiences of language barriers, cultural differences, and teacher-student rapport in a university in Vietnam:

A grounded theory approach.

Please tick the boxes if you agree with the following statements:

ㅁ I have been provided with adequate information relating to the nature and objectives of this research project. I have understood that information and have been given the opportunity to seek further clarification or explanations.

․ I understand that I may withdraw from this study at any time before the process of data analyzing starts without providing reasons, in which case all the information that I have provided will be destroyed.

ㅁ I understand that any information I provide will be kept at a secure location, and will only be available to the researcher and the supervisor. I give permission for information which I provide to be used in a thesis or any other publications that arise from this research.

․ I understand that my identity will not be disclosed to any person who is not the researcher.

․ I agree to participate in the one hour interview

․ I allow this interview to be recorded.

Please indicate your preferences for the following statements by ticking one of the options:

I would like to check the transcripts of my interview and I will return any amendments within two weeks. Y

$\mathbf{N}$

I would like to receive a summary of the results of this project when it is completed and therefore I will provide my mailing or e-mail address.

$\begin{array}{ll}\mathbf{Y} & \mathbf{N}\end{array}$

Name:

Mailing or E-mail Address:

Signature:

Date: 


\section{Appendix F: Interview guide}

\section{TIILE:}

Cambodian and Laotian students' experiences of language barriers, cultural differences, and teacher-student rapport in a university in Vietnam:

A grounded theory approach.

Interviews focus on the following issues: (a) students' expectation, levels of satisfaction, and recommendation when studying at AGU; (b) students' experiences of different culture and language when studying at AGU; (c) students' experiences and perceptions of teacher-student relationships and their academic achievement. Interviewees will be asked to explain more about their answers in the questionnaires.

\section{QUESTIONS FOR INTERVIEW}

The following questions are used as a guide of the interviews. Based on the elaboration of the interviewees, further discussion may be raised. The order of the questions is flexible.

1. What did you expect from studying at AGU?

2. Have your expectations been met?

3. What do you like most about studying at AGU?

4. Have you ever felt uncomfortable when you are in classes at AGU?

5. If yes, what made you feel uncomfortable?

6. What might you suggest to make these classes more effective?

7. What are some significant differences between Vietnamese culture and yours?

8. Do these differences in cultures negatively or positively affect your academic life? Why?

9. Are you confident in your academic Vietnamese language competence when you are studying at AGU?

10.Do you think teacher-student relationships will affect your academic achievement? Why (not)?

11. What do you suggest to improve the relationships between you and Vietnamese teachers? 
12. When you have difficulties in your study, will you ask your Vietnamese teachers for help? Why (not)?

13. What do you suggest to improve your academic achievement?

\section{Thank you for your participation in this study!}




\section{Appendix G: Information sheet (For the Head of Department)}

\section{TITLE:}

Cambodian and Laotian students' experiences of language barriers, cultural differences, and teacher-student rapport in a university in Vietnam:

A grounded theory approach.

My name is MyNgoc Doan and I am a Master of Education student at Te Kura Māori School, Faculty of Education, Victoria University of Wellington. The topic of my proposed thesis is "Cambodian and Laotian students' experiences of language barriers, cultural differences, and student-teacher rapport in a university in Vietnam: a grounded theory approach". The main aim of this study is to explore the academic experiences of Laotian and Cambodian students. The researcher will use this research to recommend new approaches aimed at improving the academic experiences of Laotian and Cambodian students at An Giang University (AGU). This research has been assessed and approved by Victoria University Faculty of Education Ethics Committee.

Data collection will include questionnaires and semi-structured interviews. All international students will be selected to participate in questionnaires. It will take them 10 minutes to complete the questionnaire. This questionnaire is designed to collect information on (a) students' background, expectation, levels of satisfaction, and recommendation; (b) students' experiences and perceptions of the effect of language and culture adaptation on students' relationship with teachers and their academic achievement; (c) students' experiences and perceptions of their academic achievement. Based on students' academic reports, six international students will be purposively selected to participate in semi-structured interviews. It will take 30 minutes to an hour to complete the semistructured interview. I would like to record the interview with students' permission. This interview is designed to collect information on: (a) students' expectation of studying at AGU; (b) students' experiences of different culture and language when studying at AGU; (c) students' experiences and perceptions of the teacher-student relationship and academic achievement.

Students' participation in this project is voluntary. Their decision to participate will not affect their grades in any way. I would like to use the information that students' provide in my thesis or in publications that arise from this research. At no time when reporting on the findings of this study will students' identity be disclosed. All the information I collect will be kept at a secure location, and 
will be only available to my supervisor, Dr. Joanna Kidman, and myself. All interview notes will be stored securely and destroyed two years after the completion of the thesis. The final thesis will be deposited in the Victoria University of Wellington Library and a conference paper and journal article may be published using the data.

I can provide you with a summary of my research findings at your request. Please indicate your preference in the consent form.

I sincerely thank you for reading this. I eamestly ask for your permission to allow me to conduct research with international students at AGU. Please complete the enclosed consent forms to show that you will allow me to conduct this research.

If you have any questions or would like to receive further information about this study, please do not hesitate to contact me via email: myngoc.doan@vuw.ac.nz or my supervisor, Dr. Joanna Kidman at Joanna.Kidman@vuw.ac.nz , or by mail at Te Kura Māori School, Faculty of Education, Victoria University of Wellington, PO Box 17 - 310, Karori, Wellington 6147. In case you would like to make a complaint, please contact the Chair of Victoria University Human Ethics Committee, Dr. Allison Kirkman at allison.kirkman@vuw.ac.nz or phone 044635676.

MyNgoc Doan 
Appendix H: Research consent form (For the Head of Department)

\section{TITLE:}

Cambodian and Laotian students' experiences of language barriers, cultural differences, and teacher-student rapport in a university in Vietnam:

A grounded theory approach.

\section{Please tick the boxes if you agree with the following statements:}

․ I have read the research information enclosed and believe that I have been provided with enough information about the nature and purpose of this research project.

a I understand that information and have been given the opportunity to raise any questions that I have and these have been answered to my satisfaction.

ㅁ I understand that as a result of allowing my students to take part means they will be involved in questionnaire and semi-structured interview.

․ I understand that any information or opinions my students provide will be kept confidential.

ㅁ I understand that the information my students will provide as part of this research will be used for this research project and in educational workshops or papers.

․ I understand that the research data will be kept secure and access to the data will be limited to the researcher and the thesis supervisor. Further, within two years of the completion of the research, all paper copies of the data will be burnt and audio data and computer files will be wiped.

․ I understand that a summary sheet of the results of this research will be provided to me if I tick the box below. Further, the full results of the research will also be published and will be made available in the library at Victoria University of Wellington.

․ I give my permission for the researcher to conduct research in my department

\section{Head of Department's signature:}

․ I would like written feedback on the findings of this research.

If you have indicated that you want written feedback on the research findings, please include the address to which the research findings should be sent to:

Name:

Mailing or E-mail Address:

Signature:

Date: 